\title{
Recent Progress and Approaches on Transition Metal Chalcogenides for Hydrogen Production
}

\author{
Sivagowri Shanmugaratnam ${ }^{1,2}$, Elilan Yogenthiran ${ }^{3}$, Ranjit Koodali ${ }^{4, *} *$, Punniamoorthy Ravirajan ${ }^{1}$, \\ Dhayalan Velauthapillai ${ }^{2}(\mathbb{D})$ and Yohi Shivatharsiny ${ }^{3, *}$ (D)
}

1 Clean Energy Research Laboratory (CERL), Department of Physics, University of Jaffna, Jaffna 40000, Sri Lanka; Sivagowrishanmugaratnam@gmail.com (S.S.); pravirajan@univ.jfn.ac.lk (P.R.)

2 Faculty of Engineering and Science, Western Norway University of Applied Sciences, P.O. Box 7030, 5020 Bergen, Norway; Dhayalan.Velauthapillai@hvl.no

3 Department of Chemistry, University of Jaffna, Jaffna 40000, Sri Lanka; elilchem01@gmail.com

4 Department of Chemistry, Western Kentucky University, 1906 College Heights Blvd., Bowling Green, KY 42101, USA

* Correspondence: ranjit.koodali@wku.edu (R.K.); yshiva@univ.jfn.ac.lk (Y.S.)

Citation: Shanmugaratnam, S.; Yogenthiran, E.; Koodali, R.;

Ravirajan, P.; Velauthapillai, D.; Shivatharsiny, Y. Recent Progress and Approaches on Transition Metal Chalcogenides for Hydrogen Production. Energies 2021, 14, 8265. https://doi.org/10.3390/en14248265

Academic Editor: Adam Revesz

Received: 1 November 2021

Accepted: 3 December 2021

Published: 8 December 2021

Publisher's Note: MDPI stays neutral with regard to jurisdictional claims in published maps and institutional affiliations.

Copyright: (c) 2021 by the authors. Licensee MDPI, Basel, Switzerland. This article is an open access article distributed under the terms and conditions of the Creative Commons Attribution (CC BY) license (https:// creativecommons.org/licenses/by/ $4.0 /)$.

\begin{abstract}
Development of efficient and affordable photocatalysts is of great significance for energy production and environmental sustainability. Transition metal chalcogenides (TMCs) with particle sizes in the 1-100 nm have been used for various applications such as photocatalysis, photovoltaic, and energy storage due to their quantum confinement effect, optoelectronic behavior, and their stability. In particular, TMCs and their heterostructures have great potential as an emerging inexpensive and sustainable alternative to metal-based catalysts for hydrogen evolution. Herein, the methods used for the fabrication of TMCs, characterization techniques employed, and the different methods of solar hydrogen production by using different TMCs as photocatalyst are reviewed. This review provides a summary of TMC photocatalysts for hydrogen production.
\end{abstract}

Keywords: transition metal chalcogenides; hydrogen production; photocatalysis; apparent quantum yield

\section{Introduction}

Renewably produced hydrogen gas is used as an alternative clean fuel for transportation. It is regarded as a clean and efficient carrier of energy and is considered as an ideal alternative to fossil fuels to meet the growing energy demand and address environmental issues [1]. When compared with other combustible fuels (i.e., deposited fossil fuels such as coal, oil, and natural gas [2]) hydrogen possesses a high energy density (140 $\left.\mathrm{MJkg}^{-1}\right)$ and the end product of this combustion reaction is only water [3,4]. Therefore, the growing energy demand requires developments in the storage of hydrogen, their transport, and production techniques. Although great progress has been made in $\mathrm{H}_{2}$ storage [5-7] and transport, the utilization of $\mathrm{H}_{2}$ energy is stymied by the lack of inexpensive and efficient production methods [8]. Hydrogen can be produced in different ways (Figure 1) including steam-methane reforming of natural gas, coal gasification, and biomass conversion [9], which are expensive and produce greenhouse gases such as carbon monoxide and carbon dioxide that are not favorable to the environment $[10,11]$. An attractive alternative technique, solar assisted water splitting, is considered as one of the most suitable and greener ways to produce hydrogen energy [12] and the technology of water splitting becomes mature day-by-day [13].

The simple method for the separation of water is electrolysis and various clean energy resources such as solar, geothermal, biomass, wind, ocean, or other renewables can be used for this process. Among them, using solar energy, water can be split by two methods: photoelectrochemical and photocatalytic water splitting. 


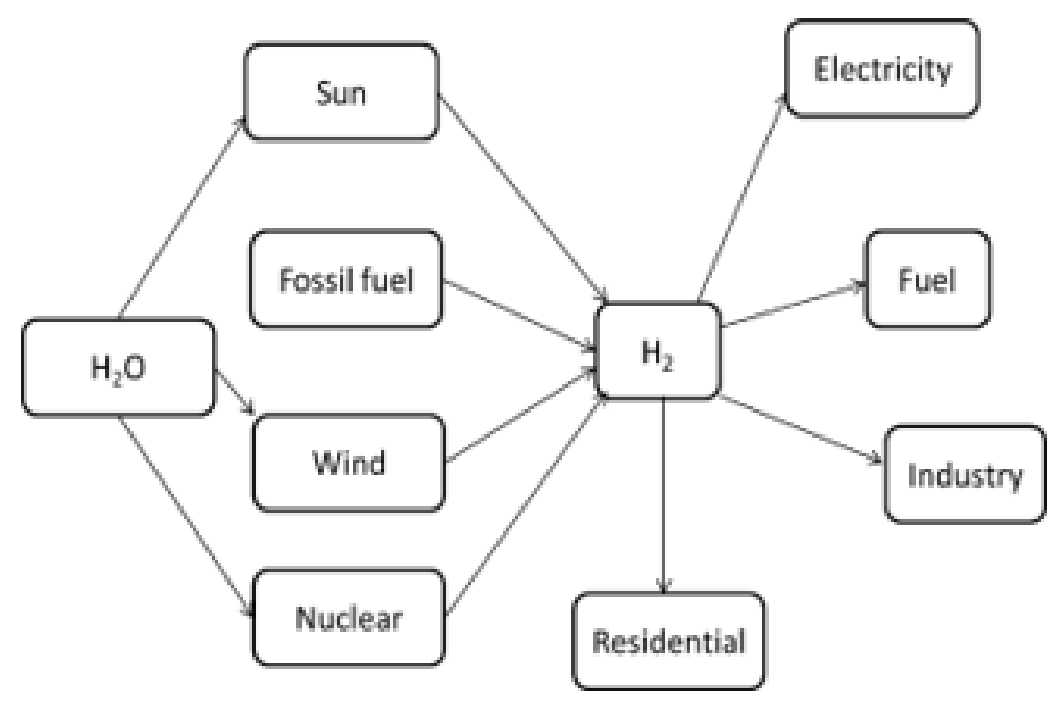

Figure 1. Web-diagram showing the primary energy sources for the production of hydrogen and its uses.

Various types of photocatalytic materials have been utilized for photocatalytic applications. $\mathrm{TiO}_{2}$ [14-17], $\mathrm{ZnO}$ [18], mixed oxide materials [19], perovskite [20,21], dye [22], and metal-doped oxide materials $[23,24]$ are some of them. Among these, transition metal chalcogenides (TMCs) have gained worldwide attention due to their electrocatalytic properties that include indirect band gaps, optoelectronic behavior, and their stability [25]. In addition, nanodots (quantum dots)/nano structures of metal chalcogenides show enhanced catalytic activity at the edges. Furthermore, by limiting their particle size in the 1-10 $\mathrm{nm}$ range, due to the quantum confinement effect, it is possible to utilize under solar simulated irradiation $[26,27]$. Generation of exciton pairs and the effective charge separation in these semiconductor photocatalysts lead to an effective photolysis process. The efficiency of charge transport mainly depends on the crystallinity, particle, and crystallite size of the materials among many other factors. Composites of TMCs with co-catalysts such as graphene [28], graphene oxides [29], carbon nitride [30], metal oxides [19,31-33], $\mathrm{CdLa}_{2} \mathrm{~S}_{4}$ [34], and metals [35] have been found to increase the conductivity of electrons, provide active sites, and effectively separate the electron and hole pairs generated by bandgap irradiation of the semiconductor photocatalysts. This review mainly focuses on the synthesis and characterization of various types of TMCs and their application in hydrogen energy production through water splitting. This review may assist researchers by providing insights on the fabrication of highly efficient photocatalysts with low cost and high efficiency.

\section{Transition Metal Chalcogenides (TMCs)}

TMCs have gained worldwide attention in recent decades. These catalysts have been used in lithium-ion batteries, solar cells, and hydrogen evolution reactions. TMCs can be excited by solar simulated irradiation and due to their indirect band gaps, optoelectronic behavior, small bandgap, and their stability are favorable candidates as photocatalysts. Nowadays, many researchers have focused on the production and photocatalytic activity of TMCs. These TMCs have been synthesized by different techniques that include single-step hydrothermal synthesis [13,36,37], solvothermal method [38], sulfidation and selenization [39], free intercalation method [40], electrospinning technique, the successive ionic layer adsorption and reaction (SILAR) method [32], ultrasonic-exfoliation [23], electrodeposition method [27,41], photoreduction method [42], refluxing method [43], chemical vapor deposition (CVD) [44], template-free one-pot method [45], successive surface modification method [46], and microwave-assisted synthesis [47-50]. The following section will elaborate on some of the above-mentioned synthesis methods in detail. 


\subsection{Synthesis Methods}

\subsubsection{Hydrothermal/Solvothermal Method}

The hydrothermal technique is one of the frequently reported methods to produce nanomaterials with various morphologies and thicknesses [51]. This method involves a heterogeneous reaction in the presence of an aqueous solvent or mineralizers under high pressure and low temperature to dissolve and recrystallize the materials that are moderately insoluble under ordinary conditions in closed steel containers called autoclaves. If the water is used as the solvent, this process is called the hydrothermal method whereas in the solvothermal method, organic solvents are used [36,52]. This method can be used to synthesize nanomaterials with high crystallinities, favorable crystal facets, tunable morphologies, and controllable sizes by varying experimental factors such as temperature, solvent, time, etc. Hydrothermal synthesis consumes relatively low energy, and most importantly, it is an environmentally friendly method $[53,54]$, and hence is a very common method. Figure 2 illustrates an example of the synthesis of $\mathrm{MoS}_{2}$.

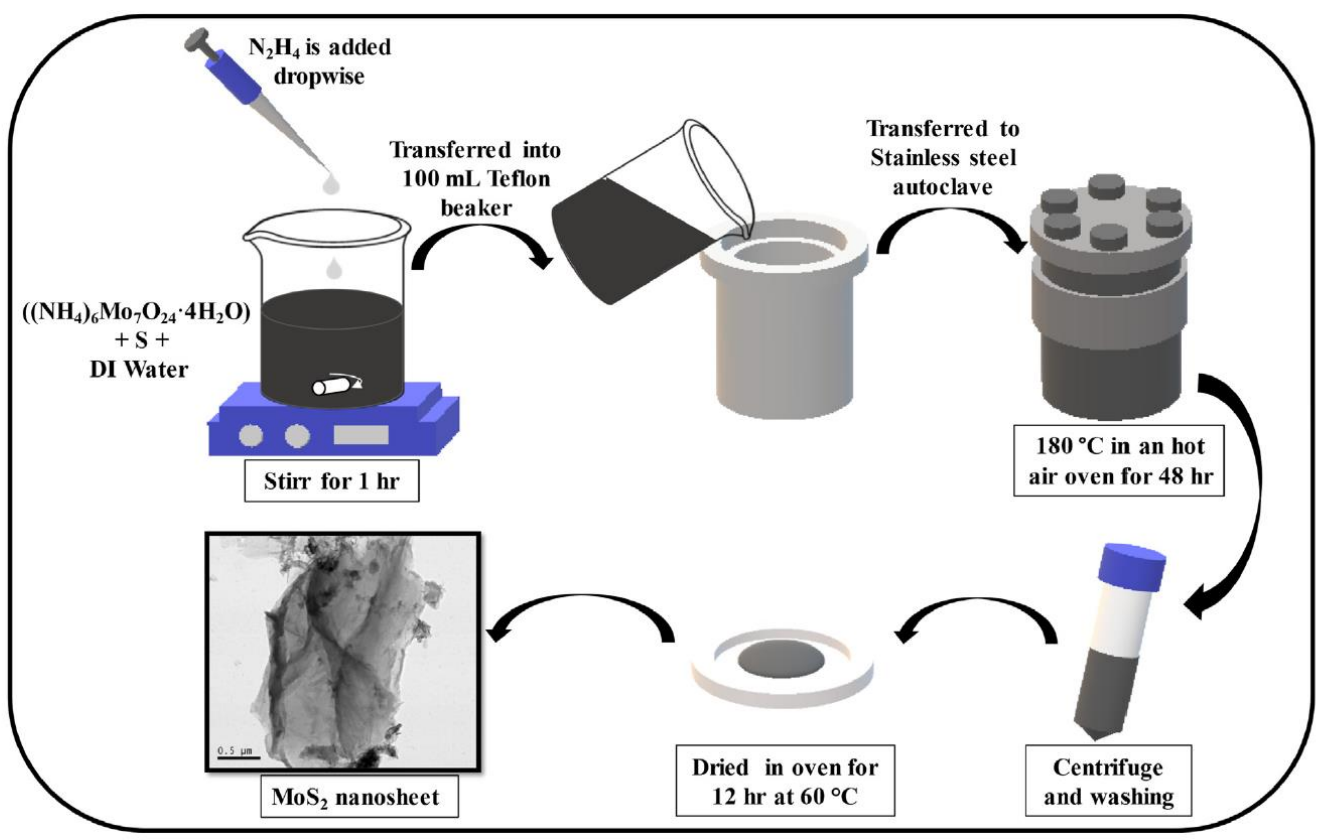

Figure 2. Schematic illustration of synthesis of $\mathrm{MoS}_{2}$ by the hydrothermal method. Reproduced with permission from [55].

Figure 2 depicts the flow diagram of the synthesis of $\mathrm{MoS}_{2}$ by the hydrothermal method. Here, ammonium-hepta molybdate tetrahydrate and sulfur (S) powder were used as precursors. The black precipitates were collected and dried to obtain the required $\mathrm{MoS}_{2}$ sample, which exhibited a layered structure [55].

In a different study, Jing Yu et al. synthesized $\mathrm{SnS}_{2}$ nanosheets by the solvothermal method. The mechanism of their synthesis is illustrated in Figure 3, where $\mathrm{Sn}^{2+}$ from $\mathrm{SnCl}_{2}$ reacts with $\mathrm{S}^{2-}$ to form orthorhombic $\mathrm{SnS}$ micro flowers stacked with decentralized sheets, and further addition of a $\mathrm{S}^{2-}$ source results in $\mathrm{SnS}_{2}$ with an increase in the reaction time [38]. 

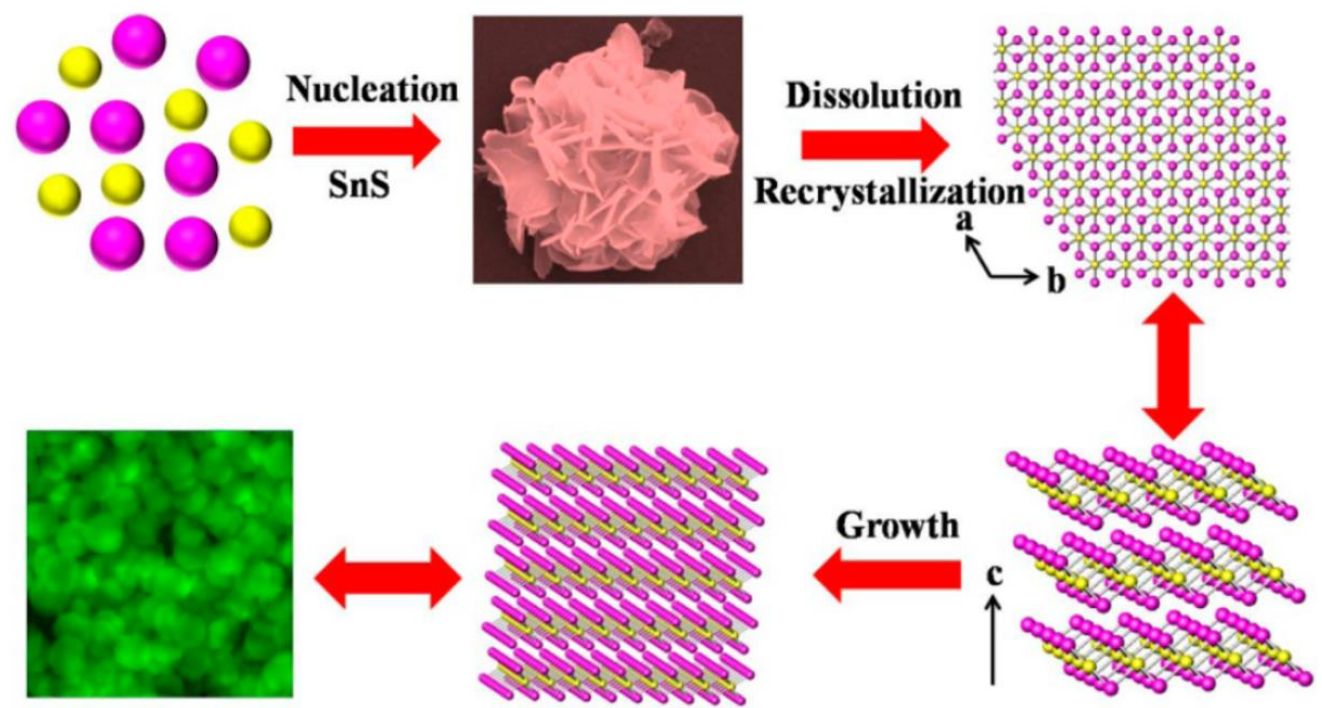

\section{Atoms: Sn}

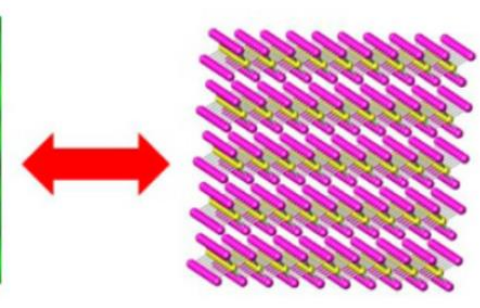

Figure 3. Formation mechanism of $\mathrm{SnS}_{2}$ nanostructures during the solvothermal process. Reproduced with permission from [38].

In addition, surfactants such as SDS (sodium dodecyl sulfate), CTAB (cetyltrimethylammonium bromide), PVP (polyvinyl pyrrolidone) [56], etc. have been used to increase the crystal growth of the nanomaterials, and a hydrothermal synthesis of a $\mathrm{WS}_{2}$ nanosphere by the addition of CTAB is discussed in Figure 4.
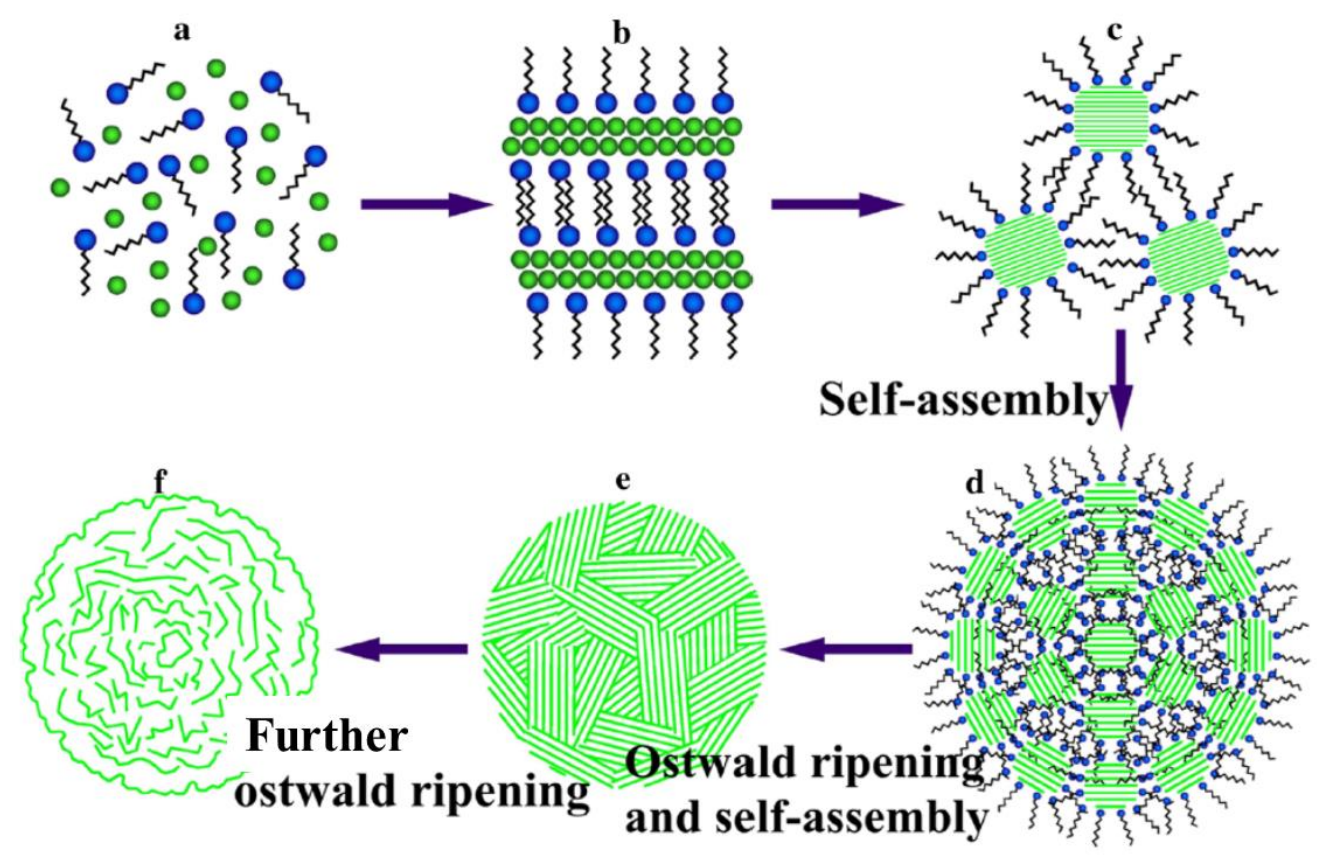

$$
\mathrm{MO}_{-} \mathrm{CTA}^{+} \mathrm{O}-\mathrm{WS}_{4}^{2-}
$$

Figure 4. Schematic diagram of the formation process of flower-like $\mathrm{WS}_{2}$ nanospheres using CTAB as aa surfactant. Reproduced with permission from [57].

Figure 4 a shows that the CTAB molecules were randomly dispersed in solution as single molecules (not aggregates) at low concentrations under the hydrothermal condition. After the amount of CTAB was adjusted to $1.5 \mathrm{mmol}$, a lamellar micelle was formed to minimize the free energy of the system. The external surface of the lamellar micelle contains 
a hydrophilic head, whereas the tail, which is hydrophobic, points to the micelle center [58]. In Figure $4 \mathrm{~b}, \mathrm{WS}_{4}{ }^{2-}$ ions tend to form lamellar micelles due to complementary electrostatic interactions between the $\mathrm{CTA}^{+}$and $\mathrm{WS}_{4}{ }^{2-}$ To keep the free energy of the system low, the lamellar micelle was formed as an ordered nano-microstructure, as indicated in Figure 4c. Figure $4 \mathrm{~d}$ shows $3-\mathrm{D}$ assemblies formed through van der Waals forces. Similar methods have been utilized to synthesize $\mathrm{FeS}_{2}, \mathrm{NiS}_{2}$, and $\mathrm{CuS}$ in a different work [37]. The $\mathrm{WS}_{2}$ nanocrystal was formed from the reduction of $\mathrm{WS}_{4}{ }^{2-}$ ions, as indicated in Figure 4e. The aggregation of $\mathrm{WS}_{2}$ colloids reduced the surface free energy and formed nanosheets. The flower-like $\mathrm{WS}_{2}$ nanospheres were obtained as indicated in Figure $4 \mathrm{f}$, and it was concluded that hydrothermal synthesis in the presence of a surfactant such as CTAB and careful control of the precursor concentration can be utilized to obtain the desired flower-like structure [57].

Apart from this hydrothermal method, there is a clean, ultrafast (60 s) synthetic technique that can be conducted using microwave heating without any inert gas protection to achieve uniform TMCs [48,59].

\subsubsection{Microwave-Assisted Synthesis}

The microwave-assisted synthesis method has also been used to prepare TMCs with controllable sizes and shapes [60]. Figure 5 illustrates the microwave-assisted synthesis of a $\mathrm{MoS}_{2}$ /graphene composite in the presence of ammonium tetrathiomolybdate (ATTM) and $\mathrm{CS}_{2}$ on a graphene support. The reaction was carried out in a glass vial with equimolar amounts of ATTM and graphene. The reactants were mixed at a constant speed, and then the $\mathrm{CS}_{2}$ solvent $(200 \mu \mathrm{L})$ was added and mixed well. The solvent was evaporated after 10 min of air drying. Then, the mixture was kept under microwave irradiation. Here, the graphene served as a substrate to absorb the microwave energy and convert the incident radiation energy to heat. During the process, ATTM was reduced first to $\mathrm{MoO}_{2}$, and then converted to $\mathrm{MoS}_{2}$, as indicated in Figure 5 [47].

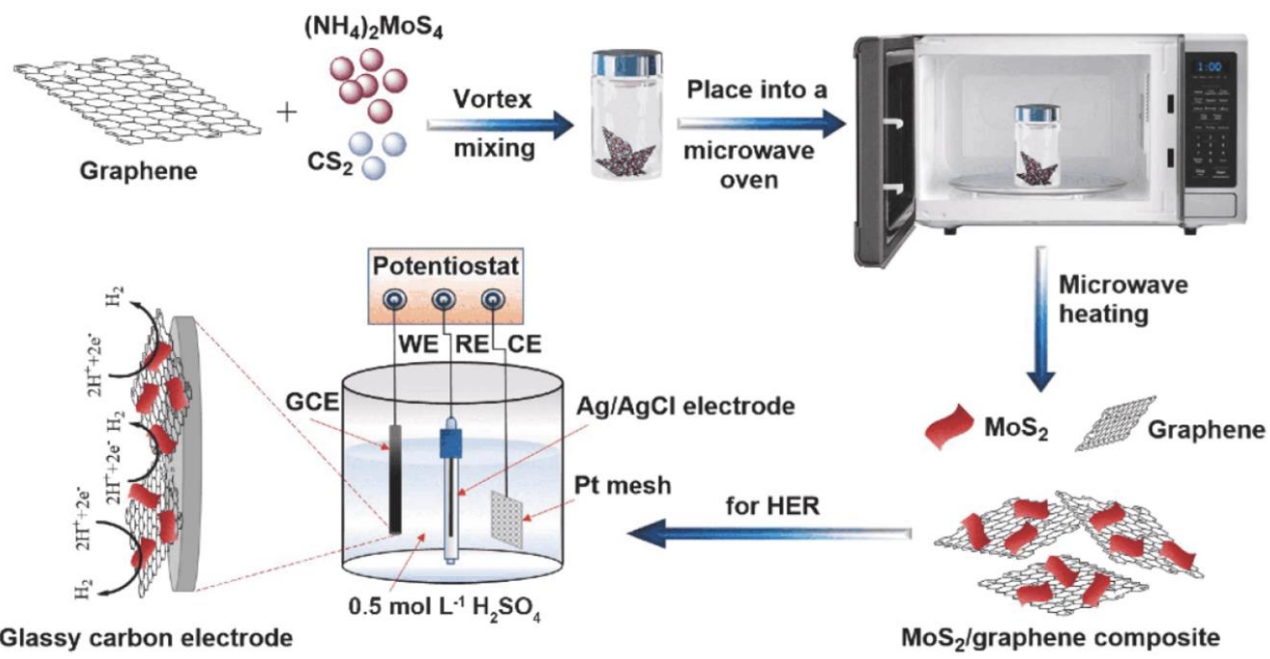

Figure 5. Schematic illustration of the microwave-assisted synthesis of the $\mathrm{MoS}_{2}$ / graphene composite. Reproduced with permission from [47].

In different works, $\mathrm{SnS}_{2}$ [61], CdS [62], $\mathrm{CuS}$ [63], $\mathrm{NiS}_{2}$ [64], $\mathrm{WS}_{2}$ [59], and $\mathrm{CoS}_{2}$ [65] nanomaterials were synthesized using the microwave-assisted synthesis method.

\subsubsection{Electrodeposition Method}

Electrodeposition is a well-established technique for the preparation of nanomaterials for a wide range of materials (e.g., metal nanoparticles, nanosheet arrays [66], nanowires [67], nanofilms [68], laminated composites [69], multilayered composite coatings [70], and nanoparticle-reinforced composite coatings [71]) and this is a rapid and single-step process. It can be used to produce homogeneous and high-purity crystalline 
materials at the cathode of the electrochemical system during the coating process because of the external current (direct or pulsed) applied to the electrodeposition system [72-74].

Figure 6 illustrates the synthesis of $\mathrm{MoS}_{2}$ quantum dots (QDs) on $\mathrm{TiO}_{2}$ nano-tube arrays (NTAs) to form heterostructures using a facile electrodeposition method with a threeelectrode system. $\mathrm{TiO}_{2} \mathrm{NTAs} / \mathrm{Ti}$ foil, $\mathrm{Pt}$ foil, and saturated $\mathrm{Ag} / \mathrm{AgCl}$ electrodes were used as the working electrode, counter electrode, and reference electrode, respectively. $\mathrm{MoS}_{2} \mathrm{QD}$ solution and citric acid-sodium citrate buffer solution $(0.1 \mathrm{M}, \mathrm{pH} 4.5)$ with a volume ratio of 1:1 was used as the electrolyte of this system. $\mathrm{MoS}_{2}$ QDs were deposited onto $\mathrm{TiO}_{2}$ NTA photoelectrodes by the electrodeposition process, and the obtained samples were rinsed with deionized water and dried at ambient temperature after different electrodeposition times of 5, 10, 20, and $30 \mathrm{~min}$., respectively [27].

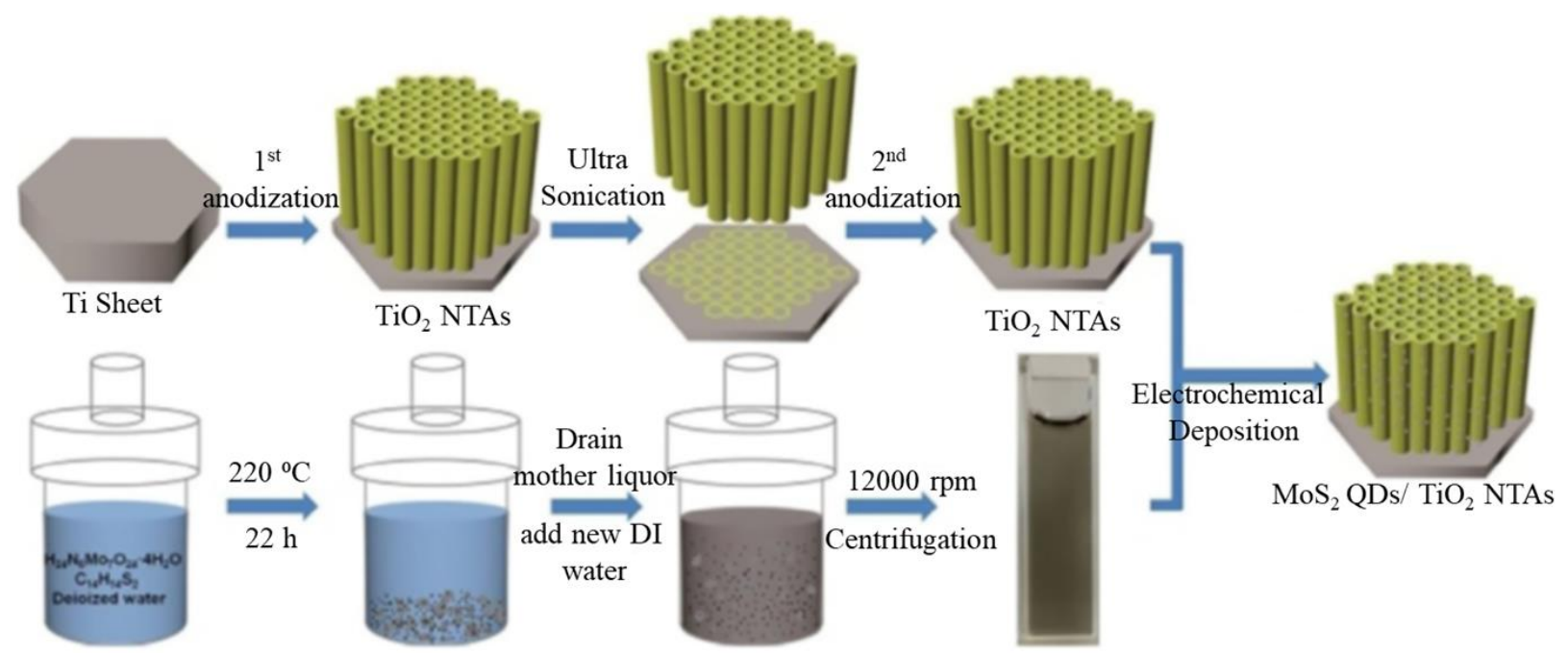

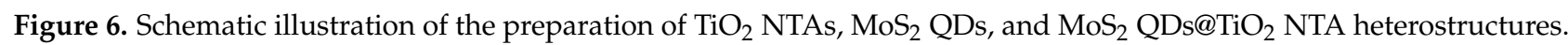
Reproduced with permission from [27].

\subsubsection{Photoreduction}

Photoreduction, for example, the photodeposition of $\mathrm{MoS}_{2}$ on $\mathrm{rGO}_{\mathrm{x}} / \mathrm{CdS}$ was also utilized to prepare metal chalcogenide materials. An appropriate amount of precursor molecule $\left(\mathrm{MoS}_{4}{ }^{2-}\right)$ and surfactants were added and the $\mathrm{pH}$ of the solution was adjusted by adding an acid or base. Then, the suspension was bubbled with nitrogen to maintain an inert environment, then irradiated with a $350 \mathrm{~W}$ Xe lamp equipped with a cutoff filter $(\lambda \geq 420 \mathrm{~nm})$ for a particular time interval. The incident intensity was $34 \mathrm{mWcm}^{-1}$. The $\mathrm{MoS}_{4}{ }^{2-}$ ions were reduced to $\mathrm{MoS}_{2}$ by the photoexcited electrons of $\mathrm{rGO}_{x} / \mathrm{CdS}$. The final product, $\mathrm{MoS}_{2} / \mathrm{rGO}_{\mathrm{x}} / \mathrm{CdS}$, was obtained by filtration. The loaded amount of $\mathrm{MoS}_{2}$ was determined by measuring the $\mathrm{MoS}_{4}{ }^{2-}$ concentrations in both the reacted solution and the washed solution on a spectrophotometer at the wavelength of $468 \mathrm{~nm}$ [42].

\subsubsection{Electron Beam Evaporation}

There have been various methods used in the preparation of $\mathrm{Au}$ deposited on a $\mathrm{NP} / \mathrm{Zn}_{\mathrm{x}} \mathrm{Cd}_{1-\mathrm{x}} \mathrm{S} \mathrm{NW}$ heterostructure. Ternary $\mathrm{Zn}_{\mathrm{x}} \mathrm{Cd}_{1-\mathrm{x}} \mathrm{S}$ nanowires were synthesized by using silicon (100) wafers as substrates (Figure 7). First, Au film was deposited on a Si substrate by the electron beam evaporation method. The substrates coated with $10 \mathrm{~nm}$ of $\mathrm{Au}$ film were placed into the downstream region of a three-zone horizontal quartz tube furnace and then annealed at $500{ }^{\circ} \mathrm{C}$ for $1 \mathrm{~h}$. 


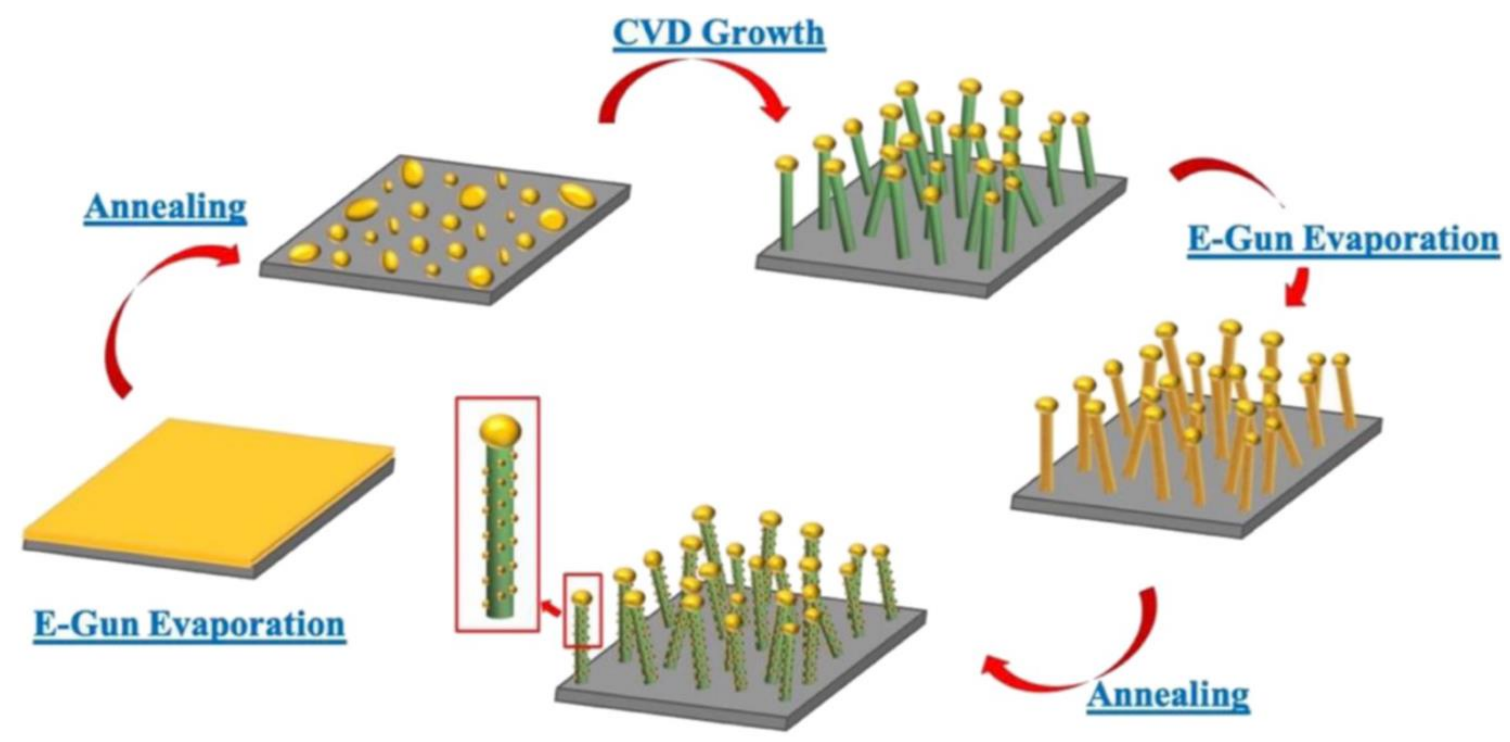

Figure 7. Schematic diagram of the fabrication of the $\mathrm{Au} \mathrm{NP} / \mathrm{Zn}_{\mathrm{x}} \mathrm{Cd}_{1-\mathrm{x}} \mathrm{S} \mathrm{NW}$ heterostructure. Reproduced with permission from [75].

The pressure was maintained at 0.01 torr throughout the annealing process. Ternary $\mathrm{Zn}_{\mathrm{x}} \mathrm{Cd}_{1-\mathrm{x}} \mathrm{S}$ nanowires were synthesized by a simple one-step process. Before growth, commercial-grade ZnS powder (99.995\%) CdS powder (99.999\%), and a piece of Si (100) substrate coated with $10 \mathrm{~nm}$ of Au film as a catalyst were annealed. Argon flow was purged during the growth as a carrier gas and the pressure was maintained. After the heating process, the samples were cooled to room temperature in the furnace. The key factor in tuning the $x$ ratio of the $\mathrm{Zn}_{\mathrm{x}} \mathrm{Cd}_{1-\mathrm{x}} \mathrm{S}$ nanowires was found to be temperature [75].

\subsubsection{Sulfidation and Selenization}

Figure 8a schematically illustrates the experimental setup used for the growth of $\mathrm{WO}_{3}$ nanowires (NWs) as well as $\mathrm{WS}_{2}, \mathrm{WSe}_{2}$, and their ternary $\mathrm{WS}_{2(1-\mathrm{x})} \mathrm{Se}_{2 \mathrm{x}}$ nanotubes (NTs) on highly flexible carbon fibers (CFs) in a horizontal two-zone tube furnace [39]. High-density $\mathrm{WO}_{3} \mathrm{NWs}$ were used to cover the entire surfaces of the CFs vertically and uniformly, as shown in Figure 8c. The diameter and length of typical $\mathrm{WO}_{3} \mathrm{NWs}$ were found to be ca. $100 \mathrm{~nm}$ and the length was measured to be $5 \mu \mathrm{m}$. Then, the $\mathrm{WS}_{2}$ and $\mathrm{WSe}_{2}$ NTs were synthesized through sulfidization and selenization of $\mathrm{WO}_{3} \mathrm{NWs}$ at $800{ }^{\circ} \mathrm{C}$, as demonstrated in Figure 8d,e.

For the synthesis of $\mathrm{WS}_{2(1-x)} \mathrm{Se}_{2 x} \mathrm{NTs}$, the ratio of $\mathrm{S}$ and Se precursors were successfully altered for the controllable element component of ternary NTs (Figure 8f). $\mathrm{As}^{\mathrm{WO}_{3}}$ NWs were used as a conversion template, the diameter and length of the $\mathrm{WS}_{2}$ and $\mathrm{WSe}_{2}$ NTs were found to be comparable to those of $\mathrm{WO}_{3} \mathrm{NWs}$. Synthesis of the $\mathrm{WS}_{2}$ NTs was conducted by the sulfidization of the $\mathrm{WO}_{3} \mathrm{NWs}$ performed at $800{ }^{\circ} \mathrm{C}$ in an $\mathrm{Ar}$ atmosphere. The chemical reaction is described as

$$
2 \mathrm{WO}_{3}+7 \mathrm{~S} \rightarrow 2 \mathrm{WS}_{2}+3 \mathrm{SO}_{2}
$$

\subsubsection{Successive Ionic Layer Adsorption and Reaction (SILAR) Method}

The SILAR method is a simple, cost effective, and rapid technique for the deposition of binary semiconducting thin films when compared with other methods. It can be applied in the deposition of large-area thin films. Since this technique was introduced by Nicolau in the mid-1980s [76], this method has been employed to grow thin films, especially CdS, $\mathrm{ZnS}$, and CdZnS. In particular, this method is appropriate for depositing thin films of chalcogenide groups I-VI, II-VI, III-VI, V-VI, VIII-VI binary, and I-III-VI, II-II-VI, II-IIIVI, II-VI-VI and II-V-VI ternary chalcogenides and composite films. The SILAR method consists of the adsorption of the cation precursor, water rinsing, adsorption of the anion 
precursor, followed by the appropriate reaction, and rinsing. These steps may be repeated.

The schematic diagram illustrated in Figure 9 explains the mechanism of the SILAR growth.

(a)
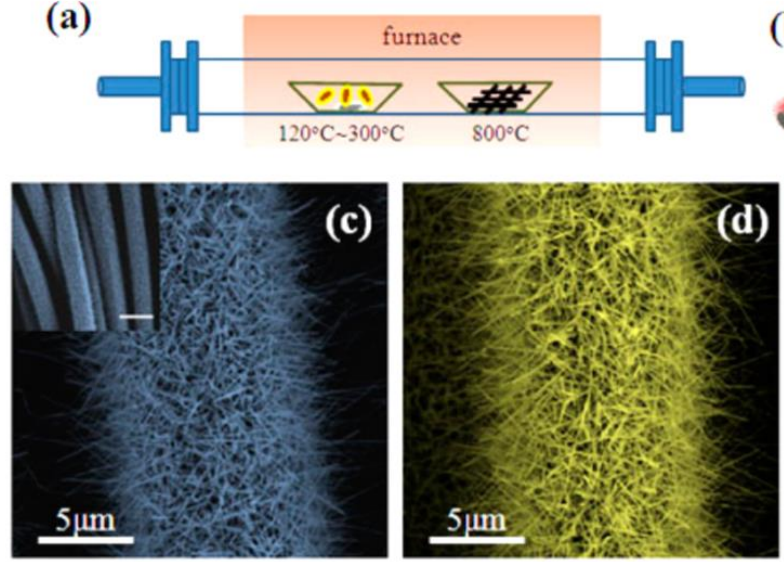

(b)
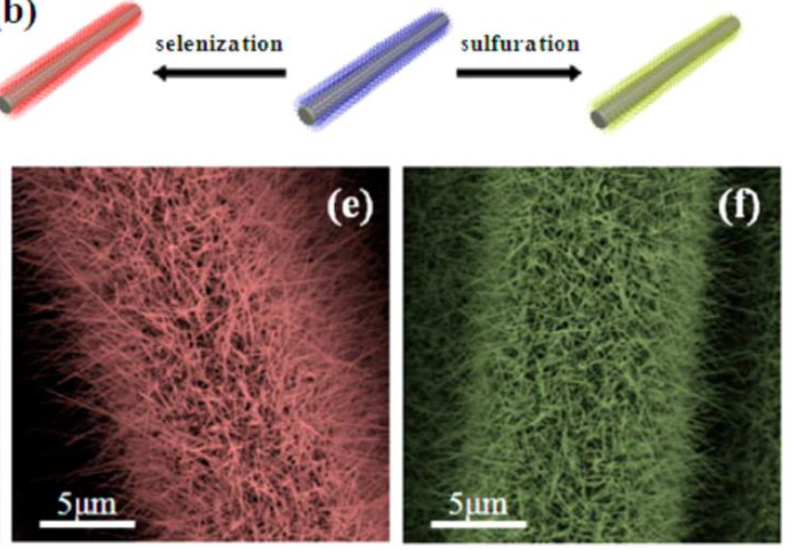

Figure 8. (a) Experimental setup of the preparation of $\mathrm{WO}_{3}$ nanowires and $\mathrm{WS}_{2}, \mathrm{WSe}_{2}$, and $\mathrm{WS}_{2(1-\mathrm{x})} \mathrm{Se}_{2 \mathrm{x}}$ nanotubes. (b) Schematic diagram of $\mathrm{WO}_{3}$ nanowires (NWs) converting to $\mathrm{WS}_{2}$ and $\mathrm{WSe}_{2}$ nanotubes (NTs) on carbon fibers by sulfidization and selenization. SEM images of (c) $\mathrm{WO}_{3} \mathrm{NWs}$ and (d) $\mathrm{WS}_{2}$, (e) WSe $\mathrm{W}_{2}$, and (f) $\mathrm{WS}_{2(1-\mathrm{x})} \mathrm{Se}_{2 \mathrm{x}}$ NTs. Reproduced with permission from [39].

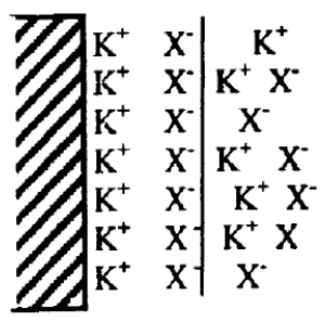

(a)

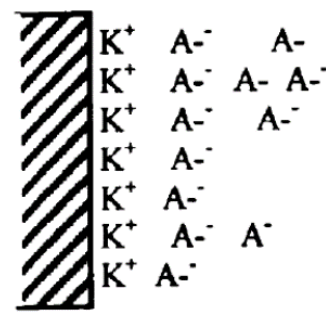

(c)

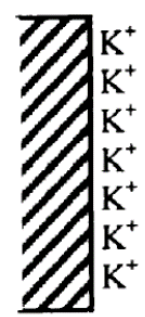

(b)

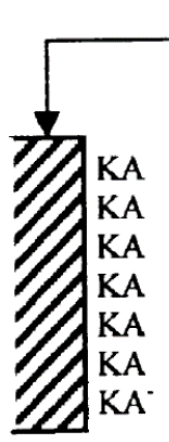

(d)

Figure 9. Schematic diagram of SILAR growth. (a) Adsorption of $\mathrm{K}^{+} \mathrm{X}^{-}$and the formation of electrical double layer, (b) first rinsing to remove excess, unabsorbed $\mathrm{K}^{+}$and $\mathrm{X}^{-}$, (c) reaction of $\mathrm{A}^{-}$with pre-adsorbed $\mathrm{K}^{+}$ions to form $\mathrm{KA}$, and (d) second rinsing to remove excess and unreacted species and form the solid solution KA on the surface of the substrate. Reproduced with permission from [77].

In a typical process, the substrate is immersed separately in two precursor solutions and washed with water to remove the loosely bound species. By controlling the experimental conditions, the growth rates of thin films in the SILAR method can be varied between a quarter and a half of a monolayer [78-80]. Therefore, the aqua ligands remain at least partially intact during adsorption, thereby lowering the density of cations and anions in one layer. Furthermore, the growth of the thin film can be controlled at an accuracy of one SILAR cycle. 
Valkonen et al. [80] studied the effect of different types of substrates by depositing ZnS, CdS films on glass, ITO-coated glass, and single crystals of GaAs (100). In this paper, they mainly focused on promoting interest in the SILAR method as applied to tin disulfide thin films. The authors used the SILAR method to prepare large-area $\left(\sim 10 \mathrm{~cm}^{2}\right) \mathrm{SnS}_{2}$ thin films on glass substrates under optimized deposition conditions. In addition, they reported $\mathrm{SnS}_{2}$ thin films on a single crystal wafer of $\mathrm{Si}$ (111) to study the effect of substrate on the crystallinity of the films. In summary, these reports explain the feasibility of using the SILAR method for the preparation of TMC thin-films/coatings.

\subsubsection{Refluxing Method}

The refluxing method is a suitable method for the large-scale synthesis of TMCs such as $\mathrm{SnS}_{2}$. In their paper, Liu et al. reported a facile refluxing method without using any templates or surfactants to synthesize $\mathrm{SnS}_{2}$ nanocrystals with controllable morphology. It was found that the as-obtained $\mathrm{SnS}_{2}$ nanostructures exhibited good adsorption ability and enhanced visible light photocatalytic activity for the degradation of Methylene Blue.

In a typical procedure, $\mathrm{SnS}_{2}$ was prepared by using $\mathrm{SnCl}_{4} \cdot 5 \mathrm{H}_{2} \mathrm{O}$ in the presence of ethylene glycol in a round bottom flask under stirring. The resultant mixture was heated to specific temperature followed by the addition of $\mathrm{Na}_{2} \mathrm{~S}$ solution under vigorous stirring. The resulting solution was refluxed under different temperature $\left(120^{\circ} \mathrm{C}\right.$ and $\left.180^{\circ} \mathrm{C}\right)$ to obtain different samples.

In another study, Aditha et al. synthesized $\mathrm{Cu}_{2} \mathrm{ZnSnS}_{4}$ using the refluxing method. The experimental setup they used in their study is illustrated in Figure 10. A round bottom flask was fitted with a condenser connected to a water inlet and outlet to condense the vapor back into the reaction vessel to keep the total volume constant. In this method, the reaction temperature is the boiling point of the solvent in the reaction vessel [81].

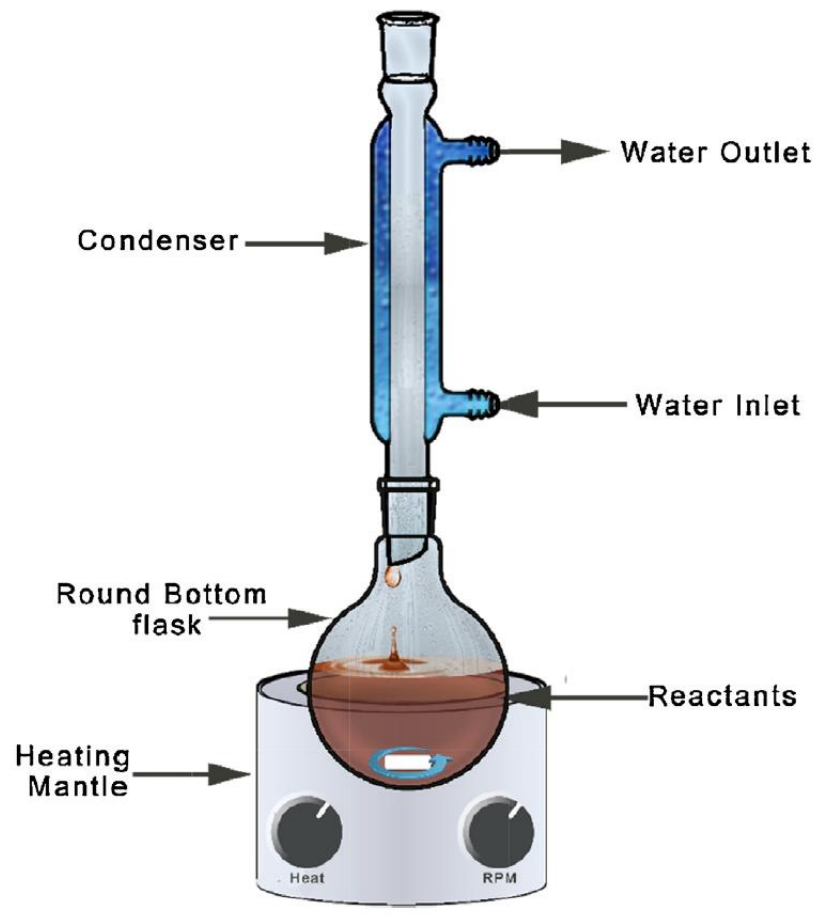

Figure 10. Schematic experimental setup of the refluxing method. Reproduced with permission from [81]. 
$\mathrm{CuCl}_{2}, \mathrm{ZnCl}_{2}, \mathrm{SnCl}_{2} \cdot 2 \mathrm{H}_{2} \mathrm{O}$, and thiourea were used as the precursor materials for producing $\mathrm{Cu}_{2} \mathrm{ZnSnS}_{4}$ and the refluxing time was $8 \mathrm{~h}$. The reaction mechanism is given below.

$$
\begin{aligned}
& 2 \mathrm{CuCl}_{2}+ \mathrm{ZnCl}_{2}+\mathrm{SnCl}_{2} \cdot 2 \mathrm{H}_{2} \mathrm{O}+4 \mathrm{SC}\left(\mathrm{NH}_{2}\right)_{2}+8 \mathrm{H}_{2} \\
& \rightarrow\left\{\mathrm{Cu}^{2+} \rightarrow \mathrm{Cu}^{+}, \mathrm{Sn}^{2+} \rightarrow \mathrm{Sn}^{4+}\right\} \\
& 2 \mathrm{Cu}^{2+}+\mathrm{Zn}^{2+}+\mathrm{Sn}^{2+}+4 \mathrm{~S}^{2-} \rightarrow \mathrm{Cu}_{2} \mathrm{ZnSnS}_{4}+\mathrm{CO}_{2}+8 \mathrm{NH}_{4} \mathrm{Cl}
\end{aligned}
$$

Further to this, several other studies have also been performed by using the refluxing method to synthesize metal chalcogenide materials such as $\mathrm{CuS}$ [82], $\mathrm{MoS}_{2}$ [83], ZnS [84], and $\mathrm{NiS}_{2}$ [85].

\subsubsection{Chemical Vapor Deposition (CVD) Method}

A typical bottom-up method, the chemical vapor deposition (CVD) method, is the process during which gaseous or vapor materials react at a certain temperature in the gas phase or gas-solid interfaces to form solid products with low structural defects [44]. In the CVD method, parameters such as choice of the precursor, temperature, pressure, flow rate, time, the distance between precursor and substrate, and the choice of substrates influences the morphology, layer number, lateral size, orientation, and degree of defects [86-88]. Kwon et al. [89] provided a deep understanding of the thermodynamic and kinetic factors influencing the CVD method. Most importantly, the CVD method exhibits prominent advantages in controlling 2-D materials at an atomic-level, which allow for clarity of the structure-activity relationships.

Tan et al. utilized $\mathrm{WS}_{2}$ materials with a graphene electrode for ultrathin 2-D photo detectors [90]. In another study, a 2-D-layered tin disulfide was synthesized by Chang et al. using the CVD method for photo detection of transistors by the thickness-controlled interface dynamics (TCID) technique, which shows high performance and great potential for several other applications [91].

Cong et al. synthesized single crystalline $\mathrm{WS}_{2}$ monolayers by the direct sulfurization of $\mathrm{WO}_{3}$ powders with sulfur powder at $750{ }^{\circ} \mathrm{C} ; 300 \mathrm{~nm}$ using $\mathrm{SiO}_{2} / \mathrm{Si}$ as the substrate. The substrate was covered with the $\mathrm{WO}_{3}$ sample and another substrate was placed face down above it. After that, the setup (Figure 11) was heated in a small end closed quartz tube, which in turn was placed inside a big quartz tube using a tubular furnace [92].

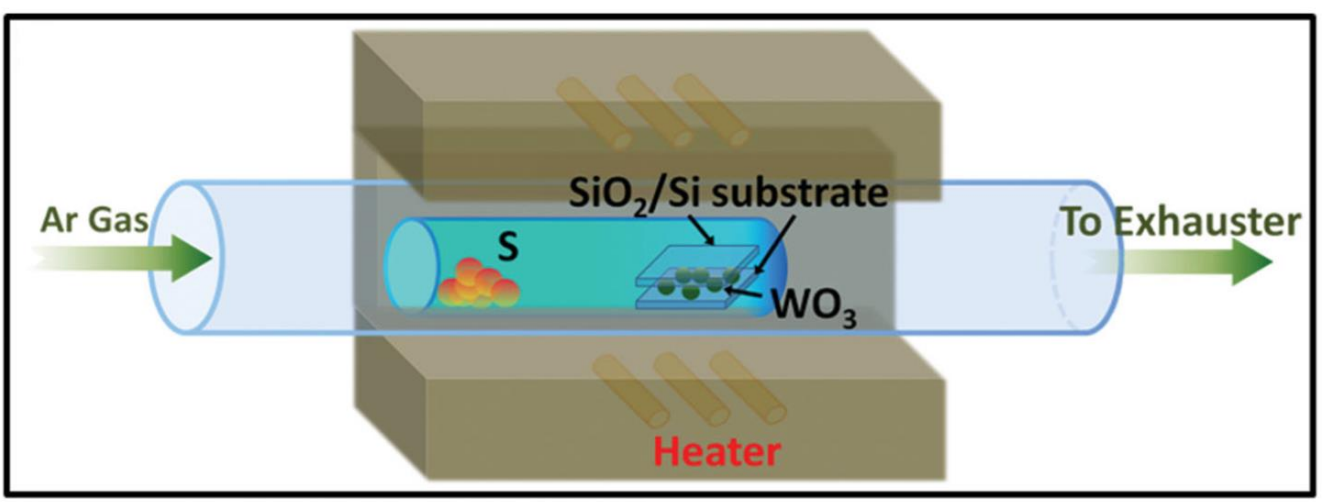

Figure 11. Schematic illustration of the chemical vapor deposition system used for the synthesis of $\mathrm{WS}_{2}$. Reproduced with permission from [92].

In addition, $\mathrm{SnS}_{2}$ [93], $\mathrm{NiS}$ [94], $\mathrm{NiS}_{2}$ [94], $\mathrm{MoS}_{2}$ [95], and $\mathrm{FeS}_{2}$ [96] nanomaterials were also synthesized by using this CVD method in different studies.

\subsubsection{Liquid Cascade Centrifugation (LCC) Method}

In addition to the above-mentioned methods, synthesis of TMC can also be performed by a liquid cascade centrifugation (LCC) method to achieve a highly efficient nanosheet 
with selected size and thickness [97]. LCC is an efficient, scalable, and versatile method that is based on a set of iterative centrifugation cascades designed to achieve highly efficient nanosheets and/or monolayer enriched dispersions. Mihai et al. synthesized liquidexfoliated 2D WS 2 and $\mathrm{MoS}_{2}$ nanosheets by the liquid centrifugation cascade method and the prepared nanosheets were used for neuromorphic computing applications [98]. Figure 12 illustrates the LCC method used in their study to separate the nanosheets efficiently according to their size and thickness.

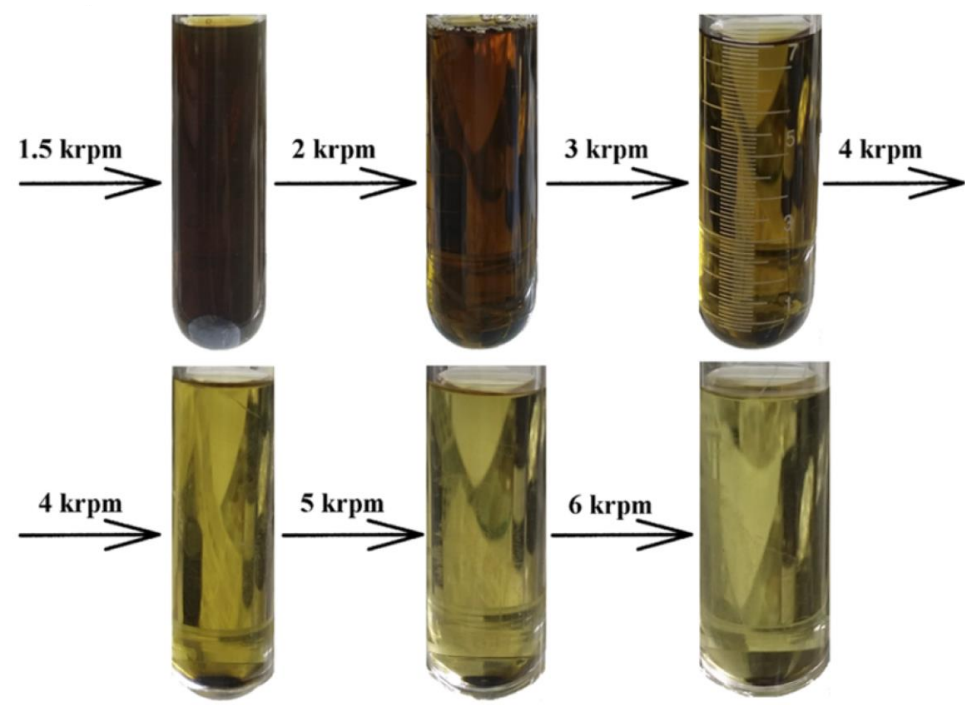

Figure 12. The LCC method used to separate the nanosheets. Reproduced with permission from [98].

The following Table 1 discusses the different synthesis methods used in the preparation of TMC nanoparticles and the specific advantage(s)/disadvantage(s).

Table 1. Summary of the different types of the synthesis method of TMC.

\begin{tabular}{|c|c|}
\hline Synthesis Methods & Advantages/Disadvantages \\
\hline Hydrothermal/Solvothermal Method & $\begin{array}{l}\text { Produce nanomaterials with various morphologies and thicknesses at high pressure and } \\
\text { low temperature; can synthesize high quality large crystals; cost of equipment is high }\end{array}$ \\
\hline Microwave-assisted Synthesis & Required less time/rapid process; size can be controlled \\
\hline Electrodeposition Method & $\begin{array}{l}\text { Rapid and single-step process; used to produce homogeneous and high-purity crystalline } \\
\text { materials at the cathode of the electrochemical system during the coating process }\end{array}$ \\
\hline Photoreduction & $\begin{array}{l}\text { Require higher photon energy; can synthesize the materials with large surface area and } \\
\text { many active sites }\end{array}$ \\
\hline Electron Beam Evaporation & $\begin{array}{l}0 \mathrm{D}, 1 \mathrm{D} \text {, and } 2 \mathrm{D} \text { materials can be prepared; used for depositing materials with high } \\
\text { melting point; as electrons can be focalized, it is possible to obtain a very localized } \\
\text { heating on the material to evaporate with a high density of evaporation power }\end{array}$ \\
\hline Sulfidation and Selenization & Solution-phase conversion; facile and selectable synthesis method \\
\hline $\begin{array}{l}\text { Successive Ionic Layer Adsorption and Reaction } \\
\text { (SILAR) Method }\end{array}$ & $\begin{array}{l}\text { Simple, cost effective, and rapid technique for the deposition of binary semiconducting } \\
\text { thin films }\end{array}$ \\
\hline Refluxing Method & Large scale synthesis method; facile and cost effective \\
\hline Chemical Vapor Deposition (CVD) Method & $\begin{array}{l}\text { Gas-phase aerosol process for producing high-purity nanoparticles; mainly used for } \\
\text { large scale thin-film production }\end{array}$ \\
\hline Liquid cascade centrifugation (LCC) method & $\begin{array}{l}\text { Used to achieve highly efficient nanosheet with selected size and thickness; most } \\
\text { efficient, scalable, and versatile method based on a set of iterative centrifugation cascades }\end{array}$ \\
\hline
\end{tabular}

\subsection{Characterization Techniques}

There have been various techniques such as X-ray diffraction spectroscopy (XRD), scanning electron microscopy (SEM), UV-Visible spectroscopy/diffuse reflectance spec- 
troscopy (UV-DRS), and X-ray photoelectron spectroscopy (XPS) used to characterize the transition metal chalcogenides, which are discussed in the following section.

\subsubsection{X-ray Diffraction Method (XRD)}

$X$-ray diffraction method is a non-disruptive technique used to characterize the crystallite size, crystallinity, crystal structure, and phase composition of the material in a powder or film.

Figure 13 shows the XRD patterns of $\mathrm{SnS}_{2}$ nanosheets (NSs) that confirm the formation of 2T-type hexagonal $\mathrm{SnS}_{2} \mathrm{NSs}$ (space group $\mathrm{P} \overline{3} \mathrm{~m} 1$ ) with cell parameters of $\mathrm{a}=\mathrm{b}=3.649 \AA$ and $c=5.899 \AA$. A high crystalline and pure product was obtained when compared with the standard diffraction data of JCPDS no. 23-0677. The highest intensity peak was assigned to the (001) facet of the indicating hexagonal phase [38]. Figure 14 shows the XRD patterns for $\mathrm{MoS}_{2}$ and $\mathrm{WS}_{2}$ on carbon cloth at different thermolysis temperatures. The peaks at $26.8^{\circ}$ and $43.5^{\circ}$ (marked as " $\mathrm{C}^{\prime \prime}$ ) can be ascribed to the carbon cloth in all samples. As shown in Figure $14 \mathrm{a}$, the presence of the (002) reflection peak at $2 \theta=14.2^{\circ}$ indexed the periodicity along the direction perpendicular to the planar structure of $\mathrm{MoS}_{2}$. This was only observed for the $\mathrm{MoS}_{2}$ samples heated at $100{ }^{\circ} \mathrm{C}$, but not at lower temperatures. For the $\mathrm{WS}_{2}$ samples, peaks were observed at lower temperatures (i.e., 200 and $400{ }^{\circ} \mathrm{C}$ ). As the thermolysis temperature increased, higher crystallinity of $\mathrm{WS}_{2}$ was observed. For $\mathrm{WS}_{2}$ samples prepared at 800 and $100{ }^{\circ} \mathrm{C}$, the reflection peak was found for $\mathrm{WO}_{3}$, which is marked with * in Figure 14b.

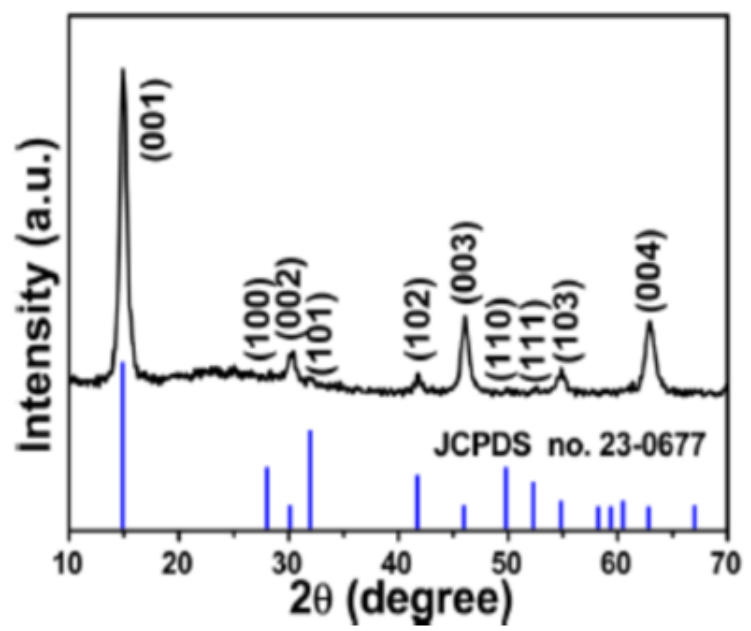

Figure 13. XRD pattern of $\mathrm{SnS}_{2}$ nanosheets (NSs) prepared at $220^{\circ} \mathrm{C}$ for $12 \mathrm{~h}$. Reproduced with permission from [38].
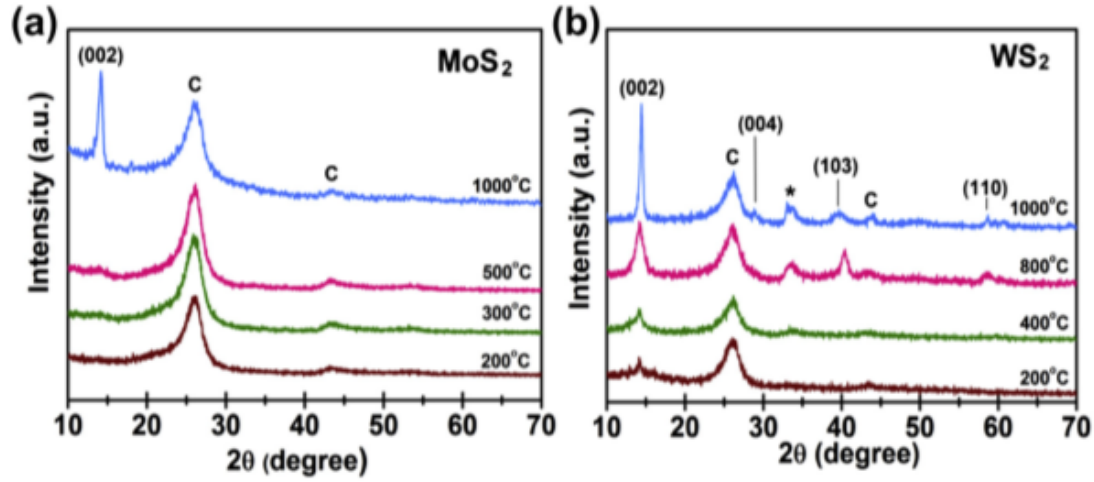

Figure 14. XRD pattern for the samples obtained at different thermolysis temperatures: (a) $\mathrm{MoS}_{2}$ on carbon cloth and (b) $\mathrm{WS}_{2}$ on carbon cloth. Peaks with notation $\mathrm{C}$ represent the carbon peaks from carbon cloth. $\left(^{*}\right)$ indicates the peaks from $\mathrm{WO}_{3}$. Reproduced with permission from [99]. 
Figure 15 shows the XRD patterns indexed to $g-\mathrm{C}_{3} \mathrm{~N}_{4}$ for different heating times and $\mathrm{MoS}_{2}$ samples. The bottom (green) XRD pattern was indexed to a hexagonal phase of $\mathrm{MoS}_{2}$ (JCPDS 37-1492) [100]. The peaks observed at $2 \theta=32.6^{\circ}$ and $58.3^{\circ}$ corresponded to the (100) and (110) crystal planes of metal chalcogenide, respectively. In addition, the XRD patterns of CN2.5, CN10, and CN20 samples showed similar peaks, as indicated in Figure 15 (JCPDS 87-1526). The peak at $2 \theta=27.4^{\circ}$ was indexed to the (002) stacking layered structure of $\mathrm{g}-\mathrm{C}_{3} \mathrm{~N}_{4}$ and the $2 \theta=13.0^{\circ}$ peak corresponded to the (100) in-plane of the repeating units [101]. The CM0.05 heterostructure pattern showed the sole $g-\mathrm{C}_{3} \mathrm{~N}_{4}$ peaks without the $\mathrm{MoS}_{2}$ peaks due to the low content of $\mathrm{MoS}_{2}$ [102-104].

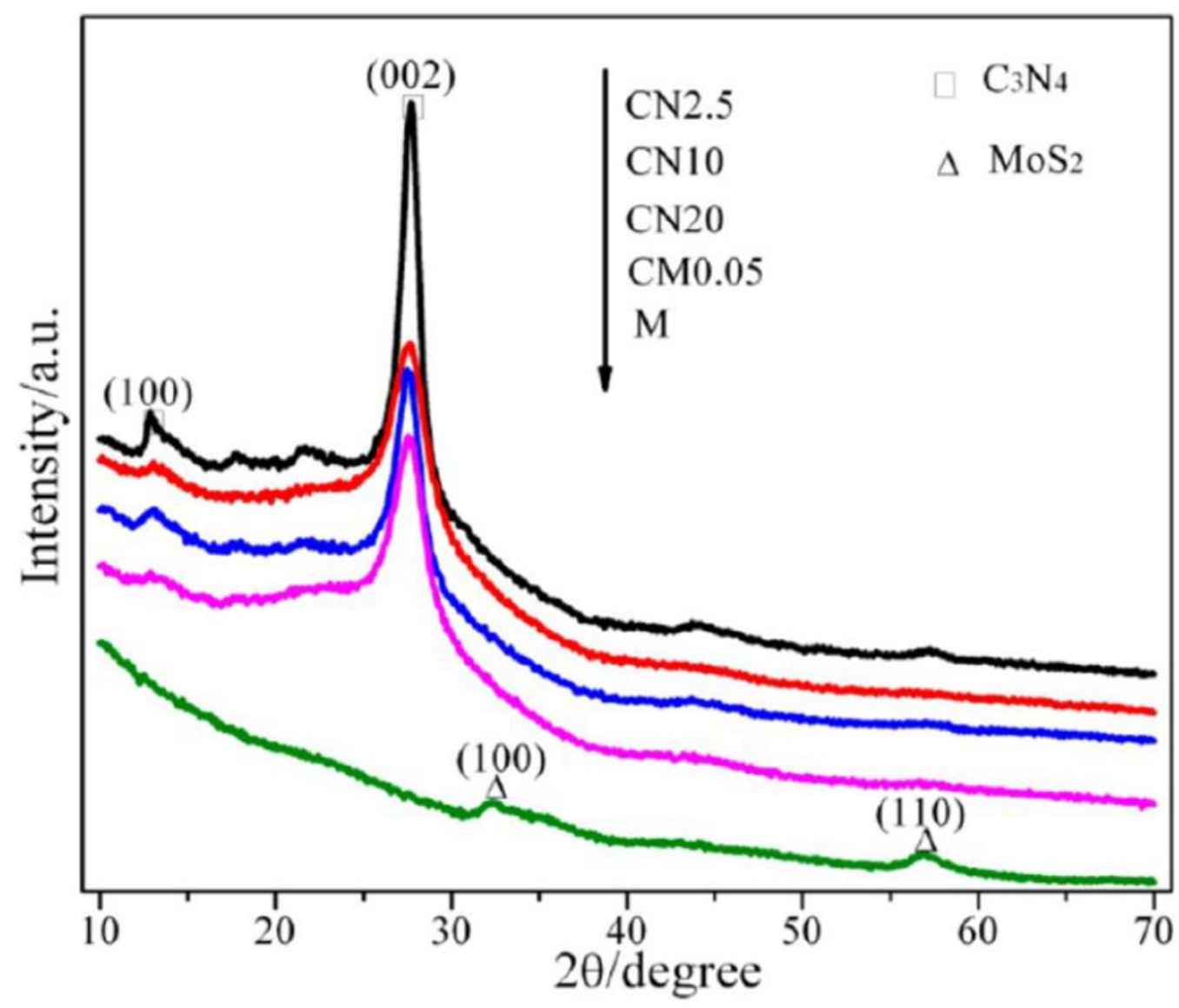

Figure 15. XRD patterns of CN2.5, CN10, CN20, CM0.05, and $\mathrm{M}\left(\mathrm{MoS}_{2}\right)$. Reproduced with permission from [101].

In a different study, pure $\mathrm{CoS}_{2}$, pure $\mathrm{TiO}_{2}$, and 10 wt. $\% \mathrm{CoS}_{2} / \mathrm{TiO}_{2}$ were successfully synthesized using the hydrothermal method [105]. XRD patterns confirmed the formation of these nanoparticles and the Figure 16 demonstrates the structural quality and phase orientation of the synthesized nanocomposite between the $2 \theta=20^{\circ}$ and $70^{\circ}$ diffraction angles. The XRD confirmed the anatase phase formation for $\mathrm{TiO}_{2}$, whereas the $\mathrm{CoS}_{2}$ phase formation was confirmed by the appearance of peaks at the $2 \theta$ degrees of $26.04^{\circ}$, $31.58^{\circ}, 37.08^{\circ}, 40.34^{\circ}, 45.34^{\circ}$, and $55.1^{\circ}$ for the (111), (200), (210), (211), (220), and (311) diffraction planes, respectively (JCPDS Card No.: 9007682). Impregnation of $\mathrm{CoS}_{2}$ on $\mathrm{TiO}_{2}$ was confirmed by the combined XRD peaks obtained with the $10 \mathrm{wt}$. \% of $\mathrm{CoS}_{2} / \mathrm{TiO}_{2}$ nanocomposite materials. 


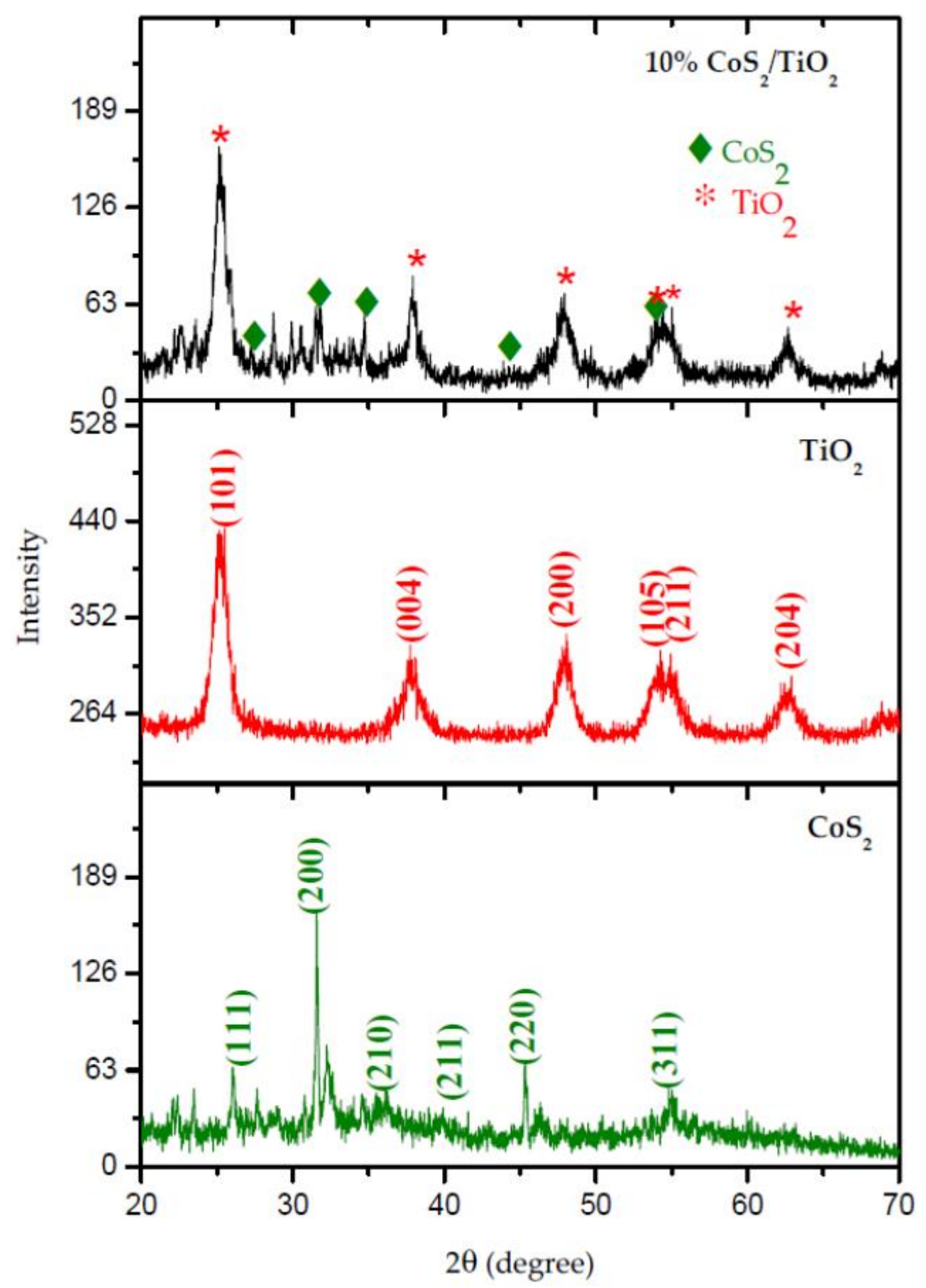

Figure 16. XRD pattern of pure $\mathrm{CoS}_{2}$, pure $\mathrm{TiO}_{2}$, and 10 wt. $\%$ of the $\mathrm{CoS}_{2} / \mathrm{TiO}_{2}$ nanocomposite. Reproduced with permission from [105].

In another study, $\mathrm{SnS}_{2} / \mathrm{TiO}_{2}$ nanocomposites were synthesized by the hydrothermal method, and XRD analysis was carried out to characterize those materials. Figure 17 shows that the peaks at the 2-theta value of $25.29,37.88,48.25,53.74,55.14,62.71,68.86,70.30$, and 75.06 for the pure $\mathrm{TiO}_{2}$ nanoparticles were due to the (101), (004), (200), (105), (211), (204), (116), (220), and (215) diffraction planes of the anatase phase of $\mathrm{TiO}_{2}$, which was well matched with the JCPDS:00-004-0477. The observed peaks at $2 \theta$ values of 14.76, 27.97, $32.00,41.79,49.92,52.41,54.79$, and 60.55 for pure $\mathrm{SnS}_{2}$ was correlated to the (001), (100), (101), (102), (110), (111), (103), and (201) diffraction planes (JCPDS:00-023-0677). 
Combined peaks of both $\mathrm{SnS}_{2}$ and $\mathrm{TiO}_{2}$ were observed with the 5, 10, 15, and 20 wt. \% $\mathrm{SnS}_{2} / \mathrm{TiO}_{2}$ (ST-5, ST-10, ST-15, and ST-20, respectively) nanocomposite and confirmed the good impregnation of $\mathrm{SnS}_{2}$ on $\mathrm{TiO}_{2}$ in their study [106].

\subsubsection{Scanning Electron Microscopy (SEM)}

Scanning electron microscopy (SEM) is an established technique used to analyze the morphology of the sample, especially given the simplicity of the sample preparation. Estimates of the sample composition can be obtained through energy dispersive X-ray spectroscopy (EDS).

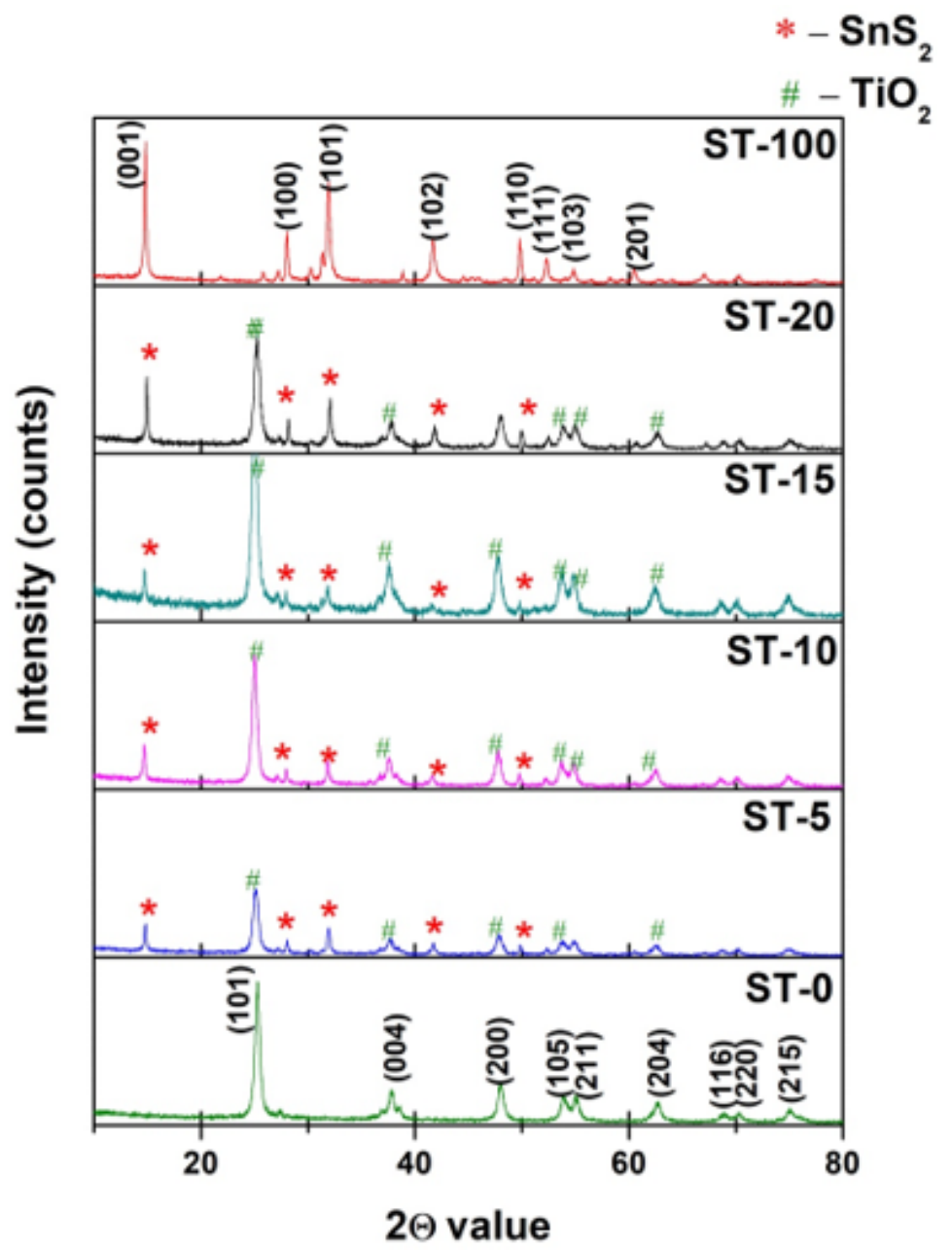

Figure 17. XRD image for pure $\mathrm{SnS}_{2}$ (ST-100), pure $\mathrm{TiO}_{2}$ (ST-0), different wt. \% of $\mathrm{SnS}_{2} / \mathrm{TiO}_{2}$ materials 5\% (ST-5), 10\% (ST-10), 15\% (ST-15), and 20\% (ST-20). Reproduced with permission from [106].

In addition, the particle size distribution can also be easily obtained with relative ease, and thus, many of the reported works have used this simple characterization technique to study the TMC materials using SEM.

Figure 18 exhibits the phase and morphology transformation of intermediates during the formation of monodispersed $\mathrm{SnS}_{2}$ nanosheets; consequently, the effects of the reaction parameters including reaction time and the dosage of polyvinylpyrrolidone (PVP) on the morphology of $\mathrm{SnS}_{2}$ was also studied. PVP was used as a steric stabilizer or capping agent to minimize aggregation of the colloidal particles. 

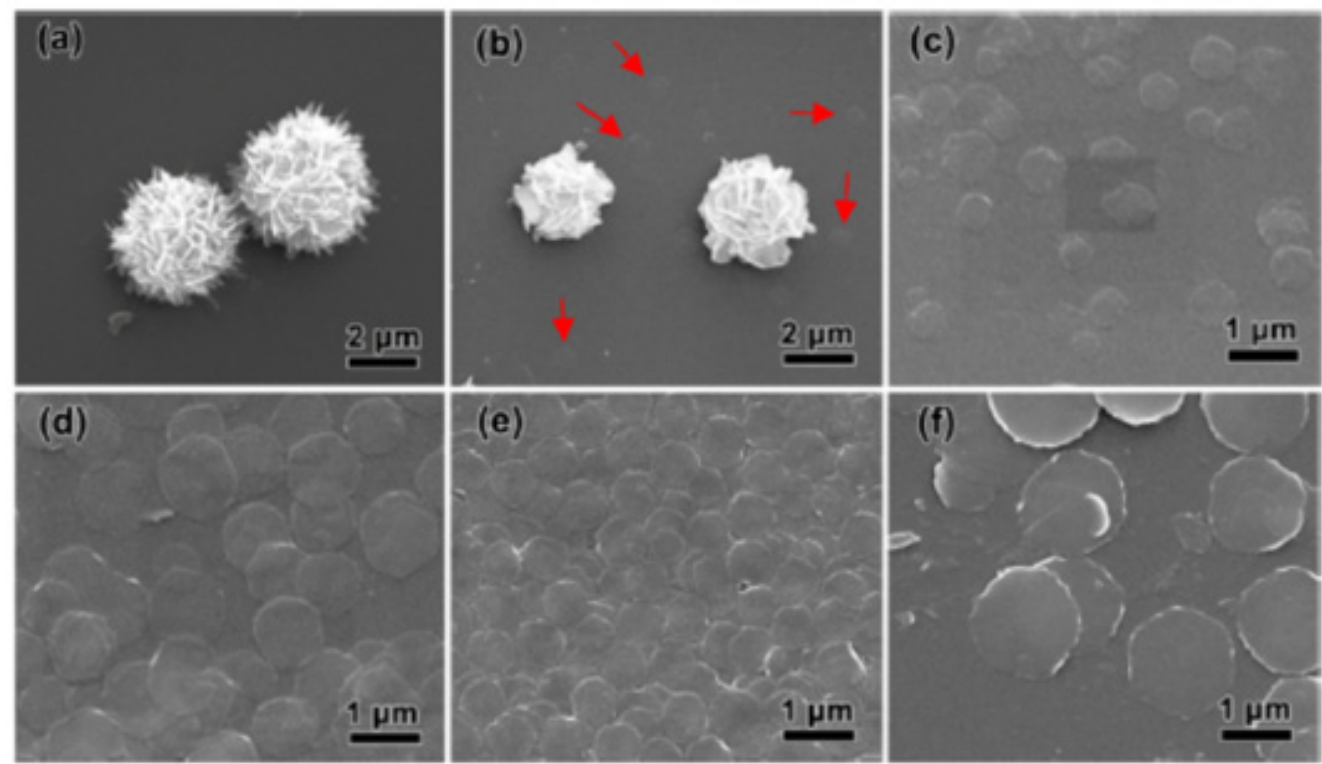

Figure 18. SEM images of the $\mathrm{SnS}_{2}$ samples prepared at different reaction times. (a) $1 \mathrm{~h}$; (b,c) 2 h; (d) $5 \mathrm{~h}$; (e) $12 \mathrm{~h}$; and (f) $24 \mathrm{~h}$. Reproduced with permission from [38].

Figure 18a shows the structure of orthorhombic SnS microspheres stacked by sheets, which were first nucleated in the primary stage of a chemical reaction. When the reaction time increased to $2 \mathrm{~h}$, small sheets expanded and grew onto larger sheets. At the same time, in Figure 18b, the spherical flower-like morphology remained and the regular nanosheets were deposited around micro-flowers. Figure 18c is the high-magnification SEM image with the reaction time of $2 \mathrm{~h}$, which exhibits the deposited nanosheets. When the reaction time was prolonged to $5 \mathrm{~h}$, uniform nanosheets were obtained with the single phase of hexagonal $\mathrm{SnS}_{2}$. Consequently, it was proven that the $\mathrm{SnS}$ phase would be oxidized into $\mathrm{SnS}_{2}$ gradually as the reaction progresses. Furthermore, as the reaction time increases, $\mathrm{SnS}_{2}$ nanosheets tend to grow and enhance their crystallinity [38], which was proven by SEM analysis.

In another study, a different $\mathrm{TMC}, \mathrm{NiS}_{2}$ particles with a hollow structure, were synthesized and characterized by FESEM. Figure 19a,b indicates the FESEM images of $\mathrm{NiS}_{2}$ hollow microspheres prepared on a large scale. Figure 19b shows that the diameter of $\mathrm{NiS}_{2}$ hollow microspheres was about $3 \mu \mathrm{m}$ and it was found that the surface of the microspheres was rough. The thickness of the wall was found to be approximately $200 \mathrm{~nm}$ (Figure 19c), and the hollow structure can be clearly seen in this image. Figure 20d shows a high-resolution TEM image that displays the lattice fringes of $\mathrm{NiS}_{2}$. The lattice distance was $0.286 \mathrm{~nm}$, which corresponds to the (200) crystal plane [13].

In a different study, $\mathrm{TMC}$ doped $\mathrm{TiO}_{2}$ materials were synthesized and studied for hydrogen production. Sivagowri et al. synthesized a $\mathrm{CoS}_{2} / \mathrm{TiO}_{2}$ nanocomposite using hydrothermal methods. As shown in the SEM images of pure $\mathrm{CoS}_{2}$ (Figure 20a,b), aggregates stacked by flake-like structures were attained. The image for pure $\mathrm{TiO}_{2}$ (Figure 20c,d) showed an irregular 3-D block-like structure covered with spongy like particles, whereas $\mathrm{CoS}_{2} / \mathrm{TiO}_{2}$ indicates a hexagonal rod like structure decorated with sponge like materials, as illustrated in Figure 20e,f [105]. 


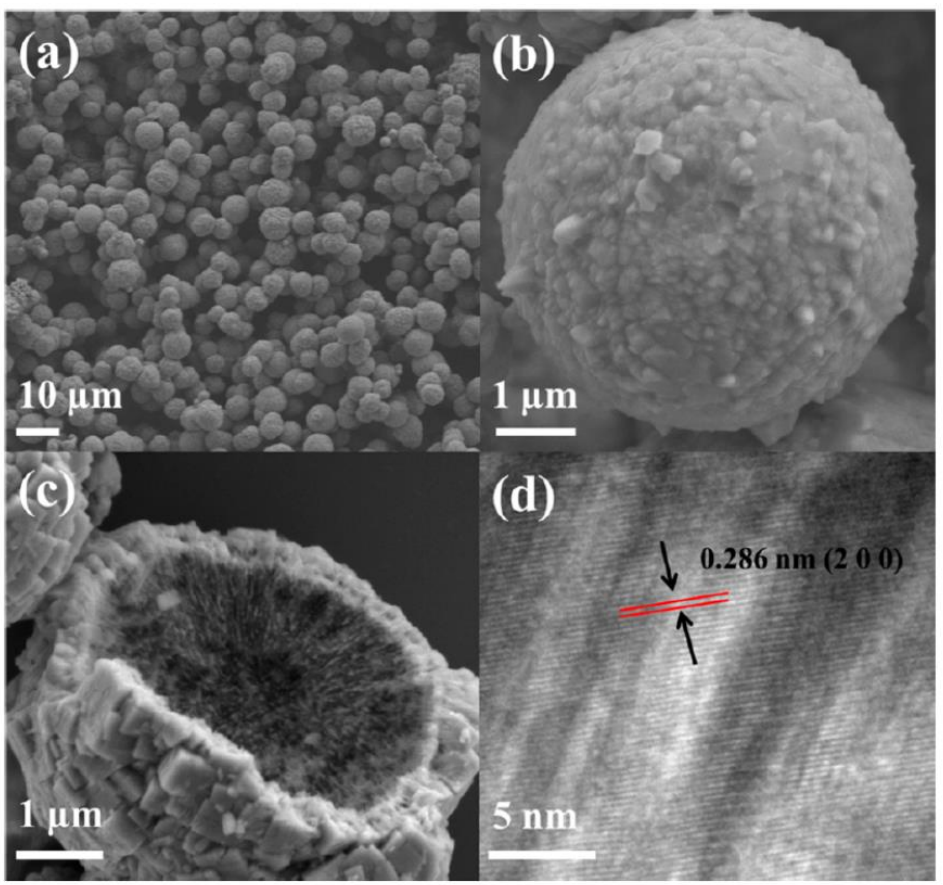

Figure 19. (a-c) Field emission scanning electron microscopy (FESEM) images of $\mathrm{NiS}_{2}$ hollow microspheres at different magnifications. (d) High-resolution transmission electron microscope (TEM) image of $\mathrm{NiS}_{2}$. Reproduced with permission from [13].

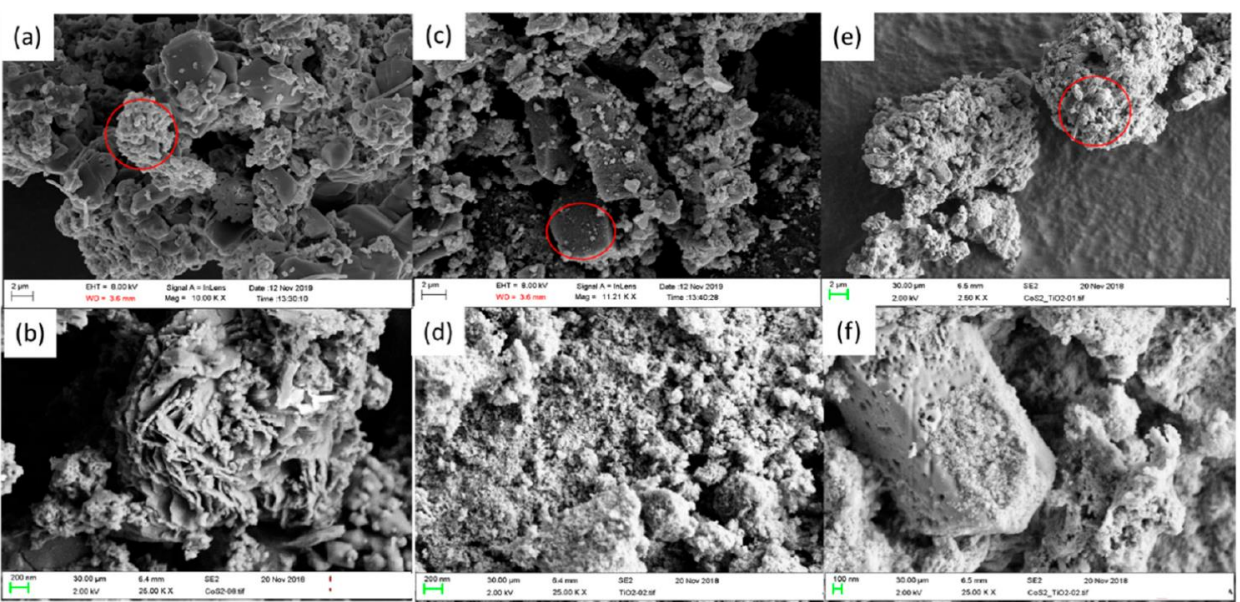

Figure 20. SEM images of $(\mathbf{a}, \mathbf{b})$ - pure $\mathrm{CoS}_{2},(\mathbf{c}, \mathbf{d})$ - pure $\mathrm{TiO}_{2}$, and $(\mathbf{e}, \mathbf{f})-\mathrm{CoS}_{2} / \mathrm{TiO}_{2}$ nanocomposites. Reproduced with permission from [105].

The same group, in a different study, reported that a different morphology was attained with $\mathrm{SnS}_{2}-\mathrm{TiO}_{2}$ nanocomposites when only the TMC was changed. In the SEM study, they observed that the pure $\mathrm{TiO}_{2}$ nanoparticle showed an irregular 3-D block-like structure covered with sponge-like particles as indicated in Figure 21a. The micrograph obtained in the higher magnification (Figure 21b) image indicates that the aggregated particles had spongy-like structures. A flower-like structure composed with nanosheets was attained for pristine $\mathrm{SnS}_{2}$ and is shown in Figure 21c,d. 

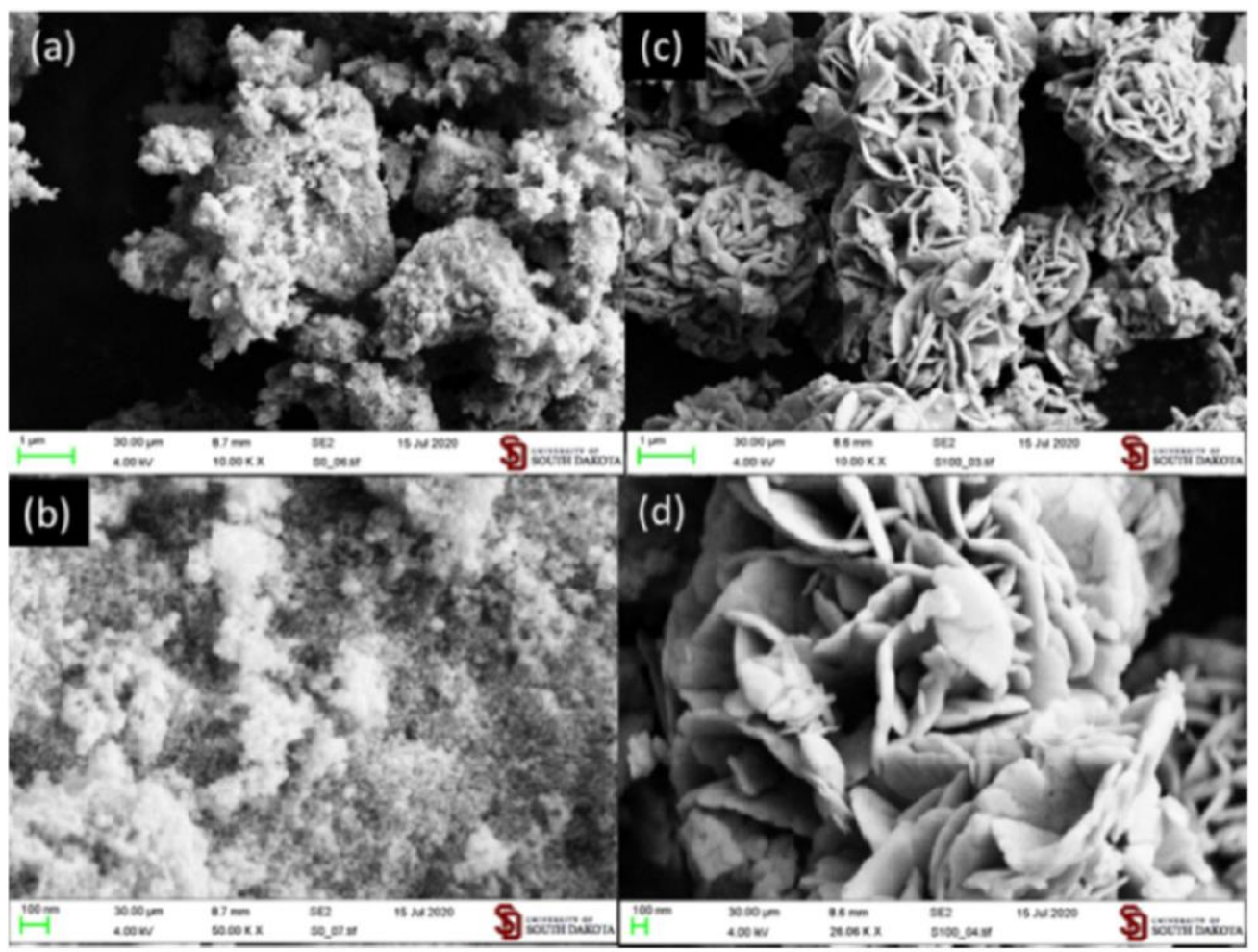

Figure 21. SEM images for $(\mathbf{a}, \mathbf{b})-$ pure $\mathrm{TiO}_{2}$ and $(\mathbf{c}, \mathbf{d})$ - pure $\mathrm{SnS}_{2}$. Reproduced with permission from [106].

The SEM images of different wt. \% of $\mathrm{SnS}_{2}$ that included 5\% (Figure 22e), 10\% (Figure 22f), 15\% (Figure 22g), and 20\% (Figure 22h) embedded $\mathrm{TiO}_{2}$ nanocomposites are shown in Figure 22. The surface morphology of these $\mathrm{SnS}_{2} / \mathrm{TiO}_{2}$ nanocomposites at different wt. \% possessed nanosheets, and it can be seen that the sponge-like materials covered the structure and, therefore, exhibited significant aggregation [106].

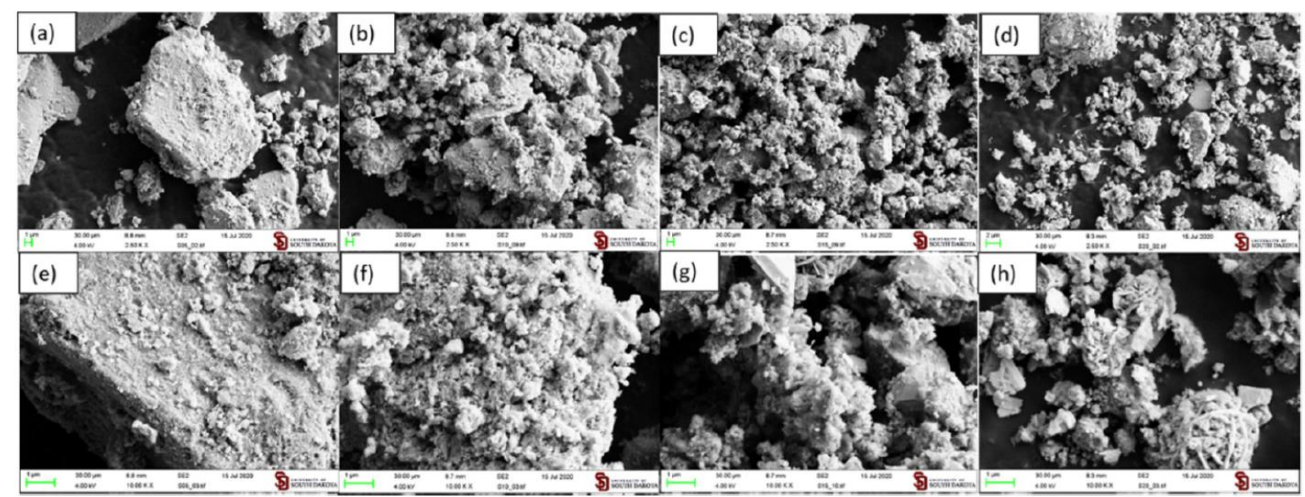

Figure 22. SEM images for different wt. \% of $\mathrm{SnS}_{2} / \mathrm{TiO}_{2}(\mathbf{a}, \mathbf{e}) 5 \%$, (b,f) $10 \%$, (c, g) $15 \%$, and (d,h) $20 \%$. nanocomposites. Reproduced with permission from [106].

\subsubsection{X-ray Photoelectron Spectroscopy (XPS) Studies}

X-ray photoelectron spectroscopy (XPS) is based on the photoelectric effect and was used to investigate the chemical state and surface elemental composition of the samples. Among the literature collected, it was found that only a few reports have presented the XPS analysis of TMC material, which may be due to the necessity of the analysis for the structure-activity correlation. In a study by Bo Gao et al., a $\mathrm{MoS}_{2}$ /candle soot composite was synthesized and analyzed using XPS. Figure 23 shows the existence of the elements $\mathrm{C}, \mathrm{Mo}$, and $\mathrm{S}$ with a small amount of $\mathrm{O}$. The corresponding peaks indicate the binding 
energies at 284.6 (C 1s), 161.5 (S 2p), 231.0 (Mo 3d), and $529.1 \mathrm{eV}$ (O 1s), respectively. In addition, the atomic ratio between $\mathrm{Mo}$ and $\mathrm{S}$ was found to be 0.43 . Figure $23 \mathrm{~b}$ illustrates the presence of peaks with binding energies of 232.8 and $229.7 \mathrm{eV}$, which may be ascribed to $\mathrm{Mo} 3 \mathrm{~d}_{3 / 2}$ and $3 \mathrm{~d}_{5 / 2}$ of $2 \mathrm{H}-\mathrm{MoS}_{2}$ at the peaks at $228.9 \mathrm{eV}$ for $3 \mathrm{~d}_{5 / 2}$, and at $231.9 \mathrm{eV}$ for $3 \mathrm{~d}_{3 / 2}$, which was ascribed to $1 \mathrm{~T}-\mathrm{MoS}_{2}$ [107]. The peak located at $226.9 \mathrm{eV}$ corresponded to the binding energy of $S$ 2s. In addition, the two weak peaks at 233.6 and $236.1 \mathrm{eV}$ were due to the presence of the $\mathrm{MoO}_{3}$ that formed during the sputtering process. From these results, they found that $\mathrm{Mo}^{4+}$ dominates the product. Similarly, the two doublet peaks located at $162.6 \mathrm{eV}$ and $164.1 \mathrm{eV}$ corresponded to the $2 \mathrm{p}_{3 / 2}$ and $2 \mathrm{p}_{1 / 2}$ orbitals of $2 \mathrm{H}-\mathrm{MoS}_{2}$. Furthermore, the binding energies at $161.6 \mathrm{eV}$ and $163.2 \mathrm{eV}$ were due to $1 \mathrm{TMoS}_{2}$. The high-resolution spectra of XPS further provides evidence for the existence of $\mathrm{MoS}_{2}$ in the hybridized samples [108].

In a different study, $\mathrm{Li}$ and coworkers used XPS characterization to study the Pt doped $\mathrm{CdS}$ materials and Figure 24a illustrates the XPS spectrum of the $\mathrm{Pt}-\mathrm{CdS}$, indicating the co-existence of $\mathrm{Cd}, \mathrm{S}$, and Pt elements in the as-prepared $\mathrm{Pt}-\mathrm{CdS}$ composite. The peaks at 405.6 and $412.3 \mathrm{eV}$ corresponded to the $\mathrm{Cd} 3 \mathrm{~d}_{5 / 2}$ and $\mathrm{Cd} 3 \mathrm{~d}_{3 / 2}$ of $\mathrm{CdS}$, respectively (Figure 24b) [25]. In Figure 24c, the $S 2 p_{1 / 2}$ and $S 2 p_{3 / 2}$ peaks are located at 163.2 and $161.9 \mathrm{eV}$, respectively.

\subsubsection{UV-Visible Spectroscopy/Diffuse Reflectance Spectroscopy (DRS)}

Like all nanomaterials, to study the bandgap and the optical behavior of the TMCs, researchers have utilized UV-Visible diffuse reflectance spectroscopy. In this regard, in the

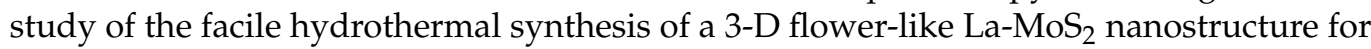
photocatalytic hydrogen energy production, Riaz et al. utilized this technique to study the bandgap of La doped $\mathrm{MoS}_{2}$ materials, as illustrated in Figure 25.
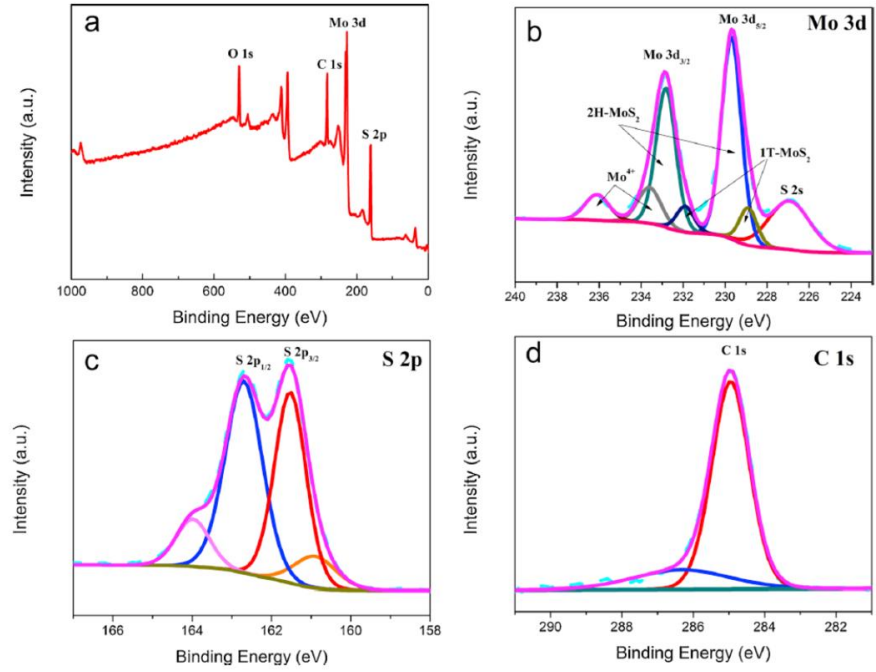

Figure 23. Full XPS spectra of (a) $\mathrm{MoS}_{2}$ / candle soot composite, (b-d) high-resolution XPS spectra of Mo 3d, S 2p, and C 1s for $\mathrm{MoS}_{2}$ /candle soot composite. Reproduced with permission from [108].
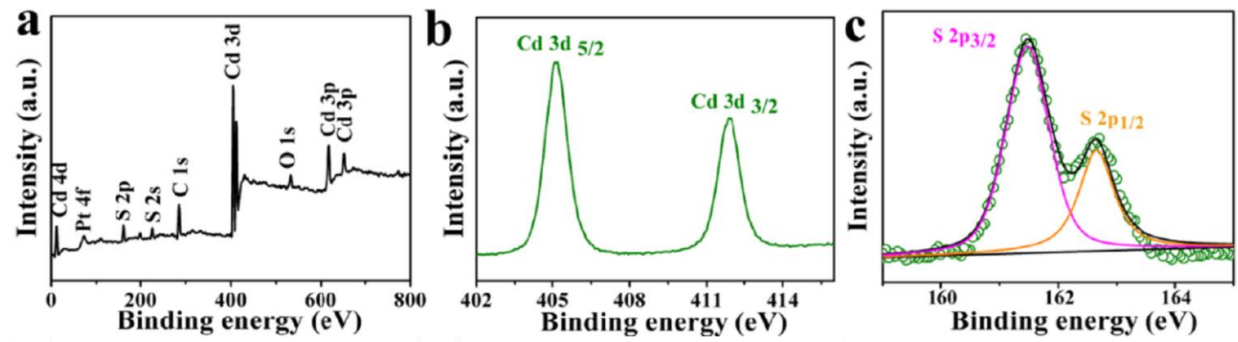

Figure 24. (a) XPS of Pt-CdS and the corresponding high-resolution XPS spectra of Pt-CdS, (b) Cd $3 d$, and (c) S 2p. Reproduced with permission from [25]. 

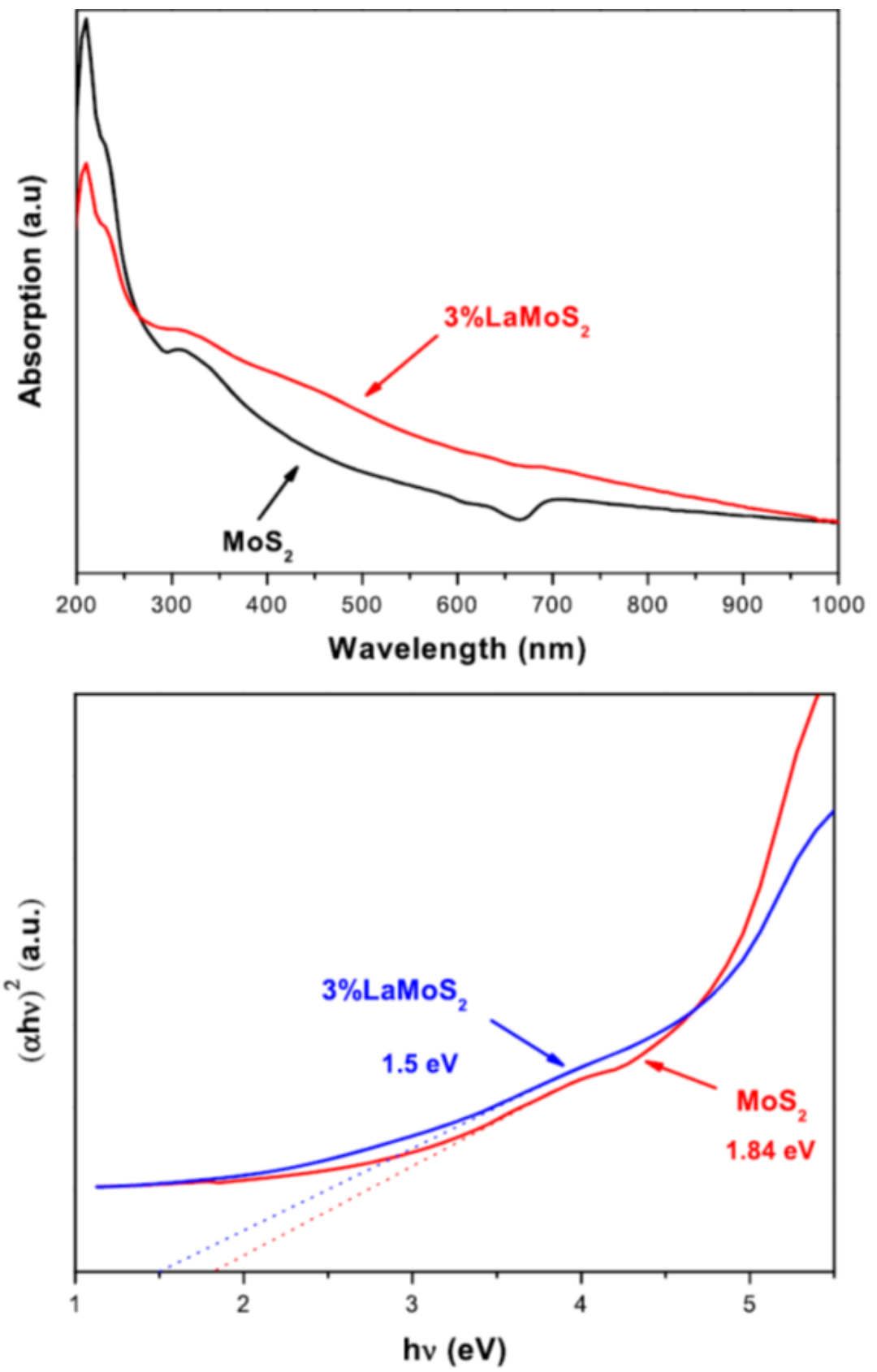

Figure 25. UV-Visible absorption spectra of 3-D flower-like $\mathrm{MoS}_{2}$ and 3\% $\mathrm{LaMoS}_{2}$ nanoflake samples. Reproduced with permission from [109].

The absorption spectra of pure $\mathrm{MoS}_{2}$ and 3\% La-MoS 2 indicate that the absorption of $\mathrm{LaMoS}_{2}$ was significantly extended toward a longer wavelength than pure $\mathrm{MoS}_{2}$ into the visible light range. Bandgap energy for pure $\mathrm{MoS}_{2}$ calculated by using the equation $(\alpha \mathrm{hv})^{2}=\mathrm{A}(\mathrm{hv}-\mathrm{Eg})$ allowed for direct transitions, resulting in a value of $1.84 \mathrm{eV}$, which is illustrated in the plot of $(\alpha \mathrm{hv})^{2}$ vs. $\mathrm{hv}(\mathrm{eV})$ (Figure 25). This value is close to the bandgap energy of $1.8 \mathrm{eV}$ for a monolayer of $\mathrm{MoS}_{2}$ [110]. However, 3\% La-MoS 2 showed a considerably small bandgap energy of $1.5 \mathrm{eV}$ due to $\mathrm{La}^{3+}$ doping, which significantly improved the light absorption properties of $\mathrm{MoS}_{2}$ [109].

Gaur et al. used $\mathrm{SnS}_{2}$ nanoparticles as photocatalysts for the reduction of $\mathrm{Cr}(\mathrm{VI})$ and their optical properties were investigated by DRS studies. Figure 26a,b shows DRS and Tauc plots of $\mathrm{SnS}_{2}$ nanoparticles. Bandgap absorption in the range between $430 \mathrm{~nm}$ and $580 \mathrm{~nm}$ was observed. The bandgap calculated by using the Tauc plot indicates values between $2.31 \mathrm{eV}$ and $2.94 \mathrm{eV}$ [111]. 
In addition to these methods, Raman spectroscopic technique and photoluminescence studies (PL) were also utilized to analyze these TMC materials. However, there is a limited number of literature available, especially with the PL and AFM studies on the TMC materials toward hydrogen production application, and thus, were omitted in this review.

\subsubsection{Raman Spectroscopy}

L. Zhu et al. synthesized $\mathrm{CoS}_{2}$-based thin films as model catalysts for the oxygen reduction reaction, which were characterized by using Raman spectroscopy. Figure 27 shows characteristic peaks at 287 and $389 \mathrm{~cm}^{-1}$ as well as a shoulder around $410 \mathrm{~cm}^{-1}$ for the $\mathrm{CoS}_{2}$ powder. This was in close agreement with the study of a $\mathrm{CoS}_{2}$ single crystal [112]. The peak at $287 \mathrm{~cm}^{-1}$ was also associated with polysulfides. In contrast, the Raman spectrum obtained from the magnetron-sputtered thin film of $\mathrm{CoS}_{2}$ showed a pronounced peak at $391 \mathrm{~cm}^{-1}$, a broad shoulder at around $410 \mathrm{~cm}^{-1}$, and another peak at $287 \mathrm{~cm}^{-1}$, which exhibited a general similarity to the spectrum obtained for the standard $\mathrm{CoS}_{2}$. Furthermore, the Raman spectrum of commercial $\mathrm{NiS}_{2}$ was also reported in their study and it showed distinctive peaks at 282 and $477 \mathrm{~cm}^{-1}$, and a shoulder at $488 \mathrm{~cm}^{-1}$ (Figure 27). From this study, they confirmed the formation of $\mathrm{CoS}_{2}$ with the expected characteristics.
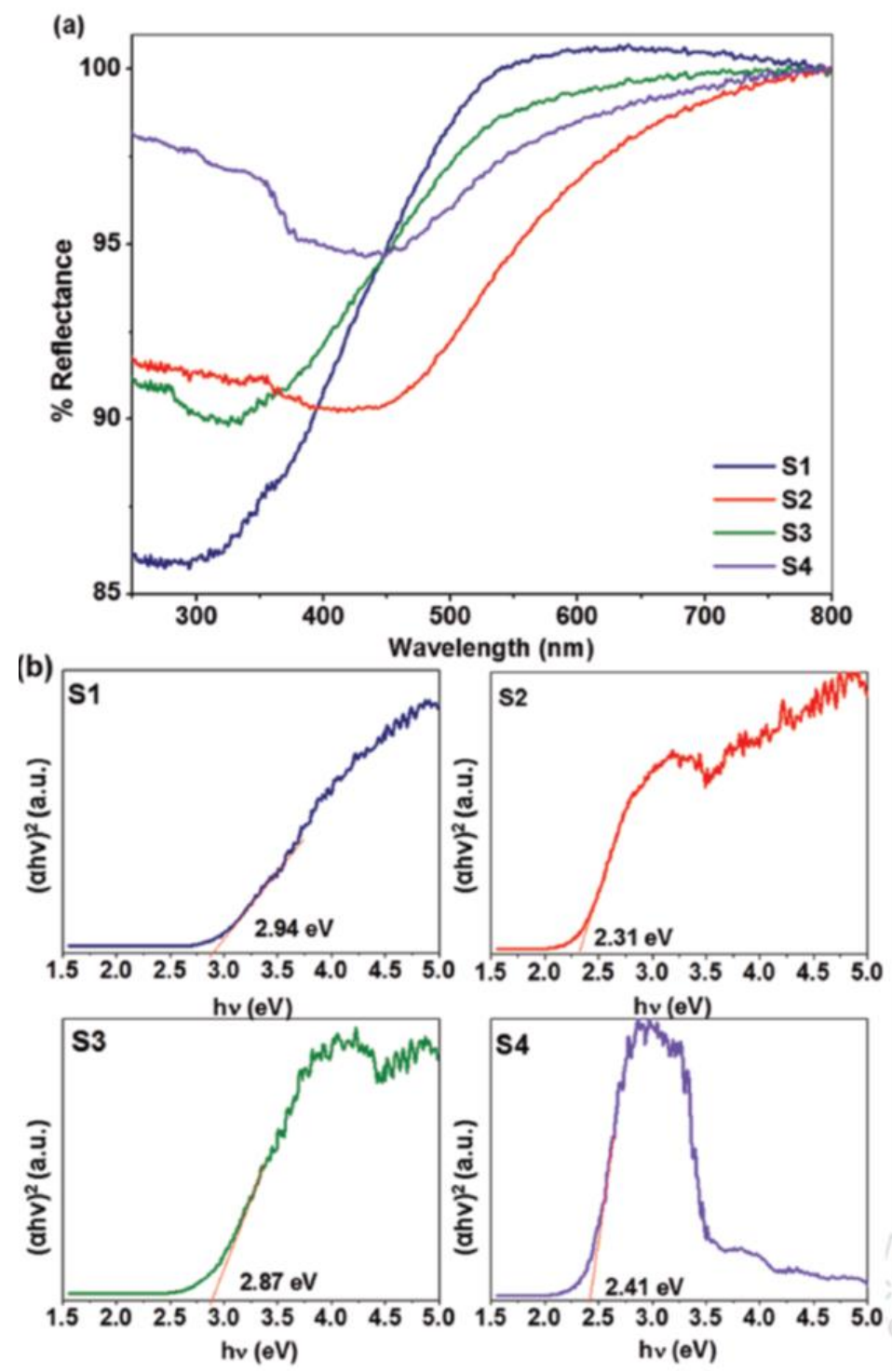

Figure 26. (a) DRS spectra and (b) Tauc plots for $\mathrm{SnS}_{2}$ nanoparticles synthesized by using different reactants and solvents. Reproduced with permission from [111]. 


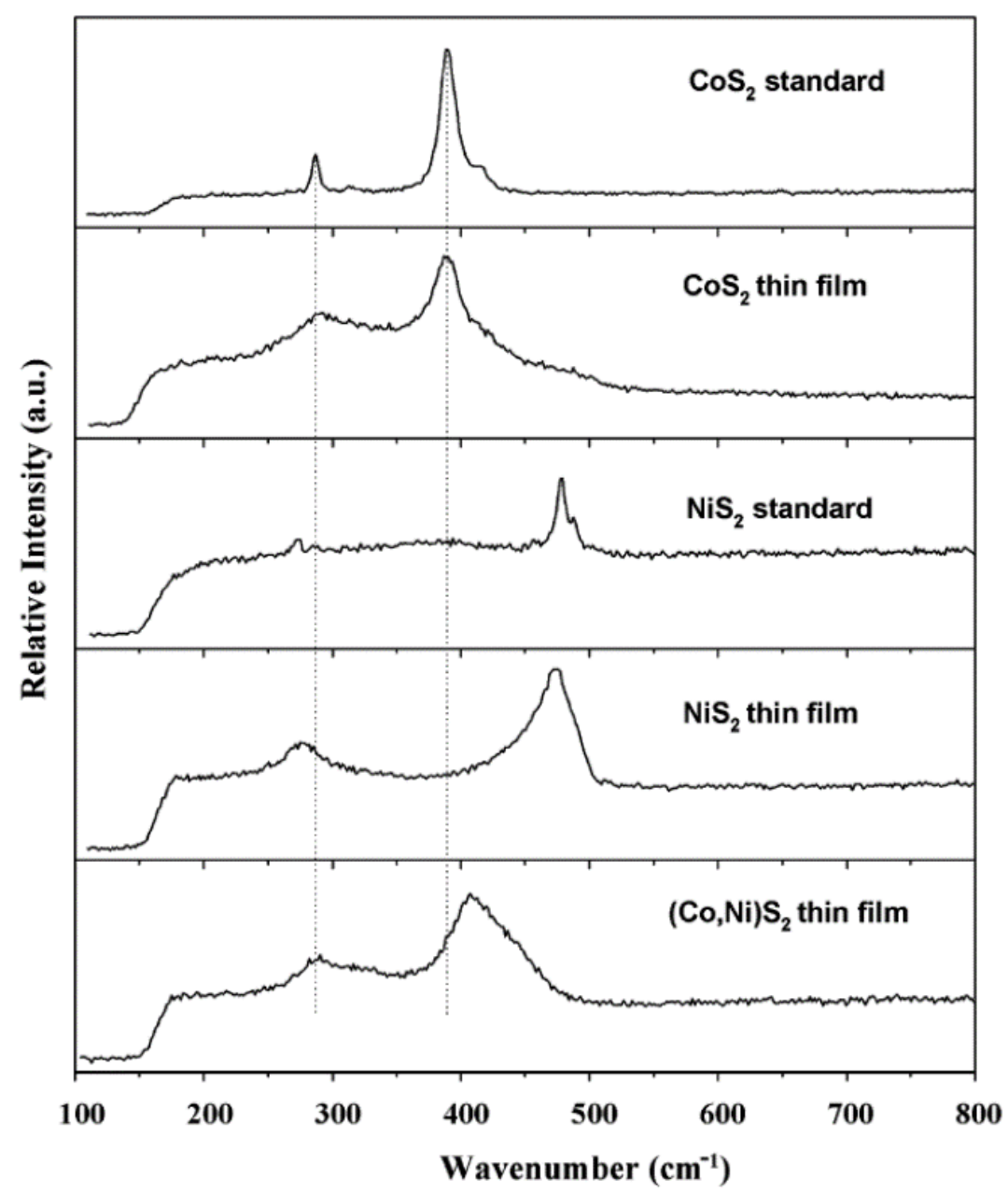

Figure 27. Raman spectra measured with $\mathrm{HeNe}$ laser for the $\mathrm{CoS}_{2}, \mathrm{NiS}_{2}$ and $(\mathrm{Co}, \mathrm{Ni}) \mathrm{S}_{2}$ thin films and compared with those measured for standard $\mathrm{CoS}_{2}$ and $\mathrm{NiS}_{2}$ samples. Reproduced with permission from [112].

\section{Hydrogen Evolution Reactions}

Production of hydrogen through water splitting is seen as an extremely important renewable and clean energy [4]. Since water is abundant, and as novel materials are synthesized and the technology of water splitting becomes mature, hydrogen can be produced from water by different methods such as thermolysis (e.g., thermochemical cycles), electrolysis (e.g., electrocatalysis), photolysis (e.g., photocatalysis), and biolysis (e.g., dark fermentation) [113].

Among them, electrolysis of water, which includes the cathodic hydrogen evolution reaction (HER) [113] and anodic oxygen evolution reaction (OER) [113], remains limited by the high cost of noble metals such as Pt [114] and Ru [115] based materials, which are typically used as electrocatalysts in different electrolyte materials that include acid and base electrolytes [116]. In addition, different photocatalytic materials are being used to utilize solar energy for splitting water $[37,105,117]$. Photoelectrochemical and photocatalytic are the two main methods for water splitting. In the photoelectrochemical method, a semiconductor photoelectrode is typically used as the working electrode and is immersed in an aqueous electrolyte. A counter and reference electrode are used to complete the cell. An electrochemical potential is then applied to the photoelectrode. A light source is used to excite the semiconductor electrode. If an n-type semiconductor is used, the photoexcited electrons generated in the photoanode travel to the counter electrode (via an external wire) and reduce protons to form hydrogen. At the working electrode, the holes oxidize water to 
produce oxygen and an anodic photocurrent is produced. Thus, the products, hydrogen and oxygen, are produced at separate electrodes.

In the photocatalytic method, the semiconductor powder is suspended in water. The slurry is irradiated by an appropriate light source. Bandgap excitation leads to the generation of electrons and holes. These charge carriers migrate to the surface and dissipate their charges and produce hydrogen and oxygen, respectively. In photocatalysis, the product separation is required. Nowadays, researchers are putting great effort into maximizing the production of hydrogen by water splitting with the eventual aim to generate hydrogen through sustainable ways [13,118-120].

The following table (Table 2) lists the different hydrogen production methods and their advantages and disadvantages.

Table 2. Different hydrogen production methods and its advantages and disadvantages.

\begin{tabular}{|c|c|c|c|c|}
\hline $\begin{array}{l}\text { Hydrogen } \\
\text { Production } \\
\text { Methods }\end{array}$ & Description & Advantages & Disadvantages & Reference \\
\hline $\begin{array}{l}\text { Steam natural } \\
\text { gas reforming }\end{array}$ & $\begin{array}{l}\text { Direct production of hydrogen } \\
\text { gas by conversion of feed } \\
\text { hydrocarbons at } \\
\text { high temperature }\end{array}$ & $\begin{array}{l}\text { Most viable technology to } \\
\text { begin building } \\
\text { hydrogen market } \\
\text { Existing feedstock } \\
\text { infrastructure }\end{array}$ & $\begin{array}{l}\text { - } \quad \text { Capital investment is high } \\
\text { High operation and } \\
\text { - } \quad \mathrm{CO}_{2} \text { byproduct } \\
\text { - } \quad \text { Dependence on fossil fuels }\end{array}$ & [121-123] \\
\hline Coal gasification & $\begin{array}{l}\text { Partial oxidation of coal with air. } \\
\text { However, it generates the } \mathrm{CO}_{2} \\
\text { through traditional combustion }\end{array}$ & $\begin{array}{l}\text { - } \quad \text { Low-cost } \\
\text { Uses abundant and } \\
\text { affordable coal feedstock }\end{array}$ & $\begin{array}{ll}\text { - } & \text { High reactor costs } \\
\text { - } & \text { System efficiency } \\
\text { - } & \text { Feedstock impurities } \\
\text { - } & \text { Carbon capture } \\
& \text { and storage }\end{array}$ & {$[123,124]$} \\
\hline Biomass gasification & $\begin{array}{l}\text { Burning of biomass using } \\
\text { limited supply of air generates } \\
\text { combustible gases, such as } \mathrm{CO} \text {, } \\
\mathrm{CO}_{2}, \mathrm{H}_{2} \mathrm{CH}_{4}, \mathrm{H}_{2} \mathrm{O} \text { and } \mathrm{N}_{2} \text { with } \\
\text { contaminants like small char } \\
\text { particles, ash and tars }\end{array}$ & $\begin{array}{l}\text { - } \mathrm{CO}_{2} \text {-neutral, abundant } \\
\text { and cheap feedstock }\end{array}$ & $\begin{array}{l}\text { - } \quad \text { Tar formation } \\
\text { Varying } \mathrm{H}_{2} \text { content due } \\
\text { to seasonal } \\
\text { - } \\
\text { Availability and feed } \\
\text { stock impurities }\end{array}$ & {$[122,125]$} \\
\hline Thermolysis & $\begin{array}{l}\text { Using high temperature from } \\
\text { concentrated solar energy and } \\
\text { chemical reactions to generate } \\
\text { the } \mathrm{H}_{2} \text { and } \mathrm{O}_{2} \text { from water. }\end{array}$ & $\begin{array}{l}\text { - Clean and Sustainable, } \\
\text { abundant feedstock } \\
\mathrm{O}_{2} \text { is the only byproduct; } \\
\text { No greenhouse } \\
\text { gas emissions }\end{array}$ & $\begin{array}{ll}- & \text { Element's toxicity } \\
- & \text { Corrosive problems } \\
- & \text { High capital costs }\end{array}$ & {$[122,123]$} \\
\hline Electrolysis & $\begin{array}{l}\text { Usage of electricity to split water } \\
\text { into hydrogen and oxygen }\end{array}$ & 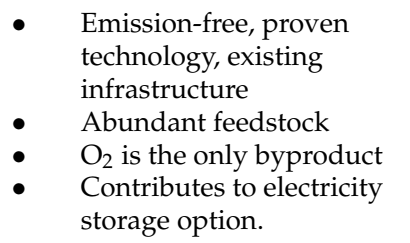 & $\begin{array}{l}\text { - } \quad \text { Low overall efficiency } \\
\text { - } \quad \text { High capital costs }\end{array}$ & {$[114,122]$} \\
\hline Photoelectrochemical & $\begin{array}{l}\text { Hydrogen is produced from } \\
\text { water in the presence of sunlight } \\
\text { and specialized semiconductors } \\
\text { immersed in water-based } \\
\text { electrolytes }\end{array}$ & $\begin{array}{l}\text { - } \quad \text { Abundant feedstock } \\
\text { - } \quad \mathrm{O}_{2} \text { is the only byproduct }\end{array}$ & $\begin{array}{l}\text { - } \quad \text { Low conversion efficiency } \\
\text { Non-effective } \\
\text { photocatalytic material }\end{array}$ & {$[10,114,126]$} \\
\hline Photocatalytic & $\begin{array}{l}\text { A simple method to produce } \\
\text { hydrogen from water in the } \\
\text { presence of catalyst and sunlight }\end{array}$ & $\begin{array}{l}\text { - Photocatalyst material } \\
\text { directly suspended in to } \\
\text { the water } \\
\text { - } \quad \text { Simple/facile method }\end{array}$ & $\begin{array}{ll}\text { - } & \text { Low yield } \\
\text { - } & \text { Separation of gases } \\
\text { - } & \text { Selection of } \\
& \text { suitable catalyst } \\
\text { - } \quad \text { Separation of } \\
\quad \text { suspended catalysts }\end{array}$ & {$[10,127,128]$} \\
\hline
\end{tabular}

In recent years, the structure of the synthesized catalyst and the hydrogen evolution activities have been investigated theoretically using density functional theory (DFT) [129]. In this regard, theoretical studies of metal chalcogenide materials have been conducted. In a recent paper, Som et al. investigated the structural property of $\mathrm{ZrS}_{2}$, Janus $\mathrm{ZrSSe}$, 
and $\mathrm{ZrSe}_{2}$ and their catalytic activity from hydrogen evolution reactions [130]. From these calculations, they found that $\mathrm{ZrS}_{2}$ possessed a larger bandgap energy of $1.58 \mathrm{eV}$, whereas $\mathrm{ZrSSe}$ and $\mathrm{ZrSe}_{2}$ exhibited bandgap energies of $1.08 \mathrm{eV}$ and $0.84 \mathrm{eV}$, respectively. In addition, Janus ZrSSe (DG $\frac{1}{4}$ 1:19 eV; DG: Gibbs free energy) was found to be the optimal catalyst [130] among the materials studied. Another study examined the electronic and optical properties and the potential applications of 2-D MoSe $2 / \mathrm{SnS}_{2}$ van der Waals heterojunction as a photocatalyst for overall water splitting. The DFT calculations showed that the $\mathrm{MoSe}_{2} / \mathrm{SnS}_{2}$ heterostructure, as a direct Z-scheme photocatalyst, effectively absorbs visible light. The separation efficiency of photo-induced carriers was enhanced due to the induced built-in electric field. Moreover, when compared with the $\mathrm{MoSe}_{2}$ and $\mathrm{SnS}_{2}$ monolayers, the absorption intensity of the $\mathrm{MoSe}_{2} / \mathrm{SnS}_{2}$ heterojunction was reinforced in the visible light region [131].

Park et al. worked on Nb-, Ta-, and Bi-based oxides/chalcogenides. They studied the crystal structure, band dispersion, effective masses of the charge carriers, band alignment, and $\mathrm{pH}$ dependence of these materials for hydrogen production and $\mathrm{CO}_{2}$ reduction. They concluded that Bi-based chalcogenide materials, $\left(\mathrm{KBiO}_{2}\right.$ and $\left.\mathrm{KBiS}_{2}\right)$ showed good performance over a wide range of $\mathrm{pH}$ conditions. In addition, the incorporation of chalcogenide narrows the bandgap and reduces the effective mass of the charge carriers when compared with their oxide counterparts [132]. Although these theoretical studies provide guidance toward the identification of materials required for efficient water splitting, it is necessary to test materials. The following sections summarize the reports of hydrogen evolution.

\subsection{Photoelectrochemical Hydrogen Evolution}

Electrochemical water splitting is a sustainable method for producing hydrogen on a large scale [133]. In photoelectrochemical hydrogen evolution, semiconductor material(s) are immersed in a water-based electrolyte and an external electric power/voltage is applied to dissociate water as hydrogen and oxygen molecules in the presence of a light source [126]. Electrochemical and photoelectrochemical hydrogen evolution have received much attention due to the fact that (i) the generation of $\mathrm{O}_{2}$ and $\mathrm{H}_{2}$ occurs at separate electrodes (Figure 28), which eliminates the separation issue(s), and (ii) the potential for operation under ambient conditions [134].

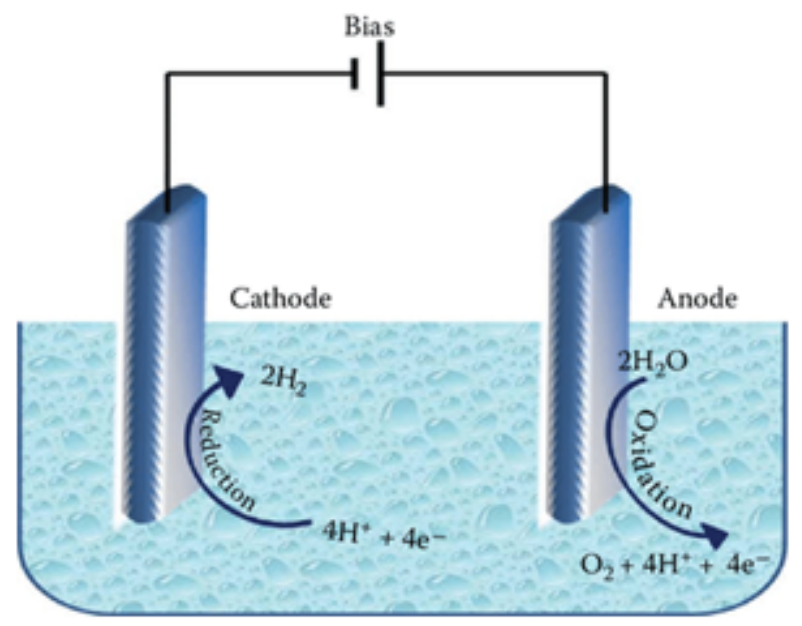

Figure 28. Schematic illustration of the experimental setup of electrochemical water splitting.

Fujishima and Honda first described the photoelectrochemical cell (PEC) splitting of water using a crystalline titanium dioxide anode and a platinum cathode under ultraviolet (UV) irradiation and an external bias [24,135]. The anodic and cathodic reactions are as indicated below [136].

Anode: $2 \mathrm{H}_{2} \mathrm{O} \rightarrow \mathrm{O}_{2}+4 \mathrm{H}^{+}+4 \mathrm{e}^{-}$

Cathode: $2 \mathrm{H}_{2} \mathrm{O}+4 \mathrm{H}^{+}+4 \mathrm{e}^{-} \rightarrow 2 \mathrm{H}_{2}+2 \mathrm{O}^{2-}$ 
Overall reaction: $2 \mathrm{H}_{2} \mathrm{O} \rightarrow 2 \mathrm{H}_{2}+\mathrm{O}_{2}$

Different studies have been conducted in the field of electrochemical water splitting wherein Pt- and Ru-based materials [137] were used as electrocatalysts for the hydrogen evolution reaction (HER) and oxygen evolution reaction (OER), respectively. In recent years, TMCs have been used. Ahn et al. used $\mathrm{CoS}_{2} / \mathrm{rGO}(2.3 \mathrm{mg} / \mathrm{mL}$ GO) hybrid materials that exhibited high electrocatalytic activity for hydrogen evolution reaction with an over potential of $-150 \mathrm{mV}$ versus RHE [138]. In another study, an impressive activity was attributed to the superior electrochemical performance of the Mo-CoS $\mathrm{x}$ skeleton, and the special configuration between $\mathrm{MoS}_{2}$ and $\mathrm{CoS}_{\mathrm{x}}$, which provide more active sites [139]. Apart from these studies, there have been several metal chalcogenide materials that have been utilized for electrochemical hydrogen evolution, which are summarized in the Table 3 below.

Table 3. Comparison of electrochemical hydrogen evolution by using different TMC photocatalysts.

\begin{tabular}{|c|c|c|c|c|c|}
\hline Material & Current Density & Over Potential & Photocurrent & Other Condition(s) & References \\
\hline $\mathrm{MoS}_{2}$ & $10 \mathrm{mAcm}^{-2}$ & $173 \mathrm{mV}$ & $109.81 \mathrm{mVdec}^{-1}$ & Nafion resin & [140] \\
\hline $\mathrm{MoSe}_{2}$ & $10 \mathrm{mAcm}^{-2}$ & $208 \mathrm{mV}$ & $65.92 \mathrm{mVdec}^{-1}$ & Nafion resin & [140] \\
\hline $\mathrm{MoTe}_{2}$ & $10 \mathrm{mAcm}^{-2}$ & $283 \mathrm{mV}$ & $102.06 \mathrm{mVdec}^{-1}$ & Nafion resin & [140] \\
\hline $\mathrm{MoS}_{2} /$ candle soot/Ni foam & $10 \mathrm{mAcm}^{-2}$ & $56 \mathrm{mV}$ & NA & $1.0 \mathrm{M} \mathrm{KOH}$ & [108] \\
\hline $3 \mathrm{D} / 2 \mathrm{D} \mathrm{TiO} 2 / \mathrm{MoSe}_{2}$ & $\begin{array}{l}1.40 \mathrm{mAcm}^{-2} \\
10 \mathrm{~mA} / \mathrm{cm}^{-2}\end{array}$ & NA & NA & $1.0 \mathrm{M} \mathrm{NaOH}$ & [141] \\
\hline $2 \mathrm{D} \mathrm{MoS} / \mathrm{MoSe}_{2}$ & $\begin{array}{c}147 \mu \mathrm{mol} \text { of } \mathrm{H}_{2} \text { in } \\
\sim 50 \mathrm{~min} .\end{array}$ & NA & NA & Wide $\mathrm{pH}$ conditions & [142] \\
\hline Amorphous-RuS 2 & $10 \mathrm{mAcm}^{-2}$ & $141 \mathrm{mV}$ & $65.6 \mathrm{mVdec}^{-1}$ & $0.5 \mathrm{M} \mathrm{H}_{2} \mathrm{SO}_{4}$ & [143] \\
\hline $\mathrm{MoS}_{2} / \mathrm{TiO}_{2}$ & $10 \mathrm{mAcm}^{-2}$ & $170 \mathrm{mV}$ & $70 \mathrm{mVdec}^{-1}$ & $0.5 \mathrm{M} \mathrm{H}_{2} \mathrm{SO}_{4}$ & [118] \\
\hline $\mathrm{GO} / \mathrm{NiS}_{2}$ & $10 \mathrm{mAcm}^{-2}$ & $\begin{array}{l}57 \mathrm{mV}-\mathrm{HER} \\
294 \mathrm{mV} \text {-OER }\end{array}$ & NA & $1.0 \mathrm{M} \mathrm{KOH}$ & [144] \\
\hline PU@PANI@FeS 2 & $\begin{array}{l}10 \mathrm{mAcm}^{-2} \\
50 \mathrm{mAcm}^{-2}\end{array}$ & $\begin{array}{l}266 \mathrm{mV} \\
372 \mathrm{mV}\end{array}$ & NA & $0.5 \mathrm{M} \mathrm{H}_{2} \mathrm{SO}_{4}$ & [145] \\
\hline $\mathrm{Cu}_{\mathrm{x}} \mathrm{S}$ & NA & $-90 \mathrm{mV}$ & $100 \mathrm{mVdec}^{-1}$ & $0.5 \mathrm{M} \mathrm{H}_{2} \mathrm{SO}_{4}$ & [146] \\
\hline $\mathrm{CoS} / \mathrm{MoS}_{2}$ & NA & $-147 \mathrm{mV}$ & $126 \mathrm{mVdec}^{-1}$ & & [147] \\
\hline Carbon $/ \mathrm{Co}_{3} \mathrm{~S}_{4}$ & $10 \mathrm{mVcm}^{-2}$ & $\begin{array}{c}250 \mathrm{mV} \text { and } 140 \mathrm{mV} \text { for OER } \\
\text { and HER }\end{array}$ & NA & $1.0 \mathrm{M} \mathrm{KOH}$ & [148] \\
\hline $\mathrm{NiWSe}_{\mathrm{x}}$ and CoWSe $\mathrm{x}_{\mathrm{x}}$ & $1 \mathrm{mAcm}^{-2}$ & $\begin{array}{c}\text { NiWSe }_{x}(231 \mathrm{mV}) \mathrm{CoWSe}_{\mathrm{x}} \\
(281 \mathrm{mV}) \text { and WSe } \\
(404 \mathrm{mV})\end{array}$ & NA & $1.0 \mathrm{M} \mathrm{KOH}$ & [149] \\
\hline $\mathrm{MoS}_{2} / \mathrm{Pt}$ & $0.642 \mathrm{mAcm}^{-2}$ & NA & $\begin{array}{l}52 \mathrm{mVdec}^{-1} \text { to } 32 \\
\mathrm{mVdec}^{-1}\end{array}$ & $0.5 \mathrm{M} \mathrm{H}_{2} \mathrm{~S} \mathrm{O}_{4}$ & [150] \\
\hline $\mathrm{G} / \mathrm{MoS}_{2}$ & $10 \mathrm{mAcm}^{-2}$ & $118 \mathrm{mV}$ & $73 \mathrm{mVedec}^{-1}$ & $0.5 \mathrm{M} \mathrm{H}_{2} \mathrm{SO}_{4}$ & [151] \\
\hline $\mathrm{NiS} / \mathrm{Pd}$ & $10 \mathrm{mAcm}^{-2}$ & $100 \mathrm{mV}$ & $50 \mathrm{mVdec}^{-1}$ & NA & [152] \\
\hline $\mathrm{Zn}_{\mathrm{x}} \mathrm{Co}_{1-\mathrm{x}} \mathrm{Se}_{2}$ & $10 \mathrm{mAcm}^{-2}$ & $\begin{array}{l}196 \mathrm{mV} \text {-HER } \\
308 \mathrm{mV} \text {-OER }\end{array}$ & NA & $\begin{array}{l}\text { HER_-acid media } \\
\text { OER-alkaline media }\end{array}$ & [153] \\
\hline Mo/CoSe & $100 \mathrm{mAcm}^{-2}$ & $186.1 \mathrm{mV}$ & $58.7 \mathrm{mV} \mathrm{dec}^{-1}$ & $0.5 \mathrm{M} \mathrm{H}_{2} \mathrm{SO}_{4}$ & [154] \\
\hline $\mathrm{MoS}_{2}$ /graphene & $1000 \mathrm{mAcm}^{-2}$ & $250 \mathrm{mV}$ & $43.3 \mathrm{mVdec}^{-1}$ & $\begin{array}{c}0.5 \mathrm{M} \\
\mathrm{H}_{2} \mathrm{SO}_{4}\end{array}$ & [47] \\
\hline $\mathrm{NiS}_{2}$ & $10 \mathrm{~mA} / \mathrm{cm}^{-2}$ & $302 \mathrm{mV}$ & NA & Nafion ethanol solution & [155] \\
\hline GaSe & $\begin{array}{c}-9.3 \mu \mathrm{Acm}^{-2} 83.4 \\
\mu \mathrm{Acm}^{-2}\end{array}$ & $+1.23 \mathrm{~V}$ vs. RHE & NA & $0.5 \mathrm{M} \mathrm{H}_{2} \mathrm{SO}_{4}$ & [156] \\
\hline $1 \mathrm{~T}-\mathrm{MoS}_{2}$ & $10 \mathrm{mAcm}^{-2}$ & $240 \mathrm{mV}$ & $68 \mathrm{mVdec}^{-1}$ & $1 \mathrm{M} \mathrm{KOH}$ & [157] \\
\hline $\mathrm{CoSe} / \mathrm{MoSe}_{2}$ & $10 \mathrm{mAcm}^{-2}$ & $\begin{array}{l}192 \text { and } 115 \mathrm{mV} \text { in acidic } \\
\text { and alkaline }\end{array}$ & NA & Nafion ethanol solution & [158] \\
\hline
\end{tabular}

NA-Not Available.

\subsection{Photocatalytic Hydrogen Evolution}

Solar-assisted photocatalytic hydrogen evolution is an attractive technique to generate hydrogen and oxygen, because water and sunlight are abundant and renewable. Furthermore, the photocatalytic process can occur at ambient conditions [14]. Semiconductor materials are used as photocatalysts and their band structure consists of a filled valance band and an empty conduction band separated by a finite bandgap. Irradiation with incident energy greater than or equal to the bandgap of a material leads to excitation of electrons from the valence band to the conduction band edge [159-161]. This leaves holes in the valence band. These photoexcited electrons and holes are potent reducing and oxidizing agents and may react with adsorbed moieties on the surface of the photocatalytic material or may recombine to generate heat $[9,136]$.

Photocatalytic reactions can be classified into two major categories that include uphill reaction, where the Gibbs free energy $\left(\Delta \mathrm{G}^{\mathrm{o}}\right)$ is positive, or downhill reaction, where the $\left(\Delta \mathrm{G}^{\mathrm{o}}\right)$ is negative (Figure 29). In this process, water molecules splitting into $\mathrm{H}_{2}$ and $\mathrm{O}_{2}$, are accompanied by a large positive change in the Gibbs free energy (i.e., an uphill 
reaction) [130]. During this process, light energy is transformed into chemical energy in a similar manner as the photosynthesis process. Therefore, this reaction is called artificial photosynthesis [136,162].
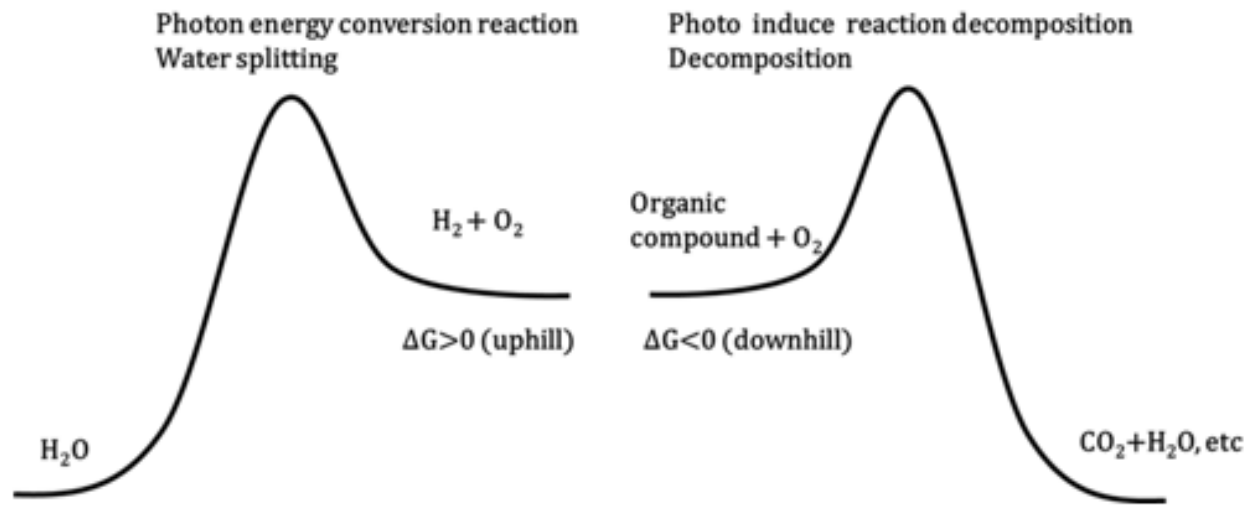

Figure 29. Types of photocatalytic reactions. Reproduced with permission from [130].

The photocatalytic hydrogen evolution through water splitting is a green route and has received significant attention toward simultaneously solving the current global environmental pollution and energy crisis [128]. Various photocatalysts have been well developed for the generation of hydrogen whereas $\mathrm{TiO}_{2}$ is still considered as a golden standard due to its exceptional stability under irradiation conditions, ease of synthesis, and cost [163]. However, a big disadvantage of $\mathrm{TiO}_{2}$ is that it requires UV light to be activated, thus limiting its utility since visible light cannot be used. Hence, other oxide and chalcogenide materials are constantly being explored and evaluated for photocatalytic hydrogen production. In addition, $\mathrm{ZnO}$ [33], mixed oxides [164], metal chalcogenides such as CdS [165], WS 2 [166], g- $\mathrm{C}_{3} \mathrm{~N}_{4}$ [30], and $\mathrm{CdLa}_{2} \mathrm{~S}_{4}$ [34] have also been utilized for the hydrogen evolution reaction.

\subsubsection{Principle and Mechanism of Photocatalytic Hydrogen Evolution}

In general, photocatalytic hydrogen evolution reaction takes place through three major steps. The first step is the absorption of light by a catalyst to create exciton pair containing electrons and holes. In the second step, the excitons may separate and migrate to the surface of the photocatalyst, and finally, in the third step, the surface reactions take place. The electrons will reduce the protons to generate hydrogen molecules, and holes oxidize water molecules to produce oxygen, as illustrated in the Figure 30 below [167].

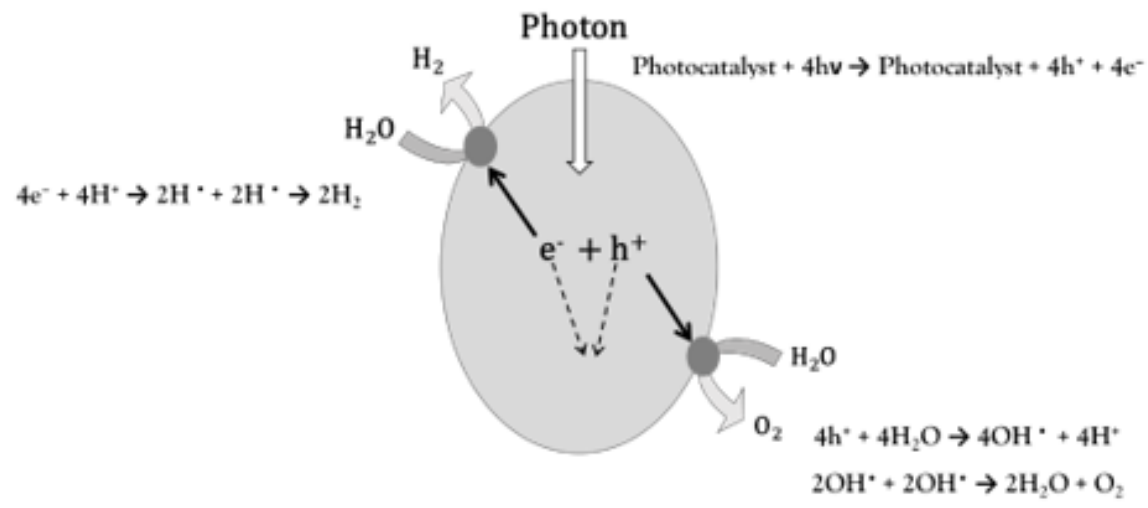

Figure 30. Schematic illustration of the process involved during water splitting with the photocatalyst under the illumination of sunlight. 
The primary reactions (1-4) occurring during the process are listed below, and as indicated, the overall reaction involves four electrons. Table 4 lists the different metal chalcogenide materials used for hydrogen production and the amount of hydrogen evolved.

$$
\begin{gathered}
\text { Photocatalyst }+4 \mathrm{hv} \rightarrow \text { Photocatalyst }+4 \mathrm{~h}^{+}+4 \mathrm{e}^{-} \\
\qquad \begin{array}{c}
4 \mathrm{e}^{-}+4 \mathrm{H}^{+} \rightarrow 2 \mathrm{H}^{\bullet}+2 \mathrm{H}^{\bullet} \rightarrow 2 \mathrm{H}_{2} \\
4 \mathrm{~h}^{+}+4 \mathrm{H}_{2} \mathrm{O} \rightarrow 4 \mathrm{OH}^{\bullet}+4 \mathrm{H}^{+} \\
2 \mathrm{OH}^{\bullet}+2 \mathrm{OH}^{\bullet} \rightarrow 2 \mathrm{H}_{2} \mathrm{O}+\mathrm{O}_{2}
\end{array}
\end{gathered}
$$

\begin{tabular}{|c|c|c|c|c|c|}
\hline Materials & $\begin{array}{c}\text { Amount of Hydrogen } \\
\text { Evolved }\end{array}$ & Light Source & $\begin{array}{l}\text { Co- } \\
\text { Catalyst }\end{array}$ & $\begin{array}{l}\text { Scavenging Agents/Other } \\
\text { Chemicals Used }\end{array}$ & Reference \\
\hline $\mathrm{SnS}_{2}$ & $\begin{array}{c}1.06 \mathrm{mmol} \mathrm{h}^{-1} \mathrm{~g}^{-1} \\
332.4 \text { and }\end{array}$ & UV-Visible & NA & $\mathrm{Na}_{2} \mathrm{~S}$ and $\mathrm{Na}_{2} \mathrm{SO}_{3}$ & {$[38]$} \\
\hline $\mathrm{Te} / \mathrm{SnS}_{2} / \mathrm{Ag}$ & $\begin{array}{c}166.2 \mu \mathrm{mol} \mathrm{h}^{-1} \text { for } \mathrm{H}_{2} \\
\text { and } \mathrm{O}_{2}\end{array}$ & UV-Visible & NA & - & {$[168]$} \\
\hline $\mathrm{SnS}_{2} / \mathrm{g}-\mathrm{C}_{3} \mathrm{~N}_{4}$ & $972.6 \mu \mathrm{mol} \mathrm{h}^{-1} \mathrm{~g}^{-1}$ & Visible & $\mathrm{Pt}$ & Triethanolamine & [169] \\
\hline $\mathrm{CdS} / \mathrm{WS}_{2}$ & $0.42 \mathrm{mmol} \mathrm{h}^{-1}$ & Visible & NA & Lactic acid & [166] \\
\hline NiS /CdS DETA & $230 \mu \mathrm{molh}^{-1}$ & Visible & NA & - & [170] \\
\hline $\begin{array}{l}\mathrm{CdS} / \mathrm{ZnO} / \mathrm{GO} \\
\mathrm{CdS} / \mathrm{Al}_{2} \mathrm{O}_{3} / \mathrm{GO}\end{array}$ & $22.12 \mathrm{mmol} \mathrm{h}^{-1} \mathrm{~g}^{-1}$ & $\begin{array}{c}500 \text { W Phoenix } \\
\text { tungsten halogen } \\
\text { lamp }\end{array}$ & $\mathrm{Pt}$ & $\mathrm{Na}_{2} \mathrm{SO}_{3}$ and $\mathrm{Na}_{2} \mathrm{~S}$ & [171] \\
\hline $\mathrm{MoS}_{2} / \mathrm{RGO} / \mathrm{CdS}$ & $99 \mu \mathrm{mol} \mathrm{h}^{-1}$ & Visible & NA & Lactic acid & [42] \\
\hline $\mathrm{MoS}_{2} / \mathrm{G}$ & $1.80 \mathrm{mmol} \mathrm{h}^{-1}$ & Visible & NA & $\mathrm{Na}_{2} \mathrm{~S}$ and $\mathrm{Na}_{2} \mathrm{~S}_{2} \mathrm{O}_{3}$ & [172] \\
\hline $\operatorname{Eosin} \mathrm{Y} / \mathrm{NiS}_{\mathrm{x}} / \mathrm{G}$ & $0.34 \mathrm{mmol} \mathrm{h}^{-1}$ & Visible & NA & Triethanolamine & [22] \\
\hline $\mathrm{NiS} / \mathrm{CdS} / \mathrm{ZnS}$ & $574 \mu \mathrm{mol} \mathrm{h}^{-1}$ & Visible & NA & $\mathrm{Na}_{2} \mathrm{~S} / \mathrm{Na}_{2} \mathrm{~S}_{2} \mathrm{O}_{3}$ & [173] \\
\hline $\mathrm{MoS}_{2}$ & $110 \mu \mathrm{mol} \mathrm{h}^{-1}$ & Visible & $\mathrm{La}^{3+}$ & Methanol & [109] \\
\hline $\mathrm{CuS}-\mathrm{MoS}_{2}-1 \mathrm{~T}$ & $9648.7 \mu \mathrm{mol} \mathrm{g}{ }^{-1} \mathrm{~h}^{-1}$ & UV-Visible & NA & $0.3 \mathrm{M} \mathrm{Na}_{2} \mathrm{SO}_{3}$ & [174] \\
\hline $\mathrm{WS}_{2} / \mathrm{TiO}_{2}$ & $596.4 \mu \mathrm{molg}^{-1}$ & Visible & $\mathrm{Pt}$ & 1 wt. $\%$ of $\mathrm{WS}_{2} / \mathrm{TiO}_{2}$ & [31] \\
\hline $\mathrm{ZnIn}_{2} \mathrm{~S}_{4} / \mathrm{g}-\mathrm{C}_{3} \mathrm{~N}_{4}$ & $450 \mu \mathrm{mol} \mathrm{g}{ }^{-1} \mathrm{~h}^{-1}$ & Visible & NA & Triethanolamine & [175] \\
\hline $\mathrm{WSe}_{2} / \mathrm{Zn}_{0.1} \mathrm{Cd}_{0.9} \mathrm{~S}$ & $147.32 \mathrm{mmol} \mathrm{g}^{-1} \mathrm{~h}^{-1}$ & Visible & NA & Lactic acid & [176] \\
\hline $\mathrm{NiCo} / \mathrm{Zn}_{0.5} \mathrm{Cd}_{0.5} \mathrm{~S}$ & $34.7 \mathrm{mmol} \mathrm{g}^{-1} \mathrm{~h}^{-1}$ & UV-Visible & NA & $\mathrm{Na}_{2} \mathrm{~S}$ and $\mathrm{Na}_{2} \mathrm{SO}_{3}$ & [177] \\
\hline $\mathrm{NiSe}_{2} / \mathrm{RP}$ & $1968.8 \mu \mathrm{mol} \mathrm{g}{ }^{-1} \mathrm{~h}^{-1}$ & UV-Visible & NA & $\mathrm{Na}_{2} \mathrm{~S}$ and $\mathrm{Na}_{2} \mathrm{SO}_{3}$ & [178] \\
\hline CdS & $3072 \mu \mathrm{mol} \mathrm{g}{ }^{-1} \mathrm{~h}^{-1}$ & UV-Visible & NA & $\mathrm{Na}_{2} \mathrm{~S}$ and $\mathrm{Na}_{2} \mathrm{SO}_{3}$ & [179] \\
\hline $\mathrm{ZnS} / \mathrm{CdS} / \mathrm{Cd}_{0.5} \mathrm{Zn}_{0.5} \mathrm{~S} / \mathrm{MoS}_{2}$ & $50.65 \mathrm{mmol} \mathrm{g}^{-1} \mathrm{~h}^{-1}$ & Visible & NA & $\begin{array}{l}\text { Lactic acid, } \mathrm{Na} 2 \mathrm{~S} \text {, and } \\
\qquad \mathrm{Na}_{2} \mathrm{SO}_{3}\end{array}$ & {$[117]$} \\
\hline $\mathrm{Cd}_{x} \mathrm{Mo}_{1-x} \mathrm{Se}$ & $911.1 \mathrm{~mol}$ in $7 \mathrm{~h}$ & Visible & NA & $\mathrm{Na}_{2} \mathrm{~S}$ and $\mathrm{Na}_{2} \mathrm{SO}_{3}$ & [180] \\
\hline $\mathrm{MoS}_{2} / \mathrm{CdIn}_{2} \mathrm{~S}_{4}$ & $1868.19 \mu \mathrm{mol} \mathrm{g}^{-1} \mathrm{~h}^{-1}$ & UV-Visible & NA & $\mathrm{Na}_{2} \mathrm{~S}$ and $\mathrm{Na}_{2} \mathrm{SO}_{3}$ & [181] \\
\hline $\mathrm{MoS}_{2} / \mathrm{CoSe}_{2} / 1 \mathrm{D}-\mathrm{CdS}$ & $191.5 \mathrm{mmol} \mathrm{g}^{-1} \mathrm{~h}^{-1}$ & UV-Visible & NA & Lactic acid & [182] \\
\hline $\mathrm{NiS} / \mathrm{CQDs} / \mathrm{ZnIn}_{2} \mathrm{~S}_{4}$ & $28.2 \mu \mathrm{mol} \mathrm{h}^{-1}$ & Visible & NA & Trimethylamine & [183] \\
\hline $\mathrm{NiSe}_{2} / \mathrm{CdS}$ & $167.1 \mathrm{mmol} \mathrm{g}^{-1} \mathrm{~h}^{-1}$ & Visible & NA & & [184] \\
\hline $\mathrm{NiS} / \mathrm{ZnIn}_{2} \mathrm{~S}_{4}$ & $5.0 \mu \mathrm{mol} \mathrm{h}^{-1}$ & Visible & NA & Methanol and lactic acid & {$[185]$} \\
\hline 1T-MoS $2-\mathrm{ZnCoS}$ & $15.47 \mathrm{mmol} \mathrm{h}^{-1} \mathrm{~g}^{-1}$ & UV-Visible & NA & $\begin{array}{c}\text { Trimethylamine, Eosin } \mathrm{Y} \text {, and } \\
\text { acetonitrile }\end{array}$ & [120] \\
\hline $\mathrm{CdS} / \mathrm{SnS}_{2}$ & $20.2 \mathrm{mmol} \mathrm{h}^{-1} \mathrm{~g}^{-1}$ & UV-Visible & NA & Lactic acid & [186] \\
\hline $\mathrm{ZnO}-\mathrm{ZnS}-\mathrm{Cu}_{2} \mathrm{~S}$ & $436 \mu \mathrm{mol} \mathrm{h}^{-1} \mathrm{~g}^{-1}$ & Visible & NA & $\mathrm{Na}_{2} \mathrm{~S}$ and $\mathrm{Na}_{2} \mathrm{SO}_{3}$ & [187] \\
\hline ZnS films & $5202.4 \mu \mathrm{mol} \mathrm{h}^{-1} \mathrm{~g}^{-1}$ & UV & NA & $\mathrm{Na}_{2} \mathrm{SO}_{3}$ & [188] \\
\hline $\mathrm{CoS}_{2} / \mathrm{TiO}_{2}$ & $2.55 \mathrm{mmol} \mathrm{g}^{-1}$ & UV & NA & Methanol & [105] \\
\hline $\mathrm{SnS}_{2} / \mathrm{TiO}_{2}$ & $195.0 \mu \mathrm{mol} \mathrm{g}^{-1}$ & Visible & NA & Methanol & [106] \\
\hline$(\mathrm{NC} @ \mathrm{Co}-\mathrm{NCT}) /(\mathrm{CdS})$ & $3.8 \mathrm{mmol} \mathrm{h}^{-1} \mathrm{~g}^{-1}$ & Visible & NA & lactic acid & {$[189]$} \\
\hline CdSe QDs $/ g-\mathrm{C}_{3} \mathrm{~N}_{4}$ & $192.3 \mu \mathrm{mol} \mathrm{h}^{-1}$ & Visible & $\mathrm{H}_{2} \mathrm{PtCl}_{6}$ & $\begin{array}{l}\text { Triethanolamine, } \\
\mathrm{Na}_{2} \mathrm{~S} \text {, and } \mathrm{Na}_{2} \mathrm{SO}_{3}\end{array}$ & [190] \\
\hline
\end{tabular}

Table 4. Photocatalytic hydrogen evolution by using different TMC photocatalysts, the experimental conditions used, and the respective references.

\subsubsection{Measurements of the Rate of Hydrogen Evolution (Quantum Yield)}

Generally, the rate of hydrogen evolution is denoted with the unit of $\mu$ molh ${ }^{-1} \mathrm{~g}^{-1}$, which indicates the number of moles of hydrogen evolved in unit time using a unit amount of catalyst. This amount depends on several experimental conditions such as reaction vessel, light source, intensity of radiation, amount of catalyst, sacrificial agent, etc. [120]. However, it is noteworthy to mention here that there are inconsistencies among researchers in reporting the rate of hydrogen evolution and hence care must be exercised in making 
comparisons from one report to another. To provide a general quantification, quantum yield measurement is important in photolytic reactions to remove any variations in experimental conditions and for making meaningful comparisons among different photocatalysts and provide consistent benchmarking. Although the number of incident photons can be measured using a thermopile, it is difficult to determine the actual number of photons absorbed by a photocatalyst because of scattering and some reflection in a dispersed system. Photocatalytic/luminescence materials convert excitation energy into photons, and this conversion is usually not $100 \%$ efficient due to various losses through alternative deactivation paths. Therefore, two additional parameters such as the quantum yield (QY) and the quantum (energy) efficiency [191] have to be defined. In preparative photochemistry, the QY is defined as the product yield of a reaction calculated by the number of moles of reactant reacted per unit time. This type of QY has been preferred as it can be measured with small expenditure. However, it depends on the time section of the reaction in which it is determined. Therefore, the QY can be considered to be an apparent quantum yield (AQY), and this yield is mainly dependent on the time at which they are considered [192]. AQY is the ratio between the number of reacted electrons and the number of incident photons, and is used for the quantification of hydrogen evolution. The following Equation (5) explains the percentage of AQY calculation [9].

$$
\begin{aligned}
& \operatorname{AQY}(\%)=\frac{\text { the number of reacted electrons }}{\text { the number of incident photons }} \times 100 \% \\
& =\frac{\text { the number of evolved } \mathrm{H}_{2} \text { molecules } \times 2}{\text { the number of incident photons }} \times 100 \%
\end{aligned}
$$

The turnover frequency (TOF) of photocatalysts based on the amount of a particular molecule can be calculated using Equation (6) [193]:

$$
\mathrm{TOF}=\frac{\text { moles of produced hydrogen }}{\text { moles of a particular molecule in photocatalyst } \times \text { reaction time }(\mathrm{h})}
$$

Mangiri R. et al. used a dual co-catalyst of $\mathrm{MoS}_{2} / \mathrm{CoSe}_{2}$ on CdS for the hydrogen evolution reaction (Figure 31), and the system evolved a higher rate of hydrogen with the yield of $191.5 \mathrm{mmol} \mathrm{g}^{-1} \mathrm{~h}^{-1}$, which was 76.6 times higher than that of pristine CdS [182].

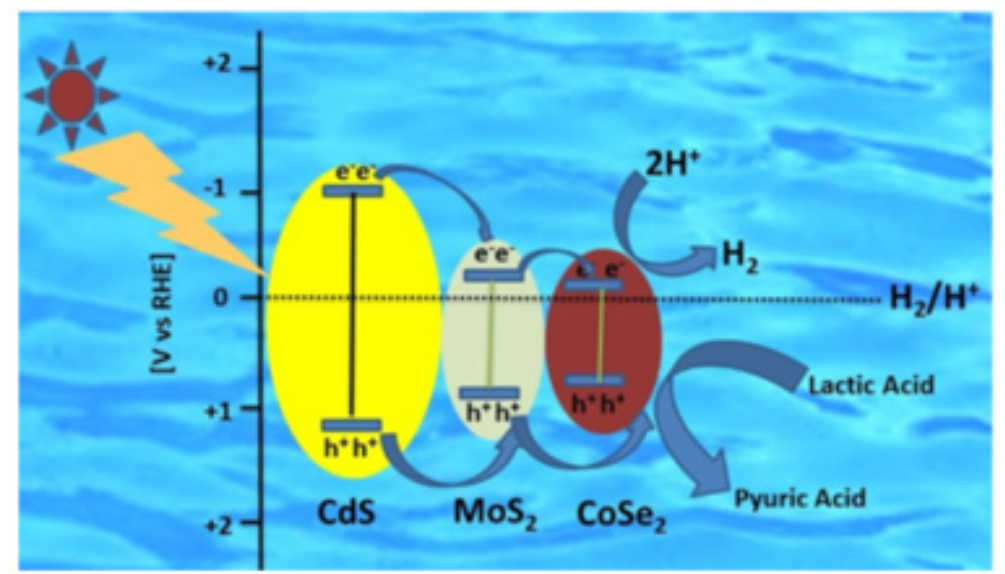

Figure 31. Schematic diagram of the mechanism of the hydrogen evolution reduction (HER) process. Reproduced with permission from [182].

In their study, CdS was used as a semiconductor, which can harvest the light and eject electrons from the conduction band of CdS to its valance band. Then, the photogenerated electrons in the conduction band of CdS can be easily transferred to $\mathrm{MoS}_{2}$ and $\mathrm{CoSe}_{2}$ due to the favorable band edge positions of the three materials. Thus, the rate of charge-carrier recombination is minimized and photocatalytic activity is enhanced in the 
composite photocatalyst in comparison to the pristine CdS materials. Here, the $\mathrm{MoS}_{2}$ and $\mathrm{CoSe}_{2}$ act as reactive sites to produce hydrogen. The holes produced can react with lactic acid and oxidize it to pyruvic acid [182].

In a different study, Riaz et al. used $3 \% \mathrm{La}^{3+}$ doped $\mathrm{MoS}_{2}$, and it exhibited an enhanced photocatalytic performance for hydrogen evolution with a 5.2 times higher hydrogen evolution rate compared with pure $\mathrm{MoS}_{2}$ [109] (Figure 32). This has been attributed to the presence of trapping energy levels formed below the conduction band of $\mathrm{MoS}_{2}$ due to the lanthanum ion-doping and minimizing recombination of electrons and holes. Surface adsorbed $\mathrm{La}^{3+}$ atoms also ensured the rapid transfer of electrons from $\mathrm{MoS}_{2}$ to capture protons for $\mathrm{H}_{2}$ production [109].

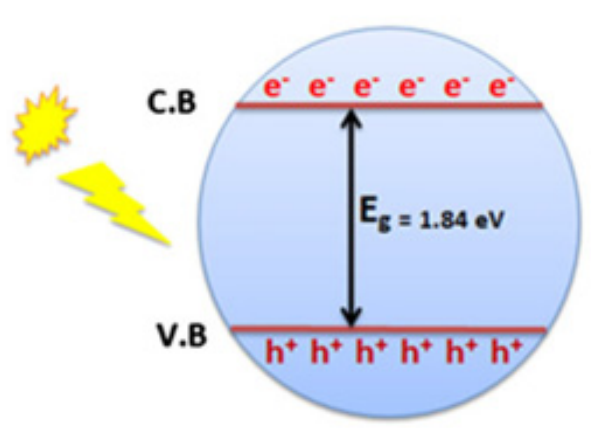

Pure $\mathrm{MoS}_{2}$

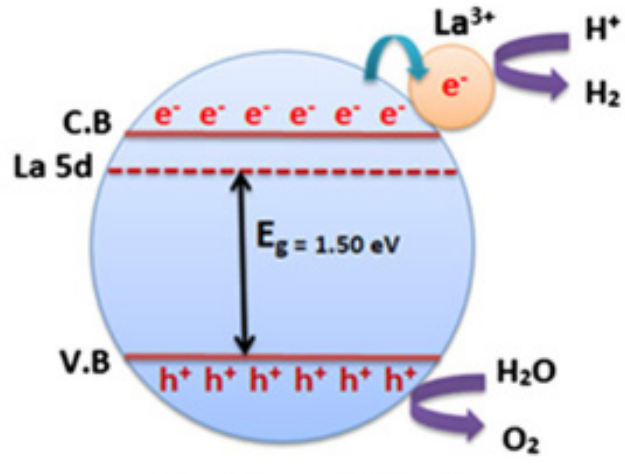

La doped $\mathrm{MoS}_{2}$

Figure 32. Schematic diagram of the proposed reaction mechanism for $\mathrm{H}_{2}$ production using the La-MoS 2 photocatalyst. Reproduced with permission from [109].

Transition metal chalcogenides with and without incorporation of other materials such as metals [168], graphene [172], graphene oxide [42], carbon nitrides [169], dyes [194], and metal oxides [33] have been utilized for hydrogen production (Table 4). It can be seen that the use of composite photocatalysts, in general, leads to a higher rate of hydrogen production than the pristine transition metal chalcogenides. This has been attributed to the presence of heterojunctions that favor vectorial transfer of electrons that minimize electron-hole recombination.

\section{Summary}

This review details the recent approaches to the hydrogen evolution reaction using TMCs, which are being considered as potential catalysts for the production of an energy carrier, hydrogen, due to their favorable electronic and optical properties. The different synthesis methods of TMCs and their characteristic properties reported in the literature are discussed in detail, providing guidance for interested researchers to explore TMCs as exploratory materials. Furthermore, the catalytic activities of TMCs for hydrogen evolution reactions were also elaborated herein. Overall, this review provides an overview of the recent approaches to hydrogen production using TMCs.

Author Contributions: Conceptualization, Y.S.; Methodology, S.S. and E.Y.; Investigation, S.S., Y.S., P.R., D.V. and R.K.; Resources, Y.S., P.R., D.V. and R.K.; Original draft preparation, S.S. and E.Y.; Writing-review \& editing, S.S., E.Y., Y.S. and R.K.; Supervision, Y.S., P.R. and D.V. All authors have read and agreed to the published version of the manuscript.

Funding: National Research Council, Sri Lanka (NRC Grant No: 20-110) and the Capacity Building and Establishment of a Research Consortium (CBERC) project, grant number LKA-3182-HRNCET and Higher Education and Research Collaboration on Nanomaterials for Clean Energy Technologies (HRNCET) project, grant number NORPART/2016/10237.

Institutional Review Board Statement: Not applicable.

Informed Consent Statement: Not applicable. 
Acknowledgments: The authors appreciate the support of the National Research Council, Sri Lanka (NRC, Grant No: 20-110) for funding the research.

Conflicts of Interest: There is no conflict of interest.

\section{References}

1. Ma, Q.; Hu, C.; Liu, K.; Hung, S.-F.; Ou, D.; Chen, H.M.; Fu, G.; Zheng, N. Identifying the electrocatalytic sites of nickel disulfide in alkaline hydrogen evolution reaction. Nano Energy 2017, 41, 148-153. [CrossRef]

2. Bai, J.; Meng, T.; Guo, D.; Wang, S.; Mao, B.; Cao, M. Co9S8@MoS 2 Core-Shell Heterostructures as Trifunctional Electrocatalysts for Overall Water Splitting and Zn-Air Batteries. ACS Appl. Mater. Interfaces 2018, 10, 1678-1689. [CrossRef] [PubMed]

3. Naik, S.G.; Rabinal, M.H.K. Molybdenum Disulphide Heterointerfaces as Potential Materials for Solar Cells, Energy Storage, and Hydrogen Evolution. Energy Technol. 2020, 8. [CrossRef]

4. Feng, K.; Huang, D.; Li, L.; Wang, K.; Li, J.; Harada, T.; Ikeda, S.; Jiang, F. MoSx-CdS/Cu ZnSnS $_{4}$-based thin film photocathode for solar hydrogen evolution from water. Appl. Catal. Environ. 2020, 268, 118438. [CrossRef]

5. Züttel, A. Hydrogen storage methods. Naturwissenschaften 2004, 91, 157-172. [CrossRef] [PubMed]

6. Züttel, A. Materials for hydrogen storage. Mater. Today 2003, 6, 24-33. [CrossRef]

7. Paquin, F.; Rivnay, J.; Salleo, A.; Stingelin, N.; Silva, C. Multi-phase semicrystalline microstructures drive exciton dissociation in neat plastic semiconductors. J. Mater. Chem. 2015, 3, 10715-10722. [CrossRef]

8. $\quad$ Lin, L.; Sherrell, P.; Liu, Y.; Lei, W.; Zhang, S.; Zhang, H.; Wallace, G.G.; Chen, J. Engineered 2D Transition Metal DichalcogenidesA Vision of Viable Hydrogen Evolution Reaction Catalysis. Adv. Energy Mater. 2020, 10. [CrossRef]

9. Kudo, A.; Miseki, Y. Heterogeneous photocatalyst materials for water splitting. Chem. Soc. Rev. 2009, 38, 253-278. [CrossRef] [PubMed]

10. Nikolaidis, P.; Poullikkas, A. A comparative overview of hydrogen production processes. Renew. Sustain. Energy Rev. 2017, 67, 597-611. [CrossRef]

11. Dincer, I. Green methods for hydrogen production. Int. J. Hydrogen Energy 2012, 37, 1954-1971. [CrossRef]

12. Ma, L.-C.; Dominguez, B.C.; Kazantzis, N.K.; Ma, Y.H. Integration of membrane technology into hydrogen production plants with $\mathrm{CO}_{2}$ capture: An economic performance assessment study. Int. J. Greenh. Gas Control. 2015, 42, 424-438. [CrossRef]

13. Luo, P.; Zhang, H.; Liu, L.; Zhang, Y.; Deng, J.; Xu, C.; Hu, N.; Wang, Y. Targeted Synthesis of Unique Nickel Sulfide (NiS, NiS 2 ) Microarchitectures and the Applications for the Enhanced Water Splitting System. ACS Appl. Mater. Interfaces 2017, 9, 2500-2508. [CrossRef] [PubMed]

14. Leung, D.Y.C.; Fu, X.; Wang, C.; Ni, M.; Leung, M.K.H.; Wang, X.; Fu, X. Hydrogen Production over Titania-Based Photocatalysts ChemSusChem 2010, 3, 681-694. [CrossRef] [PubMed]

15. Yin, Y.; Jin, Z.; Hou, F. Enhanced solar water-splitting efficiency using core/sheath heterostructure $\mathrm{CdS} / \mathrm{TiO}_{2}$ nanotube arrays. Nanotechnology 2007, 18, 495608. [CrossRef]

16. Kim, S.B.; Hong, S.C. Kinetic study for photocatalytic degradation of volatile organic compounds in air using thin film $\mathrm{TiO}_{2}$ photocatalyst. Appl. Catal. Environ. 2002, 35, 305-315. [CrossRef]

17. Matthews, R. Photooxidative degradation of coloured organics in water using supported catalysts. $\mathrm{TiO}_{2}$ on sand. Water Res. 1991, 25, 1169-1176. [CrossRef]

18. Chakrabarti, S.; Dutta, B.K. Photocatalytic degradation of model textile dyes in wastewater using ZnO as semiconductor catalyst. J. Hazard. Mater. 2004, 112, 269-278. [CrossRef]

19. Mugunthan, E.; Saidutta, M.B.; JagadeeshBabu, P.E. Photocatalytic degradation of diclofenac using $\mathrm{TiO}_{2}-\mathrm{SnO}_{2}$ mixed oxide catalysts. Environ. Technol. 2019, 40, 929-941. [CrossRef] [PubMed]

20. Kim, H.G.; Hwang, D.W.; Kim, J.; Kim, Y.G.; Lee, J.S. Highly donor-doped (110) layered perovskite materials as novel photocatalysts for overall water splitting. Chem. Commun. 1999, 2, 1077-1078. [CrossRef]

21. Kanazawa, T.; Nozawa, S.; Lu, D.; Maeda, K. Structure and Photocatalytic Activity of PdCrOx Cocatalyst on $\mathrm{SrTiO}_{3}$ for Overall Water Splitting. Catalysts 2019, 9, 59. [CrossRef]

22. Kong, C.; Min, S.; Lu, G. Dye-Sensitized NiSx Catalyst Decorated on Graphene for Highly Efficient Reduction of Water to Hydrogen under Visible Light Irradiation. ACS Catal. 2014, 4, 2763-2769. [CrossRef]

23. Zhang, W.; Xiao, X.; Zeng, X.; Li, Y.; Zheng, L.; Wan, C. Enhanced photocatalytic activity of $\mathrm{TiO}_{2}$ nanoparticles using SnS $2 /$ RGO hybrid as co-catalyst: DFT study and photocatalytic mechanism. J. Alloys Compd. 2016, 685, 774-783. [CrossRef]

24. Jafari, T.; Moharreri, E.; Amin, A.S.; Miao, R.; Song, W.; Suib, S.L. Photocatalytic Water Splitting-The Untamed Dream: A Review of Recent Advances. Molecules 2016, 21, 900. [CrossRef]

25. Li, Y.; Zhou, X.; Xing, Y. In situ thermal-assisted loading of monodispersed Pt nanoclusters on CdS nanoflowers for efficient photocatalytic hydrogen evolution. Appl. Surf. Sci. 2020, 506, 144933. [CrossRef]

26. Zheng, L.; Zhang, W.; Xiao, X. Preparation of titanium dioxide/tungsten disulfide composite photocatalysts with enhanced photocatalytic activity under visible light. Korean J. Chem. Eng. 2015, 33, 107-113. [CrossRef]

27. Wang, Q.; Huang, J.; Sun, H.; Ng, Y.H.; Zhang, K.-Q.; Lai, Y. MoS $_{2}$ Quantum Dots@TiO ${ }_{2}$ Nanotube Arrays: An ExtendedSpectrum-Driven Photocatalyst for Solar Hydrogen Evolution. ChemSusChem 2018, 11, 1708-1721. [CrossRef]

28. Ali, A.; Oh, W.-C. Photocatalytic Performance of $\mathrm{CoS}_{2}-$ Graphene-TiO 2 Ternary Composites for Reactive Black B (RBB) Degradation. J. Korean Ceram. Soc. 2017, 54, 308-313. [CrossRef] 
29. Li, Y.; Wang, H.; Xie, L.; Liang, Y.; Hong, G.; Dai, H. MoS 2 Nanoparticles Grown on Graphene: An Advanced Catalyst for the Hydrogen Evolution Reaction. J. Am. Chem. Soc. 2011, 133, 7296-7299. [CrossRef]

30. He, K.; Xie, J.; Li, M.; Li, X. In situ one-pot fabrication of g-C3N4 nanosheets/NiS cocatalyst heterojunction with intimate interfaces for efficient visible light photocatalytic H2 generation. Appl. Surf. Sci. 2018, 430, 208-217. [CrossRef]

31. Jing, D.; Guo, $\mathrm{L} \mathrm{WS}_{2}$ sensitized mesoporous $\mathrm{TiO}_{2}$ for efficient photocatalytic hydrogen production from water under visible light irradiation. Catal. Commun. 2007, 8, 795-799. [CrossRef]

32. Wang, Y.; Yang, X.; Wang, Z.; Lv, X.; Jia, H.; Kong, J.; Yu, M. CdS and $\mathrm{SnS}_{2}$ nanoparticles co-sensitized $\mathrm{TiO}_{2}$ nanotube arrays and the enhanced photocatalytic property. J. Photochem. Photobiol. Chem. 2016, 325, 55-61. [CrossRef]

33. Ma, D.; Shi, J.-W.; Zou, Y.; Fan, Z.; Ji, X.; Niu, C. Highly Efficient Photocatalyst Based on a CdS Quantum Dots/ZnO Nanosheets 0D/2D Heterojunction for Hydrogen Evolution from Water Splitting. ACS Appl. Mater. Interfaces 2017, 9, 25377-25386. [CrossRef] [PubMed]

34. Yuan, Y.-P.; Cao, S.-W.; Yin, L.-S.; Xu, L.; Xue, C. NiS 2 Co-catalyst decoration on $\mathrm{CdLa}_{2} \mathrm{~S}_{4}$ nanocrystals for efficient photocatalytic hydrogen generation under visible light irradiation. Int. J. Hydrogen Energy 2013, 38, 7218-7223. [CrossRef]

35. Sun, B.; Liu, A.; Li, J.; Wang, J.; Wang, S. Development of novel highly stable synergistic quaternary photocatalyst for the efficient hydrogen evolution reaction. Appl. Surf. Sci. 2020, 510, 145498. [CrossRef]

36. Makwana, N.M.; Tighe, C.J.; Gruar, R.I.; McMillan, P.F.; Darr, J.A. Pilot plant scale continuous hydrothermal synthesis of nano-titania; effect of size on photocatalytic activity. Mater. Sci. Semicond. Process. 2016, 42, 131-137. [CrossRef]

37. Huerta-Flores, A.M.; Torres-Martínez, L.M.; Moctezuma, E.; Singh, A.P.; Wickman, B. Green synthesis of earth-abundant metal sulfides $\left(\mathrm{FeS}_{2}, \mathrm{CuS}\right.$, and $\left.\mathrm{NiS}_{2}\right)$ and their use as visible-light active photocatalysts for $\mathrm{H}_{2}$ generation and dye removal. J. Mater. Sci. Mater. Electron. 2018, 29, 11613-11626. [CrossRef]

38. Yu, J.; Xu, C.; Ma, F.; Hu, S.-P.; Zhang, Y.-W.; Zhen, L. Monodisperse $\mathrm{SnS}_{2}$ Nanosheets for High-Performance Photocatalytic Hydrogen Generation. ACS Appl. Mater. Interfaces 2014, 6, 22370-22377. [CrossRef]

39. Xu, K.; Wang, F.; Wang, Z.; Zhan, X.; Wang, Q.; Cheng, Z.; Safdar, M.; He, J. Component-Controllable WS2(1-x)Se2x Nanotubes for Efficient Hydrogen Evolution Reaction. ACS Nano 2014, 8, 8468-8476. [CrossRef]

40. Voiry, D.; Salehi, M.; Silva, R.; Fujita, T.; Chen, M.; Asefa, T.; Shenoy, V.B.; Eda, G.; Chhowalla, M. Conducting MoS 2 Nanosheets as Catalysts for Hydrogen Evolution Reaction. Nano Lett. 2013, 13, 6222-6227. [CrossRef] [PubMed]

41. Sun, Y.; Liu, C.; Grauer, D.C.; Yano, J.; Long, J.R.; Yang, P.; Chang, C.J. Electrodeposited Cobalt-Sulfide Catalyst for Electrochemical and Photoelectrochemical Hydrogen Generation from Water. J. Am. Chem. Soc. 2013, 135, 17699-17702. [CrossRef] [PubMed]

42. Li, Y.; Wang, H.; Peng, S. Tunable Photodeposition of $\mathrm{MoS}_{2}$ onto a Composite of Reduced Graphene Oxide and CdS for Synergic Photocatalytic Hydrogen Generation. J. Phys. Chem. C 2014, 118, 19842-19848. [CrossRef]

43. Liu, J.-H.; Huang, G.-F.; Huang, W.-Q.; Miao, H.; Zhou, B.-X. Morphology-controlled SnS 2 nanostructures synthesized by refluxing method with high photocatalytic activity. Mater. Lett. 2015, 161, 480-483. [CrossRef]

44. Wang, Q.; Lei, Y.; Wang, Y.; Liu, Y.; Song, C.; Zeng, J.; Song, Y.; Duan, X.; Wang, D.; Li, Y. Atomic-scale engineering of chemicalvapor-deposition-grown $2 \mathrm{D}$ transition metal dichalcogenides for electrocatalysis. Energy Environ. Sci. 2020, 13, 1593-1616. [CrossRef]

45. Luo, M.; Liu, Y.; Hu, J.; Liu, H.; Li, J. One-Pot Synthesis of CdS and Ni-Doped CdS Hollow Spheres with Enhanced Photocatalytic Activity and Durability. ACS Appl. Mater. Interfaces 2012, 4, 1813-1821. [CrossRef] [PubMed]

46. Wang, Y.; Li, L.; Yao, W.; Song, S.; Sun, J.T.; Pan, J.; Ren, X.; Li, C.; Okunishi, E.; Wang, Y.-Q.; et al. Monolayer PtSe2, a New Semiconducting Transition-Metal-Dichalcogenide, Epitaxially Grown by Direct Selenization of Pt. Nano Lett. 2015, 15, 4013-4018. [CrossRef] [PubMed]

47. Sarwar, S.; Nautiyal, A.; Cook, J.; Yuan, Y.; Li, J.; Uprety, S.; Shahbazian-Yassar, R.; Wang, R.; Park, M.; Bozack, M.J.; et al. Facile microwave approach towards high performance $\mathrm{MoS}_{2}$ /graphene nanocomposite for hydrogen evolution reaction. Sci. China Mater. 2020, 63, 62-74. [CrossRef]

48. Jiao, F.; Yen, H.; Hutchings, G.S.; Yonemoto, B.; Lua, Q.; Kleitz, F. Synthesis, structural characterization, and electrochemical performance of nanocast mesoporous Cu-/Fe-based oxides. J. Mater. Chem. A 2014, 2, 3065-3071. [CrossRef]

49. Panigrahi, P.K.; Pathak, A. Microwave-assisted synthesis of $\mathrm{WS}_{2}$ nanowires through tetrathiotungstate precursors. Sci. Technol. Adv. Mater. 2008, 9, 045008. [CrossRef] [PubMed]

50. Liu, H.; Su, Y.; Chen, P.; Wang, Y. Microwave-assisted solvothermal synthesis of 3D carnation-like SnS 2 nanostructures with high visible light photocatalytic activity. J. Mol. Catal. Chem. 2013, 378, 285-292. [CrossRef]

51. Rao, B.G.; Mukherjee, D.; Reddy, B.M. Novel Approaches for Preparation of Nanoparticles; Elsevier Inc.: Amsterdam, The Netherlands, 2017; ISBN 9780323461481.

52. Kumar, A. Different Methods Used for the Synthesis of $\mathrm{TiO}_{2}$ Based Nanomaterials: A Review. Am. J. Nano Res. Appl. 2018, 6, 1-10. [CrossRef]

53. Aliofkhazraei, M. (Ed.) Handbook of Nanoparticles; Springer International Publishing: Cham, Switzerland, 2016.

54. Pokrovski, G.S.; Roux, J.; Hazemann, J.-L.; Borisova, A.; Gonchar, A.A.; Lemeshko, M.P. In situ X-ray absorption spectroscopy measurement of vapour-brine fractionation of antimony at hydrothermal conditions. Miner. Mag. 2008, 72, 667-681. [CrossRef]

55. Gautam, A.K.; Faraz, M.; Khare, N. Enhanced thermoelectric properties of $\mathrm{MoS}_{2}$ with the incorporation of reduced graphene oxide (RGO). J. Alloys Compd. 2020, 838, 155673. [CrossRef] 
56. Bricha, M.; Belmamouni, Y.; Essassi, E.M.; Ferreira, J.; El Mabrouk, K. Surfactant-Assisted Hydrothermal Synthesis of Hydroxyapatite Nanopowders. J. Nanosci. Nanotechnol. 2012, 12, 8042-8049. [CrossRef]

57. Cao, S.; Liu, T.; Zeng, W.; Hussain, S.; Peng, X.; Pan, F. Synthesis and characterization of flower-like $\mathrm{WS}_{2}$ nanospheres via a facile hydrothermal route. J. Mater. Sci. Mater. Electron. 2014, 25, 4300-4305. [CrossRef]

58. Naskar, B.; Dan, A.; Ghosh, S.; Aswal, V.; Moulik, S.P. Revisiting the self-aggregation behavior of cetyltrimethylammonium bromide in aqueous sodium salt solution with varied anions. J. Mol. Liq. 2012, 170, 1-10. [CrossRef]

59. Vollath, D.; Szabó, D.V. Synthesis of nanocrystalline $\mathrm{MoS}_{2}$ and $\mathrm{WS}_{2}$ in a microwave plasma. Mater. Lett. 1998, 35, $236-244$. [CrossRef]

60. Shanmugaratnam, S.; Rasalingam, S. Transition Metal Chalcogenide (TMC) Nanocomposites for Environmental Remediation Application over Extended Solar Irradiation. In Nanocatalysts; IntechOpen: London, UK, 2012. [CrossRef]

61. Park, S.; Park, J.; Selvaraj, R.; Kim, Y. Facile microwave-assisted synthesis of $\mathrm{SnS}_{2}$ nanoparticles for visible-light responsive photocatalyst. J. Ind. Eng. Chem. 2015, 31, 269-275. [CrossRef]

62. Choubey, S.K.; Tiwary, K.P. Microwave assisted synthesis of CdS nanoparticles for structural and optical characterization. IJIRSET 2014, 3, 10670-10674.

63. Nethravathi, C.; Rajamathi, J.T.; Rajamathi, M. Microwave-Assisted Synthesis of Porous Aggregates of CuS Nanoparticles for Sunlight Photocatalysis. ACS Omega 2019, 4, 4825-4831. [CrossRef] [PubMed]

64. Pang, H.; Wei, C.; Li, X.; Li, G.; Ma, Y.; Li, S.; Chen, J.; Zhang, J. Microwave-assisted synthesis of NiS 2 nanostructures for supercapacitors and cocatalytic enhancing photocatalytic $\mathrm{H}_{2}$ production. Sci. Rep. 2014, 4, 1-8. [CrossRef]

65. Amaresh, S.; Karthikeyan, K.; Jang, I.-C.; Lee, Y.S. Single-step microwave mediated synthesis of the $\mathrm{CoS}_{2}$ anode material for high rate hybrid supercapacitors. J. Mater. Chem. A 2014, 2, 11099-11106. [CrossRef]

66. Liu, B.; Qu, S.; Kou, Y.; Liu, Z.; Chen, X.; Wu, Y.; Han, X.; Deng, Y.; Hu, W.; Zhong, C. In Situ Electrodeposition of Cobalt Sulfide Nanosheet Arrays on Carbon Cloth as a Highly Efficient Bifunctional Electrocatalyst for Oxygen Evolution and Reduction Reactions. ACS Appl. Mater. Interfaces 2018, 10, 30433-30440. [CrossRef] [PubMed]

67. Ghahremaninezhad, A.; Asselin, E.; Dixon, D.G. Electrodeposition and Growth Mechanism of Copper Sulfide Nanowires. J. Phys. Chem. C 2011, 115, 9320-9334. [CrossRef]

68. Mammadov, M.N.; Sh Aliyev, A.; Elrouby, M. Electrodeposition of cadmium sulfide. Int. J. Thin Film Sci. Tec. $2012,1,43-53$.

69. Huang, J.; Daryadel, S.; Minary-Jolandan, M. Low-Cost Manufacturing of Metal-Ceramic Composites through Electrodeposition of Metal into Ceramic Scaffold. ACS Appl. Mater. Interfaces 2019, 11, 4364-4372. [CrossRef]

70. Maharana, H.; Basu, A.; Mondal, K. Structural and tribological correlation of electrodeposited solid lubricating Ni-WSe 2 composite coating. Surf. Coatings Technol. 2018, 349, 328-339. [CrossRef]

71. Safavi, M.S.; Fathi, M.; Charkhesht, V.; Jafarpour, M.; Ahadzadeh, I. Electrodeposition of Co-P Coatings Reinforced by MoS $2+$ $\mathrm{Y}_{2} \mathrm{O}_{3}$ Hybrid Ceramic Nanoparticles for Corrosion-Resistant Applications: Influences of Operational Parameters. Met. Mater. Trans. A 2020, 51, 6740-6758. [CrossRef]

72. Jayakrishnan, D.S. Electrodeposition: The Versatile Technique for Nanomaterials; Woodhead Publishing Limited: Sawston, UK, 2012.

73. Aruna, S.; Bindu, C.; Selvi, V.E.; Grips, V.W.; Rajam, K. Synthesis and properties of electrodeposited Ni/ceria nanocomposite coatings. Surf. Coatings Technol. 2006, 200, 6871-6880. [CrossRef]

74. Shariza, S.; Anand, T.J.S. Effect of deposition time on the structural and optical properties of molybdenum chalcogenides thin films. Chalcogenide Lett. 2011, 8, 529-539.

75. Chen, Y.-C.; Huang, Y.-S.; Huang, H.; Su, P.-J.; Perng, T.-P.; Chen, L.-J. Photocatalytic enhancement of hydrogen production in water splitting under simulated solar light by band gap engineering and localized surface plasmon resonance of $\mathrm{Zn}_{\mathrm{x}} \mathrm{Cd} \mathrm{d}_{1-\mathrm{x}} \mathrm{S}$ nanowires decorated by Au nanoparticles. Nano Energy 2020, 67, 104225. [CrossRef]

76. Sankapal, B.R.; Mane, R.S.; Lokhande, C.D. Successive ionic layer adsorption and reaction (SILAR) method for the deposition of large area $\left(\sim 10 \mathrm{~cm}^{2}\right)$ tin disulfide $\left(\mathrm{SnS}_{2}\right)$ thin films. Mater. Res. Bull. 2000, 35, 2027-2035. [CrossRef]

77. Pathan, H.M.; Lokhande, C.D. Deposition of metal chalcogenide thin films by successive ionic layer adsorption and reaction (SILAR) method. Bull. Mater. Sci 2004, 27, 85-111.

78. Leskell, M. Deposition of manganese-doped successive ionic layer adsorption zinc sulfide thin films by the and reaction (SILAR) method. Thin Solid Film. 1995, 263, 79-84.

79. Lindroos, S.; Kanniainen, T.; Leskelä, M. Growth of zinc sulfide thin films by the successive ionic layer adsorption and reaction (SILAR) method on polyester substrates. Mater. Res. Bull. 1997, 32, 1631-1636. [CrossRef]

80. Valkonen, M.P.; Kanniainen, T.; Lindroos, S.; Leskelä, M.; Rauhala, E. Growth of ZnS, CdS and multilayer ZnS/CdS thin films by SILAR technique. Appl. Surf. Sci. 1997, 115, 386-392. [CrossRef]

81. Aditha, S.K.; Kurdekar, A.D.; Chunduri, L.A.A.; Patnaik, S.; Kamisetti, V. Aqueous based reflux method for green synthesis of nanostructures: Application in CZTS synthesis. MethodsX 2016, 3, 35-42. [CrossRef] [PubMed]

82. Phuruangrat, A.; Thoonchalong, P.; Thongtem, S.; Thongtem, T. Synthesis of cus with different morphologies by refluxing method: Nanopaticles in clusters and nanoflakes in sponge-like clusters. Chalcogenide Lett. 2012, 9, 421-426.

83. Wang, L.-C.; Bao, S.-K.; Luo, J.; Wang, Y.-H.; Nie, Y.-C.; Zou, J.-P. Efficient exfoliation of bulk MoS $_{2}$ to nanosheets by mixed-solvent refluxing method. Int. J. Hydrogen Energy 2016, 41, 10737-10743. [CrossRef] 
84. Phuruangrat, A.; Karthik, K.; Kuntalue, B.; Dumrongrojthanath, P.; Thongtem, S.; Thongtem, T.; Yai, H.; Nadu, T.; Science, M. Refuxing synthesis and characterization of zns nanoparticles and their photocatalytic properties. Chalcogenide Lett. 2019, 16, 387-393.

85. Dai, Z.; Zang, X.; Yang, J.; Sun, C.; Si, W.; Huang, W.; Dong, X. Template Synthesis of Shape-Tailorable NiS 2 Hollow Prisms as High-Performance Supercapacitor Materials. ACS Appl. Mater. Interfaces 2015, 7, 25396-25401. [CrossRef] [PubMed]

86. Li, J.; Yang, X.; Liu, Y.; Huang, B.; Wu, R.; Zhang, Z.; Zhao, B.; Ma, H.; Dang, W.; Wei, Z.; et al. General synthesis of twodimensional van der Waals heterostructure arrays. Nat. Cell Biol. 2020, 579, 368-374. [CrossRef] [PubMed]

87. Gong, Y.; Lin, J.; Wang, X.; Shi, G.; Lei, S.; Lin, Z.; Zou, X.; Ye, G.; Vajtai, R.; Yakobson, B.I.; et al. Vertical and in-plane heterostructures from $\mathrm{WS}_{2} / \mathrm{MoS}_{2}$ monolayers. Nat. Mater. 2014, 13, 1135-1142. [CrossRef] [PubMed]

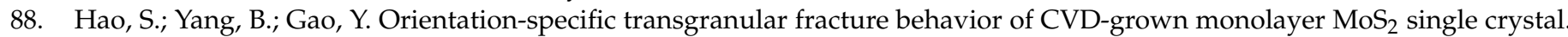
Appl. Phys. Lett. 2017, 110, 153105. [CrossRef]

89. Kim, S.; Kwak, J.; Ciobanu, C.V.; Kwon, S. Recent Developments in Controlled Vapor-Phase Growth of 2D Group 6 Transition Metal Dichalcogenides. Adv. Mater. 2019, 31, e1804939. [CrossRef]

90. Tan, H.; Fan, Y.; Zhou, Y.; Chen, Q.; Xu, W.; Warner, J.H. Ultrathin 2D Photodetectors Utilizing Chemical Vapor Deposition Grown $\mathrm{WS}_{2}$ With Graphene Electrodes. ACS Nano 2016, 10, 7866-7873. [CrossRef] [PubMed]

91. Chang, R.-J.; Tan, H.; Wang, X.; Porter, B.; Chen, T.; Sheng, Y.; Zhou, Y.; Huang, H.; Bhaskaran, H.; Warner, J.H. High-Performance All 2D-Layered Tin Disulfide: Graphene Photodetecting Transistors with Thickness-Controlled Interface Dynamics. ACS Appl. Mater. Interfaces 2018, 10, 13002-13010. [CrossRef] [PubMed]

92. Cong, C.; Shang, J.; Wu, X.; Cao, B.; Peimyoo, N.; Qiu, C.; Sun, L.; Yu, T. Synthesis and Optical Properties of Large-Area Single-Crystalline 2D Semiconductor $\mathrm{WS}_{2}$ Monolayer from Chemical Vapor Deposition. Adv. Opt. Mater. 2014, 2, 131-136. [CrossRef]

93. Ye, G.; Gong, Y.; Lei, S.; He, Y.; Li, B.; Zhang, X.; Jin, Z.; Dong, L.; Lou, J.; Vajtai, R.; et al. Synthesis of large-scale atomic-layer SnS 2 through chemical vapor deposition. Nano Res. 2017, 10, 2386-2394. [CrossRef]

94. Dai, C.; Li, B.; Li, J.; Zhao, B.; Wu, R.; Ma, H.; Duan, X. Controllable synthesis of NiS and NiS 2 nanoplates by chemical vapor deposition. Nano Res. 2020, 13, 2506-2511. [CrossRef]

95. Ardahe, M.; Hantehzadeh, M.R.; Ghoranneviss, M. Effect of Growth Temperature on Physical Properties of MoS 2 Thin Films Synthesized by CVD. J. Electron. Mater. 2019, 49, 1002-1008. [CrossRef]

96. Samad, L.; Cabán-Acevedo, M.; Shearer, M.; Park, K.; Hamers, R.; Jin, S. Direct Chemical Vapor Deposition Synthesis of Phase-Pure Iron Pyrite $\left(\mathrm{FeS}_{2}\right)$ Thin Films. Chem. Mater. 2015, 27, 3108-3114. [CrossRef]

97. Backes, C.; Szydłowska, B.M.; Harvey, A.; Yuan, S.; Vega-Mayoral, V.; Davies, B.R.; Zhao, P.-L.; Hanlon, D.; Santos, E.J.G.; Katsnelson, M.I.; et al. Production of Highly Monolayer Enriched Dispersions of Liquid-Exfoliated Nanosheets by Liquid Cascade Centrifugation. ACS Nano 2016, 10, 1589-1601. [CrossRef]

98. Mihai, C.; Sava, F.; Galca, A.C.; Velea, A. Low power non-volatile memory switching in monolayer-rich $2 \mathrm{D} \mathrm{WS}_{2}$ and $\mathrm{MoS}_{2}$ devices. AIP Adv. 2020, 10, 025102. [CrossRef]

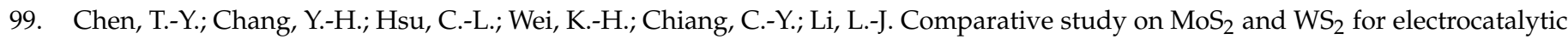
water splitting. Int. J. Hydrogen Energy 2013, 38, 12302-12309. [CrossRef]

100. Ma, L.; Chen, W.-X.; Xu, Z.-D.; Xia, J.-B.; Li, X. Carbon nanotubes coated with tubular MoS 2 layers prepared by hydrothermal reaction. Nanotechnology 2006, 17, 571-574. [CrossRef]

101. Li, Q.; Zhang, N.; Yang, Y.; Wang, G.; Ng, D.H.L. High Efficiency Photocatalysis for Pollutant Degradation with $\mathrm{MoS}_{2} / \mathrm{C}_{3} \mathrm{~N}_{4}$ Heterostructures. Langmuir 2014, 30, 8965-8972. [CrossRef] [PubMed]

102. Lukowski, M.A.; Daniel, A.S.; Meng, F.; Forticaux, A.; Li, L.; Jin, S. Enhanced Hydrogen Evolution Catalysis from Chemically Exfoliated Metallic $\mathrm{MoS}_{2}$ Nanosheets. J. Am. Chem. Soc. 2013, 135, 10274-10277. [CrossRef]

103. Peng, Y.; Meng, Z.; Zhong, C.; Lu, J.; Yu, W.; Jia, Y.; Qian, Y. Hydrothermal synthesis and characterization of single-molecular-layer $\mathrm{MoS}_{2}$ and $\mathrm{MoSe}_{2}$. Chem. Lett. 2001, 30, 772-773. [CrossRef]

104. Afanasiev, P.; Xia, G.-F.; Berhault, G.; Jouguet, B.; Lacroix, M. Surfactant-Assisted Synthesis of Highly Dispersed Molybdenum Sulfide. Chem. Mater. 1999, 11, 3216-3219. [CrossRef]

105. Shanmugaratnam, S.; Velauthapillai, D.; Ravirajan, P.; Christy, A.A.; Shivatharsiny, Y. $\mathrm{CoS}_{2} / \mathrm{TiO}_{2}$ Nanocomposites for Hydrogen Production under UV Irradiation. Materials 2019, 12, 3882. [CrossRef] [PubMed]

106. Shanmugaratnam, S.; Selvaratnam, B.; Baride, A.; Koodali, R.; Ravirajan, P.; Velauthapillai, D.; Shivatharsiny, Y. SnS $2 / \mathrm{TiO}_{2}$ Nanocomposites for Hydrogen Production and Photodegradation under Extended Solar Irradiation. Catalysts 2021, 11, 589. [CrossRef]

107. Cao, J.; Zhou, J.; Zhang, Y.; Wang, Y.; Liu, X. Dominating Role of Aligned $\mathrm{MoS}_{2} / \mathrm{Ni}_{3} \mathrm{~S}_{2}$ Nanoarrays Supported on ThreeDimensional Ni Foam with Hydrophilic Interface for Highly Enhanced Hydrogen Evolution Reaction. ACS Appl. Mater. Interfaces 2018, 10, 1752-1760. [CrossRef]

108. Gao, B.; Du, X.; Ma, Y.; Li, Y.; Li, Y.; Ding, S.; Song, Z.; Xiao, C. 3D flower-like defected $\mathrm{MoS}_{2}$ magnetron-sputtered on candle soot for enhanced hydrogen evolution reaction. Appl. Catal. Environ. 2020, 263, 117750. [CrossRef]

109. Nadeem Riaz, K.; Yousaf, N.; Bilal Tahir, M.; Israr, Z.; Iqbal, T. Facile hydrothermal synthesis of 3D flower-like La-MoS 2 nanostructure for photocatalytic hydrogen energy production. Int. J. Energy Res. 2019, 43, 491-499. [CrossRef] 
110. Radisavljevic, B.; Radenovic, A.; Brivio, J.; Giacometti, V.; Kis, A. Single-layer $\mathrm{MoS}_{2}$ transistors. Nat. Nanotechnol. 2011, 6, 147-150. [CrossRef]

111. Gaur, R.; Jeevanandam, P. Synthesis of $\mathrm{SnS}_{2}$ Nanoparticles and Their Application as Photocatalysts for the Reduction of Cr(VI). J. Nanosci. Nanotechnol. 2018, 18, 165-177. [CrossRef]

112. Zhu, L.; Susac, D.; Teo, M.; Wong, K.; Wong, P.; Parsons, R.; Bizzotto, D.; Mitchell, K.; Campbell, S. Investigation of CoS2-based thin films as model catalysts for the oxygen reduction reaction. J. Catal. 2008, 258, 235-242. [CrossRef]

113. Wang, J.; Yin, Y. Fermentative hydrogen production using pretreated microalgal biomass as feedstock. Microb. Cell Factories 2018, 17, 1-16. [CrossRef]

114. Kye, J.; Shin, M.; Lim, B.; Jang, J.-W.; Oh, I.; Hwang, S. Platinum Monolayer Electrocatalyst on Gold Nanostructures on Silicon for Photoelectrochemical Hydrogen Evolution. ACS Nano 2013, 7, 6017-6023. [CrossRef]

115. Mckone, J.R.; Pieterick, A.P.; Gray, H.B.; Lewis, N.S. Supporting Information: Hydrogen Evolution from Pt / Ru-Coated p-Type WSe $_{2}$ Photocathodes. J. Am. Chem. Soc. 2013, 135, 223-231. [CrossRef] [PubMed]

116. Wiensch, J.D.; John, J.; Velazquez, J.M.; Torelli, D.A.; Pieterick, A.P.; McDowell, M.T.; Sun, K.; Zhao, X.; Brunschwig, B.S.; Lewis, N.S. Comparative Study in Acidic and Alkaline Media of the Effects of $\mathrm{pH}$ and Crystallinity on the Hydrogen-Evolution Reaction on $\mathrm{MoS}_{2}$ and $\mathrm{MoSe}_{2}$. ACS Energy Lett. 2017, 2, 2234-2238. [CrossRef]

117. Sun, B.; Wang, H.; Wu, J.; Geng, Y.; Xu, J.; Wang, Y.; Li, Y.; Lin, H.; Wang, L. Designed synthesis of unique ZnS@CdS@Cd $0.5 Z_{0.5} S-$ $\mathrm{MoS}_{2}$ hollow nanospheres for efficient visible-light-driven $\mathrm{H}_{2}$ evolution. CrystEngComm 2020, 22, 2743-2755. [CrossRef]

118. Komba, N.; Zhang, G.; Pu, Z.; Wu, M.; Rosei, F.; Sun, S. $\mathrm{MoS}_{2}$-supported on free-standing $\mathrm{TiO}_{2}$-nanotubes for efficient hydrogen evolution reaction. Int. J. Hydrogen Energy 2020, 45, 4468-4480. [CrossRef]

119. Zhao, X.; Ma, X.; Sun, J.; Li, D.; Yang, X. Enhanced Catalytic Activities of Surfactant-Assisted Exfoliated WS 2 Nanodots for Hydrogen Evolution. ACS Nano 2016, 10, 2159-2166. [CrossRef] [PubMed]

120. Mao, Q.; Chen, J.; Chen, H.; Chen, Z.; Chen, J.; Li, Y. Few-layered 1T-MoS 2 -modified ZnCoS solid-solution hollow dodecahedra for enhanced photocatalytic hydrogen evolution. J. Mater. Chem. A 2019, 7, 8472-8484. [CrossRef]

121. Oertel, M.; Schmitz, J.; Weirich, W.; Jendryssek-Neumann, D.; Schulten, R. Vapour-liquid Equilibrium Data Collec-tion' dechema Frankfurt. Izv. Vyss. Uchebn. Zaved. Khim. Tekhnol. 1987, 27, 686-691.

122. Kumar, S.S.; Himabindu, V. Hydrogen production by PEM water electrolysis-A review. Mater. Sci. Energy Technol. 2019, 2, 442-454. [CrossRef]

123. Dehghanimadvar, M.; Shirmohammadi, R.; Sadeghzadeh, M.; Aslani, A.; Ghasempour, R. Hydrogen production technologies: Attractiveness and future perspective. Int. J. Energy Res. 2020, 44, 8233-8254. [CrossRef]

124. FreedomCAR and Fuel Partnership Hydrogen Offers Sustainable Solutions to Our Nation's Energy and Climate Challenges. Table of Contents Sustainability Urban Air Quality. 2009. Available online: https:/ / www1.eere.energy.gov/hydrogenandfuelcells/ pdfs/h2_tech_roadmap.pdf (accessed on 11 October 2021).

125. Luo, X.; Wu, T.; Shi, K.; Song, M.; Rao, Y. Biomass Gasification: An Overview of Technological Barriers and Socio-Environmental Impact. Gasif. Low-Grade Feedstock 2018, 3-18. [CrossRef]

126. Ding, Q.; Song, B.; Xu, P.; Jin, S. Efficient Electrocatalytic and Photoelectrochemical Hydrogen Generation Using MoS 2 and Related Compounds. Chem 2016, 1, 699-726. [CrossRef]

127. Chu, D.; Zhang, C.; Yang, P.; Du, Y.; Lu, C. $\mathrm{WS}_{2}$ as an Effective Noble-Metal Free Cocatalyst Modified TiSi 2 for Enhanced Photocatalytic Hydrogen Evolution under Visible Light Irradiation. Catalysts 2016, 6, 136. [CrossRef]

128. Zhang, J.; Hu, W.; Cao, S.; Piao, L. Recent progress for hydrogen production by photocatalytic natural or simulated seawater splitting. Nano Res. 2020, 13, 2313-2322. [CrossRef]

129. Liu, J.; Yu, G.; Zhang, R.; Huang, X.; Chen, W. Theoretical predication of the high hydrogen evolution catalytic activity for the cubic and tetragonal SnP systems. Phys. Chem. Chem. Phys. 2019, 21, 5521-5530. [CrossRef] [PubMed]

130. Som, N.N.; Jha, P.K. Hydrogen evolution reaction of metal di-chalcogenides: $\mathrm{ZrS}_{2}, \mathrm{ZrSe}_{2}$ and Janus ZrSSe. Int. J. Hydrogen Energy 2020, 45, 23920-23927. [CrossRef]

131. Wang, B.; Wang, X.; Yuan, H.; Zhou, T.; Chang, J.; Chen, H. Direct Z-scheme photocatalytic overall water splitting on two dimensional $\mathrm{MoSe}_{2} / \mathrm{SnS}_{2}$ heterojunction. Int. J. Hydrogen Energy 2020, 45, 2785-2793. [CrossRef]

132. Park, H.; Akande, A.; Sanvito, S.; El-Mellouhi, F. The rise of Nb-, Ta-, and Bi-based oxides/chalcogenides for photocatalytic applications. Int. J. Hydrogen Energy 2021, 1-13. [CrossRef]

133. Ran, N.; Qiu, W.; Song, E.; Wang, Y.; Zhao, X.; Liu, Z.; Liu, J. Bond Electronegativity as Hydrogen Evolution Reaction Catalyst Descriptor for Transition Metal (TM = Mo, W) Dichalcogenides. Chem. Mater. 2020, 32, 1224-1234. [CrossRef]

134. Faraji, M.; Yousefi, M.; Yousefzadeh, S.; Zirak, M.; Naseri, N.; Jeon, T.H.; Choi, W.; Moshfegh, A.Z. Two-dimensional materials in semiconductor photoelectrocatalytic systems for water splitting. Energy Environ. Sci. 2019, 12, 59-95. [CrossRef]

135. Huang, D.; Wen, M.; Zhou, C.; Li, Z.; Cheng, M.; Chen, S.; Xue, W.; Lei, L.; Yang, Y.; Xiong, W.; et al. Zn $\mathrm{Zn}_{\mathrm{x}} \mathrm{Cd}_{1-\mathrm{x}} \mathrm{S}$ based materials for photocatalytic hydrogen evolution, pollutants degradation and carbon dioxide reduction. Appl. Catal. Environ. 2020, 267, 118651. [CrossRef]

136. Kudo, A.; Kato, H.; Tsuji, I. Strategies for the Development of Visible-light-driven Photocatalysts for Water Splitting. Chem. Lett. 2004, 33, 1534-1539. [CrossRef] 
137. Li, K.; Li, Y.; Wang, Y.; Ge, J.; Liu, C.; Xing, W. Enhanced electrocatalytic performance for the hydrogen evolution reaction through surface enrichment of platinum nanoclusters alloying with ruthenium in situ embedded in carbon. Energy Environ. Sci. 2018, 11, 1232-1239. [CrossRef]

138. Ahn, S.; Yang, J.; Lim, H.; Shin, H.S. Selective synthesis of pure cobalt disulfide on reduced graphene oxide sheets and its high electrocatalytic activity for hydrogen evolution reaction. Nano Converg. 2016, 3, 1-7. [CrossRef] [PubMed]

139. Gao, C.; Hua, H.; Du, M.; Liu, J.; Wu, X.; Pu, Y.; Li, X. 1T/2H MoS 2 nanoflowers decorated amorphous Mo-CoS $x$ skeleton: A ZIF-based composite electrocatalyst for the hydrogen evolution reaction. Appl. Surf. Sci. 2020, 515, 145842. [CrossRef]

140. Bhat, K.S.; Nagaraja, H. Performance evaluation of molybdenum dichalcogenide (MoX2; X=S, Se, Te) nanostructures for hydrogen evolution reaction. Int. J. Hydrogen Energy 2019, 44, 17878-17886. [CrossRef]

141. Li, H.; Yang, C.; Wang, X.; Zhang, J.; Xi, J.; Du, G.; Ji, Z. Mixed 3D/2D dimensional $\mathrm{TiO}_{2}$ nanoflowers/MoSe 2 nanosheets for enhanced photoelectrochemical hydrogen generation. J. Am. Ceram. Soc. 2020, 103, 1187-1196. [CrossRef]

142. Sharma, M.D.; Mahala, C.; Basu, M. 2D Thin Sheet Heterostructures of $\mathrm{MoS}_{2}$ on $\mathrm{MoSe}_{2}$ as Efficient Electrocatalyst for Hydrogen Evolution Reaction in Wide pH Range. Inorg. Chem. 2020, 59, 4377-4388. [CrossRef]

143. Xia, Y.; Wu, W.; Wang, H.; Rao, S.; Zhang, F.; Zou, G. Amorphous RuS 2 electrocatalyst with optimized active sites for hydrogen evolution. Nanotechnology 2020, 31, 145401. [CrossRef] [PubMed]

144. Zhang, D.; Mou, H.; Chen, L.; Wang, D.; Song, C. Design and in-situ synthesis of unique catalyst via embedding graphene oxide shell membrane in $\mathrm{NiS}_{2}$ for efficient hydrogen evolution. Appl. Surf. Sci. 2020, 510, 145483. [CrossRef]

145. Manjunathaae, C.; Patil, R.S.; Sudeep, M.; Srinivasa, N.; Kumar, R.C.; Aan, M.S.; Ashoka, S. Rational design and synthesis of hetero-nanostructured electrospun PU@PANI@FeS 2 : A surface tailored hybrid catalyst for $\mathrm{H}_{2}$ production via electrochemical splitting of water. Surf. Interfaces 2020, 18, 100445. [CrossRef]

146. Zeng, X.; Jiao, Q.; Li, N.; Wang, J. Facile synthesis of CuxS coated electrodes for the efficient hydrogen evolution reaction. Appl. Surf. Sci. 2020, 513, 145785. [CrossRef]

147. Li, Z.; Liu, P.; Yang, G. Efficient All-2D Amorphous Cobalt Sulfide Nanosheets/Multilayered Molybdenum Disulfide Hybrid Heterojunction Catalyst for Electrochemical Hydrogen Evolution. Glob. Chall. 2020, 4, 1900066. [CrossRef] [PubMed]

148. Zhu, X.; Dai, J.; Li, L.; Zhao, D.; Wu, Z.; Tang, Z.; Ma, L.-J.; Chen, S. Hierarchical carbon microflowers supported defect-rich Co3S4 nanoparticles: An efficient electrocatalyst for water splitting. Carbon 2020, 160, 133-144. [CrossRef]

149. Aslan, E.; Sarilmaz, A.; Yanalak, G.; Chang, C.S.; Cinar, I.; Ozel, F.; Patir, I.H. Facile preparation of amorphous NiWSex and CoWSex nanoparticles for the electrocatalytic hydrogen evolution reaction in alkaline condition. J. Electroanal. Chem. 2019, 856, 113674. [CrossRef]

150. Li, G.; Chen, Z.; Li, Y.; Zhang, D.; Yang, W.; Liu, Y.; Cao, L. Engineering Substrate Interaction to Improve Hydrogen Evolution Catalysis of Monolayer $\mathrm{MoS}_{2}$ Films beyond Pt. ACS Nano 2020, 14, 1707-1714. [CrossRef] [PubMed]

151. Nguyen, V.-T.; Le, P.A.; Hsu, Y.-C.; Wei, K.-H. Plasma-Induced Exfoliation Provides Onion-Like Graphene-Surrounded MoS 2 Nanosheets for a Highly Efficient Hydrogen Evolution Reaction. ACS Appl. Mater. Interfaces 2020, 12, 11533-11542. [CrossRef] [PubMed]

152. Shi, Q.; Zhou, Y.; Sun, W.; Wang, H.; Li, S.; Zhang, X.; Wan, J. Hydrogen Evolution and Wastewater Treatment of Hydrangeal-like Catalyst Decroatedby the NiS Nanosheet and PdNanoparticle. ChemistrySelect 2020, 5, 1041-1046. [CrossRef]

153. Zhao, A.; Zhang, L.; Xu, G.; Zhang, X.; Zhang, S.; Xiao, Y. Hollow $\mathrm{Zn}_{\mathrm{x}} \mathrm{Co}_{1-\mathrm{x}} \mathrm{Se}_{2}$ microcubes derived from Metal-Organic framework as efficient bifunctional electrocatalysts for hydrogen evolution and oxygen evolution reactions. Int. J. Hydrogen Energy 2020, 45, 2607-2616. [CrossRef]

154. Zhou, Y.; Zhang, J.; Ren, H.; Pan, Y.; Yan, Y.; Sun, F.; Wang, X.; Wang, S.; Zhang, J. Mo doping induced metallic CoSe for enhanced electrocatalytic hydrogen evolution. Appl. Catal. B Environ. 2020, 268, 118467. [CrossRef]

155. Liang, Y.; Yang, Y.; Xu, K.; Yu, T.; Yao, S.; Peng, Q.; Yuan, C. Crystal plane dependent electrocatalytic performance of NiS 2 nanocrystals for hydrogen evolution reaction. J. Catal. 2020, 381, 63-69. [CrossRef]

156. Friedman, F.; Hastie, T.; John, T.; Weatherwax, R.L.; Epstein, D.; Wasserman, L.; Abu-El-Haija, S.; Do, C.B.; Batzoglou, S.; Resknik, C.; et al. Solution-processed GaSe nanoflake-based films for photoelectrochemical water splitting and photoelectrochemical-type J. Chem. Inf. Model. 2013, 67, 1689-1699. [CrossRef]

157. Ma, F.; Liang, Y.; Zhou, P.; Tong, F.; Wang, Z.; Wang, P.; Liu, Y.; Dai, Y.; Zheng, Z.; Huang, B. One-step synthesis of Co-doped $1 \mathrm{~T}-\mathrm{MoS}_{2}$ nanosheets with efficient and stable HER activity in alkaline solutions. Mater. Chem. Phys. 2020, 244, 122642. [CrossRef]

158. Song, W.; Wang, K.; Jin, G.; Wang, Z.; Li, C.; Yang, X.; Chen, C. Two-Step Hydrothermal Synthesis of CoSe/MoSe 2 as Hydrogen Evolution Electrocatalysts in Acid and Alkaline Electrolytes. ChemElectroChem 2019, 6, 4842-4847. [CrossRef]

159. Yang, J.-X.; Yu, W.-B.; Li, C.-F.; Dong, W.-D.; Jiang, L.-Q.; Zhou, N.; Zhuang, Z.-P.; Liu, J.; Hu, Z.-Y.; Zhao, H.; et al. PtO nanodots promoting $\mathrm{Ti} 3 \mathrm{C} 2 \mathrm{MXene}$ in-situ converted $\mathrm{Ti} 3 \mathrm{C} 2 / \mathrm{TiO}_{2}$ composites for photocatalytic hydrogen production. Chem. Eng. J. 2021, 420, 129695. [CrossRef]

160. Guayaquil-Sosa, J.; Rosales, B.S.; Valadés-Pelayo, P.; De Lasa, H. Photocatalytic hydrogen production using mesoporous TiO 2 doped with Pt. Appl. Catal. Environ. 2017, 211, 337-348. [CrossRef]

161. Zhao, H.; Li, C.-F.; Hu, Z.-Y.; Liu, J.; Li, Y.; Hu, J.; Van Tendeloo, G.; Chen, L.-H.; Su, B.-L. Size effect of bifunctional gold in hierarchical titanium oxide-gold-cadmium sulfide with slow photon effect for unprecedented visible-light hydrogen production. J. Colloid Interface Sci. 2021, 604, 131-140. [CrossRef] [PubMed] 
162. Yerga, R.M.N.; Alvarez-Galvan, M.C.; Del Valle, F.; De La Mano, J.A.V.; Fierro, J.L.G. Water Splitting on Semiconductor Catalysts under Visible-Light Irradiation. ChemSusChem 2009, 2, 471-485. [CrossRef] [PubMed]

163. Wang, Q.; Huang, J.; Sun, H.; Zhang, K.-Q.; Lai, Y. Uniform carbon dots@ $\mathrm{TiO}_{2}$ nanotube arrays with full spectrum wavelength light activation for efficient dye degradation and overall water splitting. Nanoscale 2017, 9, 16046-16058. [CrossRef]

164. Onsuratoom, S.; Chavadej, S.; Sreethawong, T. Hydrogen production from water splitting under UV light irradiation over Agloaded mesoporous-assembled $\mathrm{TiO}_{2}-\mathrm{ZrO}_{2}$ mixed oxide nanocrystal photocatalysts. Int. J. Hydrogen Energy 2011, 36, 5246-5261. [CrossRef]

165. Chen, J.; Wu, X.-J.; Yin, L.; Li, B.; Hong, X.; Fan, Z.; Chen, B.; Xue, C.; Zhang, H. One-pot Synthesis of CdS Nanocrystals Hybridized with Single-Layer Transition-Metal Dichalcogenide Nanosheets for Efficient Photocatalytic Hydrogen Evolution. Angew. Chem. Int. Ed. 2015, 54, 1210-1214. [CrossRef]

166. Zong, X.; Han, J.; Ma, G.; Yan, H.; Wu, G.; Li, C. Photocatalytic $\mathrm{H}_{2}$ Evolution on CdS Loaded with WS 2 as Cocatalyst under Visible Light Irradiation. J. Phys. Chem. C 2011, 115, 12202-12208. [CrossRef]

167. Ran, J.; Zhang, J.; Yu, J.; Jaroniec, M.; Qiao, S.Z. Earth-abundant cocatalysts for semiconductor-based photocatalytic water splitting. Chem. Soc. Rev. 2014, 43, 7787-7812. [CrossRef] [PubMed]

168. Yan, C.; Xue, X.; Zhang, W.; Li, X.; Liu, J.; Yang, S.; Hu, Y.; Chen, R.; Yan, Y.; Zhu, G.; et al. Well-designed Te/SnS2/Ag artificial nanoleaves for enabling and enhancing visible-light driven overall splitting of pure water. Nano Energy 2017, 39, 539-545. [CrossRef]

169. Liu, E.; Chen, J.; Ma, Y.; Feng, J.; Jia, J.; Fan, J.; Hu, X. Fabrication of $2 \mathrm{D} \mathrm{SnS}_{2} / \mathrm{g}_{-} \mathrm{C}_{3} \mathrm{~N}_{4}$ heterojunction with enhanced $\mathrm{H}_{2}$ evolution during photocatalytic water splitting. J. Colloid Interface Sci. 2018, 524, 313-324. [CrossRef] [PubMed]

170. Ke, X.; Dai, K.; Zhu, G.; Zhang, J.; Liang, C. In situ photochemical synthesis noble-metal-free NiS on CdS-diethylenetriamine nanosheets for boosting photocatalytic H2 production activity. Appl. Surf. Sci. 2019, 481, 669-677. [CrossRef]

171. Khan, Z.; Chetia, T.R.; Vardhaman, A.K.; Barpuzary, D.; Sastri, C.V.; Qureshi, M. Visible light assisted photocatalytic hydrogen generation and organic dye degradation by CdS-metal oxide hybrids in presence of graphene oxide. RSC Adv. 2012, 2, 1212212128. [CrossRef]

172. Chang, K.; Mei, Z.; Wang, T.; Kang, Q.; Ouyang, S.; Ye, J. MoS 2 /Graphene Cocatalyst for Efficient Photocatalytic H2 Evolution under Visible Light Irradiation. ACS Nano 2014, 8, 7078-7087. [CrossRef]

173. Jiang, D.; Zhu, L.; Irfan, R.M.; Zhang, L.; Du, P. Integrating noble-metal-free NiS cocatalyst with a semiconductor heterojunction composite for efficient photocatalytic H 2 production in water under visible light. Chin. J. Catal. 2017, 38, 2102-2109. [CrossRef]

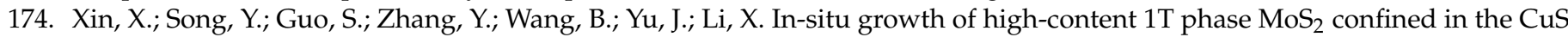
nanoframe for efficient photocatalytic hydrogen evolution. Appl. Catal. Environ. 2020, 269, 118773. [CrossRef]

175. Nagappagari, L.R.; Samanta, S.; Sharma, N.; Battula, V.R.; Kailasam, K. Synergistic effect of a noble metal free $\mathrm{Ni}(\mathrm{OH})_{2} \mathrm{co-catalyst}$ and a ternary ZnIn2S4/g-C3N4 heterojunction for enhanced visible light photocatalytic hydrogen evolution. Sustain. Energy Fuels 2020, 4, 750-759. [CrossRef]

176. Guo, X.; Guo, P.; Wang, C.; Chen, Y.; Guo, L. Few-layer WSe 2 nanosheets as an efficient cocatalyst for improved photocatalytic hydrogen evolution over $\mathrm{Zn}_{0.1} \mathrm{Cd}_{0.9} \mathrm{~S}$ nanorods. Chem. Eng. J. 2020, 383, 123183. [CrossRef]

177. Li, Y.; Zhang, D.; Xi, X.; Shen, Y.; Chang, S.; Zhu, J.; Chen, Y.; Jiang, L.; Zhang, J. Noble metal-free bimetallic NiCo decorated $\mathrm{Zn}_{0.5} \mathrm{Cd}_{0.5} \mathrm{~S}$ solid solution for enhanced photocatalytic $\mathrm{H} 2$ evolution under visible light. Int. J. Hydrogen Energy 2020, 45, 8300-8309. [CrossRef]

178. Jia, J.; Bai, X.; Zhang, Q.; Hu, X.; Liu, E.; Fan, J. Porous honeycomb-like NiSe2/red phosphorus heteroarchitectures for photocatalytic hydrogen production. Nanoscale 2020, 12, 5636-5651. [CrossRef] [PubMed]

179. Zhu, Y.; Chen, J.; Shao, L.; Xia, X.; Liu, Y.; Wang, L. Oriented facet heterojunctions on CdS nanowires with high photoactivity and photostability for water splitting. Appl. Catal. B Environ. 2020, 268, 118744. [CrossRef]

180. Han, J.; Liu, Y.; Wang, Y.; Zhao, R.; Wang, L. Construction of ternary CdxMo1-xSe quantum dots for enhanced photocatalytic hydrogen production. J. Mater. Sci. 2019, 55, 1117-1125. [CrossRef]

181. Beall, C.; Piipari, K.; Al-qassab, H.; Smith, M.A. $\mathrm{MoS}_{2} / \mathrm{Cd} \operatorname{In}_{2} \mathrm{~S}_{4}$ flower-like heterojunctions with enhanced photocatalytic degradation and $\mathrm{H}_{2}$ evolution activity. Biochem. J. 2010, 53, 1-14.

182. Mangiri, R.; Reddy, D.A.; Subramanyam, K.; Kumar, K.S.; Sudharani, A.; Poornaprakash, B.; Vijayalakshmi, R. Decorating MoS 2 and $\mathrm{CoSe}_{2}$ nanostructures on 1D-CdS nanorods for boosting photocatalytic hydrogen evolution rate. J. Mol. Liq. 2019, 289 , 2-11. [CrossRef]

183. Wang, B.; Ding, Y.; Deng, Z.; Li, Z. Rational design of ternary NiS/CQDs/ $\mathrm{ZnIn}_{2} \mathrm{~S}_{4}$ nanocomposites as efficient noble-metal-free photocatalyst for hydrogen evolution under visible light. Chin. J. Catal. 2019, 40, 335-342. [CrossRef]

184. Chen, Z.; Gong, H.; Liu, Q.; Song, M.; Huang, C. NiSe2 Nanoparticles Grown in Situ on CdS Nanorods for Enhanced Photocatalytic Hydrogen Evolution. ACS Sustain. Chem. Eng. 2019, 7, 16720-16728. [CrossRef]

185. Yan, A.; Shi, X.; Huang, F.; Fujitsuka, M.; Majima, T. Efficient photocatalytic $\mathrm{H}_{2}$ evolution using NiS/ZnIn $\mathrm{S}_{4}$ heterostructures with enhanced charge separation and interfacial charge transfer. Appl. Catal. Environ. 2019, 250, 163-170. [CrossRef]

186. Rangappa, A.P.; Kumar, D.P.; Gopannagari, M.; Reddy, D.A.; Hong, Y.; Kim, Y.; Kim, T.K. Highly efficient hydrogen generation in water using $1 \mathrm{D}$ CdS nanorods integrated with $2 \mathrm{D} \mathrm{SnS}_{2}$ nanosheets under solar light irradiation. Appl. Surf. Sci. 2020, 508, 144803. [CrossRef] 
187. Ranjith, K.S.; Kumar, D.R.; Huh, Y.S.; Shanmugam, R.K.; Uyar, T.; Kumar, R.T.R. Promotional Effect of Cu 2 S-ZnS Nanograins as a Shell Layer on ZnO Nanorod Arrays for Boosting Visible Light Photocatalytic $\mathrm{H}_{2}$ Evolution. J. Phys. Chem. C 2020, 124, 3610-3620. [CrossRef]

188. Puentes-Prado, E.; Garcia, C.; Oliva, J.; Galindo, R.; Bernal-Alvarado, J.; Torres, L.D.; Gomez-Solis, C. Enhancing the solar photocatalytic hydrogen generation of ZnS films by UV radiation treatment. Int. J. Hydrogen Energy 2020, 45, 12308-12317. [CrossRef]

189. Li, X.; Song, S.; Gao, Y.; Ge, L.; Song, W.; Ma, T.; Liu, J. Identification of the Charge Transfer Channel in Cobalt Encapsulated Hollow Nitrogen-Doped Carbon Matrix@CdS Heterostructure for Photocatalytic Hydrogen Evolution. Small 2021, 17, 2101315. [CrossRef]

190. Zhang, Z.; Kang, Y.; Yin, L.-C.; Niu, P.; Zhen, C.; Chen, R.; Kang, X.; Wu, F.; Liu, G. Constructing CdSe QDs modified porous $\mathrm{g}^{-} \mathrm{C}_{3} \mathrm{~N}_{4}$ heterostructures for visible light photocatalytic hydrogen production. J. Mater. Sci. Technol. 2021, 95, 167-171. [CrossRef]

191. Wong, K.-L.; Bünzli, J.-C.G.; Tanner, P.A. Quantum yield and brightness. J. Lumin. 2020, 224, 117256. [CrossRef]

192. Bouas-Laurent, H.; Dürr, H. Organic photochromism (IUPAC Technical Report) Republication or reproduction of this report or its storage and/or dissemination by electronic means is permitted without the need for formal IUPAC permission on condition that an acknowledgment, with full re. Photochromism 2003, 73, 639-665. [CrossRef]

193. Meng, X.; Zhang, C.; Dong, C.; Sun, W.; Ji, D.; Ding, Y. Carbon quantum dots assisted strategy to synthesize Co@NC for boosting photocatalytic hydrogen evolution performance of CdS. Chem. Eng. J. 2020, 389, 124432. [CrossRef]

194. Yuan, Y.; Lu, H.; Ji, Z.; Zhong, J.; Ding, M.; Chen, D.; Li, Y.; Tu, W.; Cao, D.; Yu, Z.; et al. Enhanced visible-light-induced hydrogen evolution from water in a noble-metal-free system catalyzed by ZnTCPP-MoS $/ \mathrm{TiO}_{2}$ assembly. Chem. Eng. J. 2015, 275, 8-16. [CrossRef] 